Utilização de serviços na integração de aplicações empresariais 

SERVIÇO DE PÓS-GRADUAÇÃO DO ICMC-USP

Data de Depósito:

Assinatura:

\title{
Utilização de serviços na integração de aplicações empresariais
}

\author{
Eliana Kaneshima
}

Orientadora: Prof ${ }^{a}$. Dr ${ }^{a}$. Rosana Teresinha Vaccare Braga

Dissertação apresentada ao Instituto de Ciências Matemáticas e de Computação - ICMC-USP, como parte dos requisitos para obtenção do título de Mestre em Ciências - Ciências de Computação e Matemática Computacional. VERSÃO REVISADA 
Ficha catalográfica elaborada pela Biblioteca Prof. Achille Bassi e Seção Técnica de Informática, ICMC/USP, com os dados fornecidos pelo(a) autor(a)

Kaneshima, Eliana
K16u Utilizaçăo de empresariais / Eliana Kaneshima; orientadora Prof ${ }^{\text {. }}$ $\mathrm{Dr}^{a}$. Rosana Teresinha Vaccare Braga. -- São Carlos, 2012 .

$157 \mathrm{p}$.

Dissertação (Mestrado - Programa de Pós-Graduação e Ciências de Computação e Matemática Computacional) -Instituto de Ciềncias Matemáticas e de Computação, Universidade de Săo Paulo, 2012.

1. Web Services, 2. SOA. 3. EAI. 4. Padrōes, 5. Experimento em engenharia de software. I. Braga, Prof ${ }^{a}$. Dr . Rosana Teresinha Vaccare, orient. II. Titulo. 


\section{Dedicatória}

Ao meu Pai, Luiz Kaneshima (in memorian)

À minha Mãe, Yolanda Yamada Kaneshima

À Lenita Jacob de Oliveira (in memorian) 

“Tudo posso naquele que me fortalece” (Filipenses: 4. 13) 

Em primeiro lugar à Deus, por ter me dado forças para prosseguir e coragem nos momentos difíceis.

À Nossa Senhora, por "Passar na frente" nas dificuldades.

À Santa Rita de Cássia, pelas "causas impossíveis".

À minha Yolanda, a quem sempre me incentivou.

Aos meus irmãos Edson e Edilson, que choravam comigo nas derrotas e se alegraram com as minhas vitórias.

Ao meu sobrinho Luis Filipe e minhas sobrinhas Juliana e Natália, pelo carinho.

Às minhas cunhadas Clarice e Alice, pelo apoio.

À minha prima Cecília Massae e Celso, pela ajuda.

Aos tios Guissu, Luís, Noriko e Nádia, pela ajuda e apoio.

À Professora Dra. Rosana Teresinha Vaccare Braga, pela paciência, amizade, conhecimentos compartilhados e confiança durante a orientação deste trabalho.

Ao Professor Dr. Paulo C. Masiero, pelos ensinamentos e ajuda.

Ao Professor Dr. Valter Vieira de Camargo, pelas sugestões e correções apresentadas no exame de qualificação.

Ao meu conselheiro acadêmico na Embrapa, Dr. José Renato Bouças Farias, pelo apoio e confiança.

Ao Chefe Geral da Embrapa Soja, Dr. Alexandre José Cattelan, por ter permitido que eu me ausentasse por mais de 2 anos para me aprimorar nos estudos.

À Embrapa, em especial o CNPSO de Londrina, que me deram esta oportunidade de estudar e me aprimorar tanto intelectualmente como profissionalmente.

Ao supervisor da área de informática, Reginaldo, pelo apoio e paciência.

Ao pessoal da informática da Embrapa: Marcos, Mário, Flávio, Renan, Paulo e Helton, pela paciência, ajuda e apoio.

À turminha do mestrado de 2010, Arineiza, Joice, Rodolfo, Eduardo, Harry, Draylson e Silvana, por me aceitarem na turma, apesar da diferença de idade.

Ao pessoal do Labes: Marcelo Eler, Lucas, Rafael (Frotinha), Endo, Vania, Nardi, Marcão, Mauricio e Luciano, pela ajuda, conselhos e pelo cafezinho.

Aos outros colegas da USP, Ricardo Ramos, Wilian Watanabe, Professor Daniel Kaster, Rosa,

Edwin, Pedro, Marleny, Renato e Rony.

Aos meus "irmãozinhos" de orientação: Gabriel, Marcelo e André, pelos conselhos e conhecimentos.

Ao meu "irmãozinho peruano": Ivar, pela amizade, apoio e ensinamentos.

A Pamela, pela ajuda na matéria de algoritmos.

Ao pessoal do vôlei, pela amizade e pelos momentos de divertimento e descontração.

Aos meus amigos: D. Rosa, Maria Betetto, Hugo, Flávio (Biólogo), Vanusa, Eliza, Brenda, Sandra e Gegê, pelo incentivo e pela amizade.

Ao pessoal da Embrapa: Sueli, Izilda, Rani, Ademir (biblioteca), Dr Pedro Moreira, Dra Maria

Cristina, Dr. Alexandre Nepomuceno, Fabinho, Waldemar, César, Jovenil, Rubson, Verinha, Roseli, Neiva,

Tania, Alda, Tica, João Roberto, Arnold, Ivani e João Tolentino pelo apoio, ensinamentos e amizade.

Aos meus irmãos de oração: Marco, Rita de Cássia, Ana Cláudia, Carmem, Pessoal do SOS oração de Londrina, Grupo de Oração Hesed de São Carlos, Grupo de Oração Embrapa e o Grupo de Reflexão de Londrina.

Às pessoas que, sem eu conhecer direito me ajudaram: Rael Gugelmin, Edilson, Robson e Roselito da Embrapa de São Carlos, Fada e Sr. Roberto (porteiro do flat).

Ao pessoal da Lanchonete de Araraquara, que cuidavam da minha mala enquanto eu ia comprar a passagem.

Ao professor Dr Rodrigo Bonifácio e aos participantes do SugarLoafPLoP'2012 pelas contribuições.

Aos Professores e Funcionários do ICMC, pela disposição e atenção.

Ao Professor Dr. João Porto, pelas contribuições nas correções deste trabalho.

À todas as pessoas que, de alguma forma, contribuíram para a realização deste trabalho. 



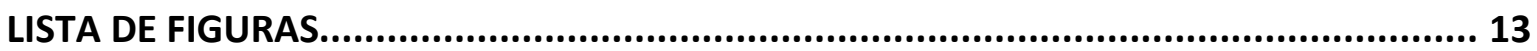

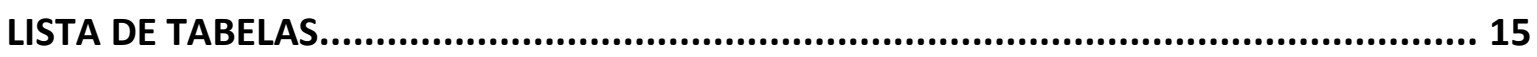

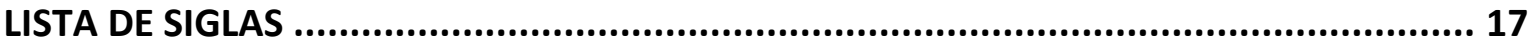

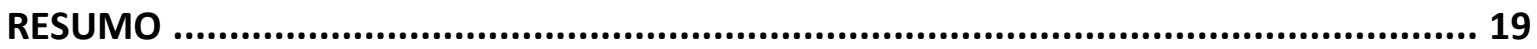

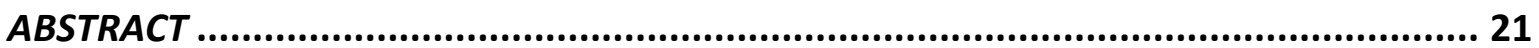

1. INTRODUÇÃO ………………………………………................................. 23

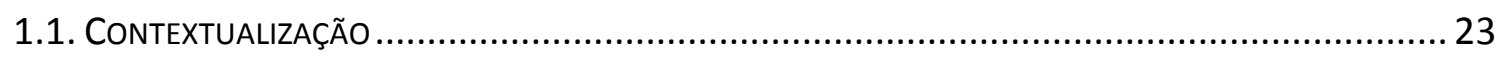

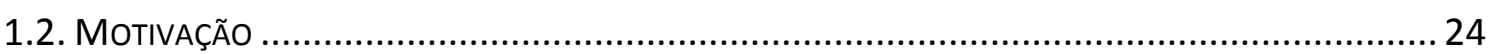

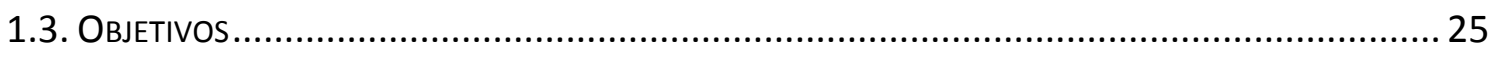

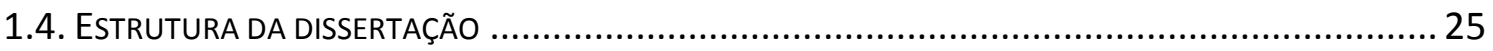

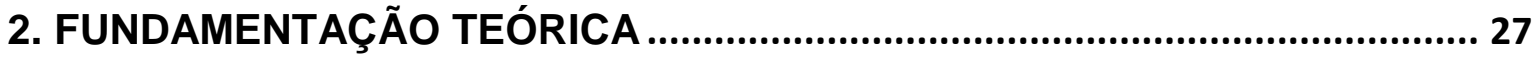

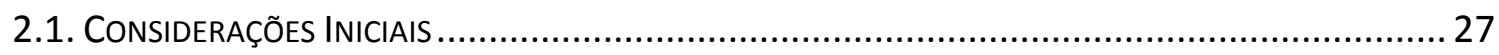

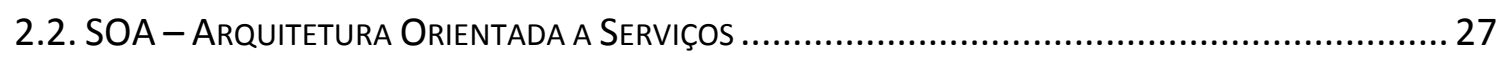

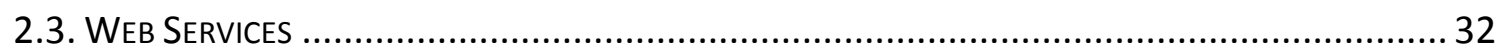

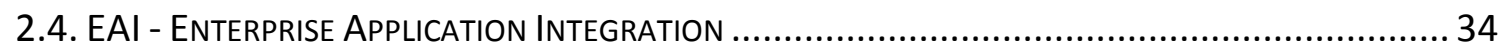

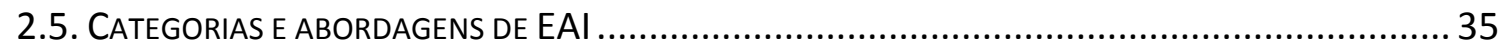

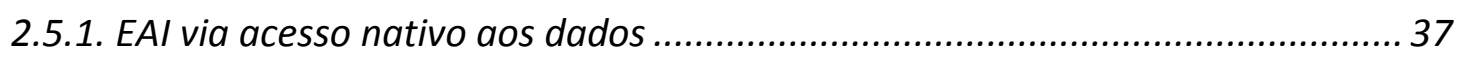

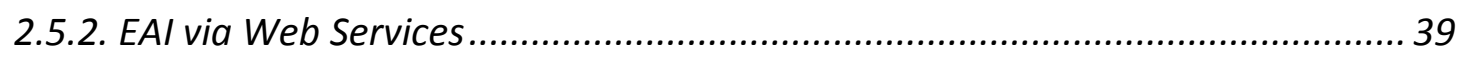

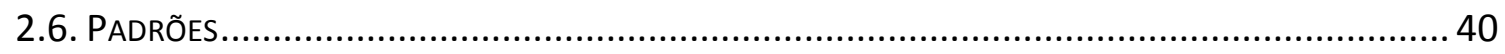

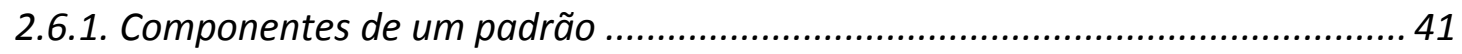

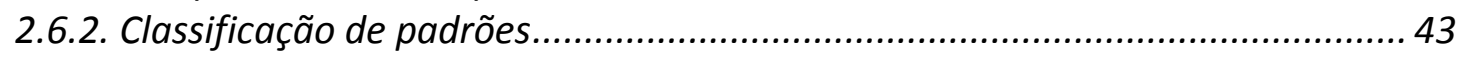

2.6.3. Regras para derivação de novos padrões.................................................... 44

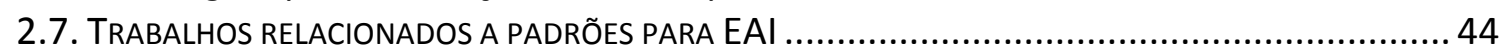

2.7.1. Shared database (base de dados compartilhada)........................................... 45

2.7.2. Remote Procedure Invocation (Chamadas de procedimentos remotos)........... 45

2.7.3. File Transfer (Transferência de dados) ........................................................... 46

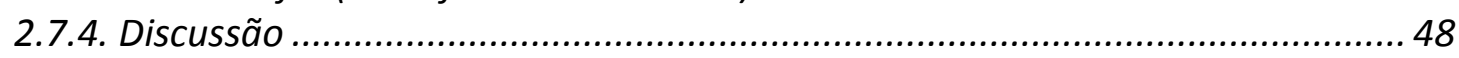

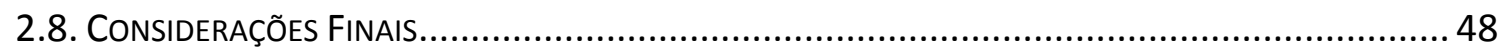

3. COMPARAÇÃO DAS ABORDAGENS EAI VIA WS X EAI VIA DADOS........................... 49

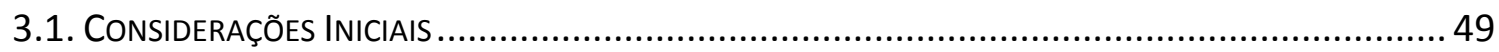

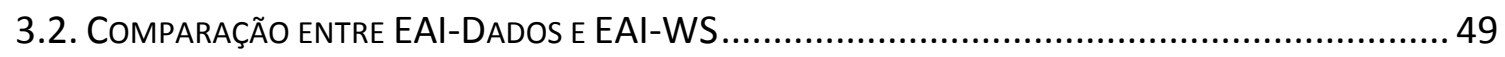

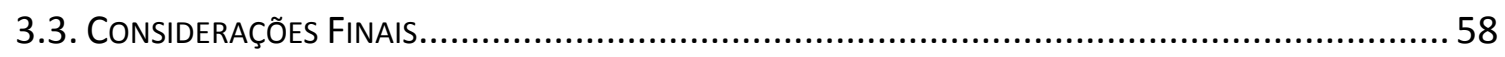

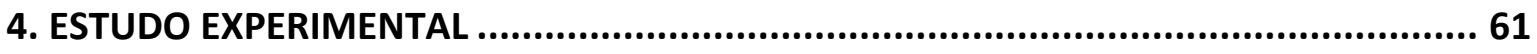

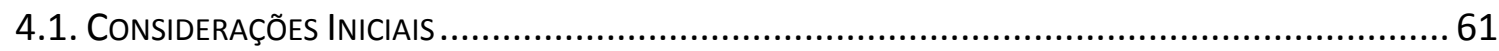

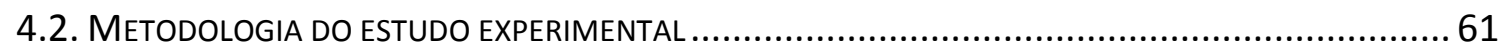

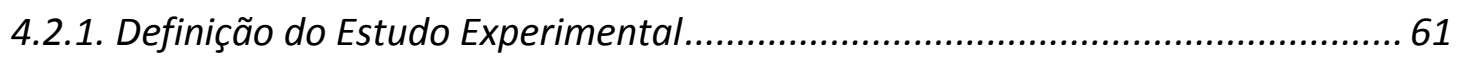

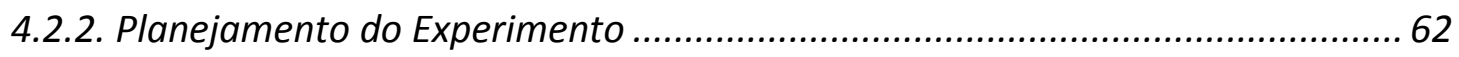

4.2.3. Execução do estudo experimental e validação dos dados ............................... 63

4.2.4. Análise dos resultados e avaliação das hipóteses do estudo experimental...... 64 


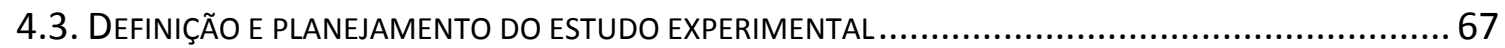

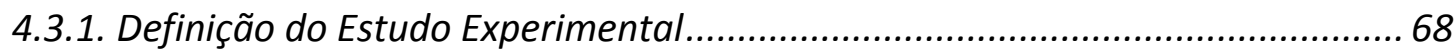

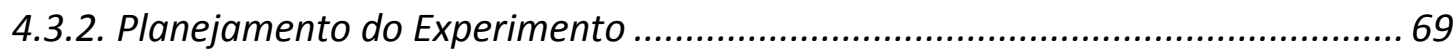

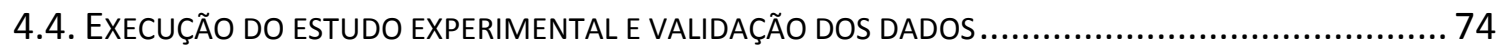

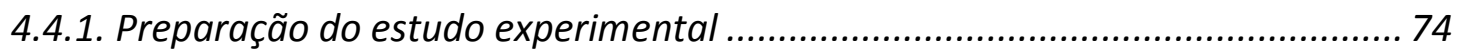

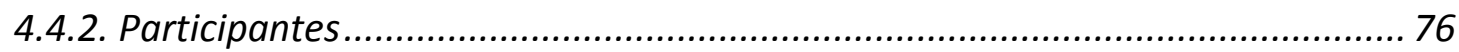

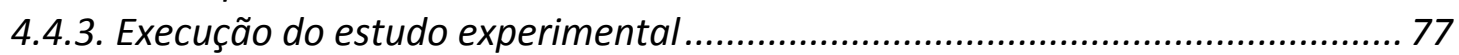

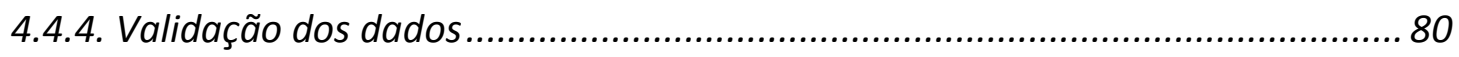

4.5. ANÁLISE DOS RESULTADOS E AVALIAÇÃO DAS HIPÓTESES DO ESTUDO EXPERIMENTAL.................... 80

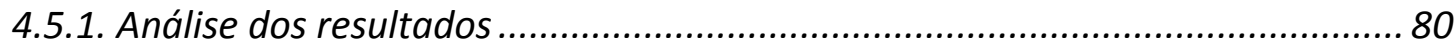

Resultado da análise exploratória ....................................................................... 81

4.5.2. Análise das dificuldades encontradas pelos participantes e suas impressões

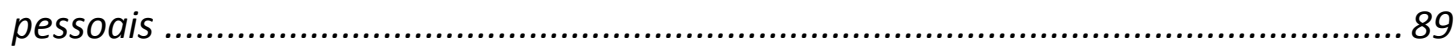

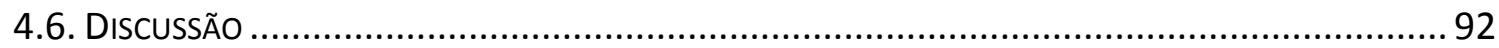

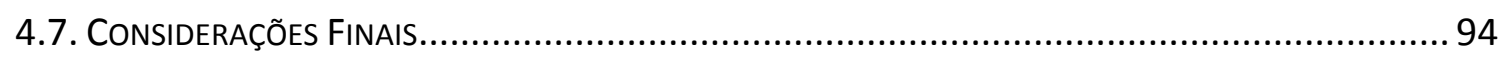

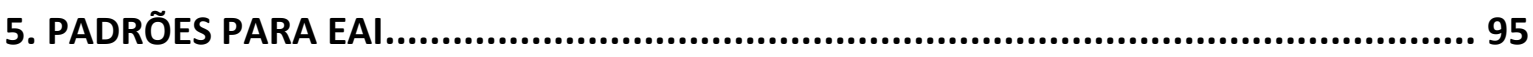

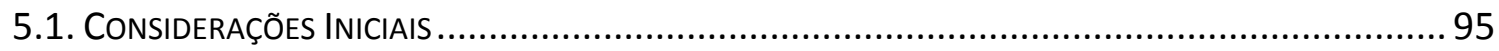

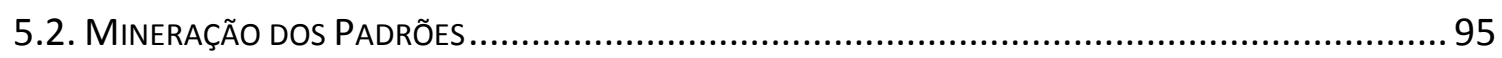

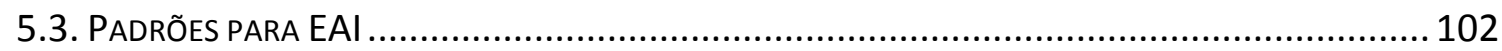

5.3.1. Objetivos e Motivação para os padrões ..................................................... 102

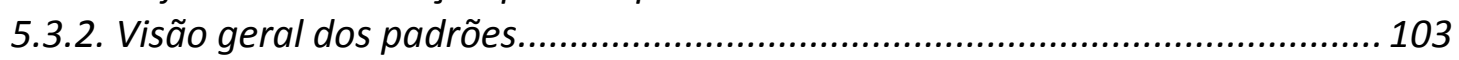

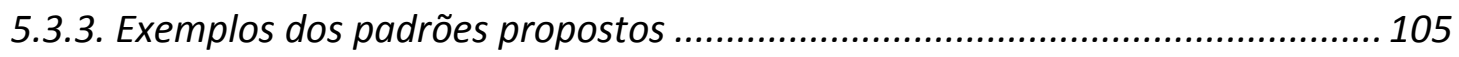

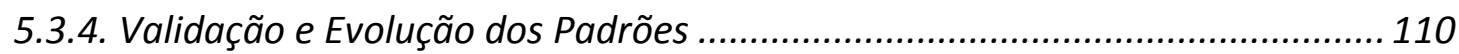

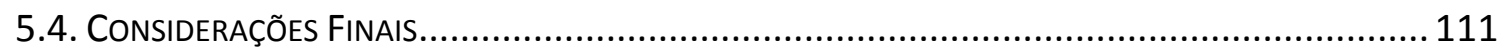

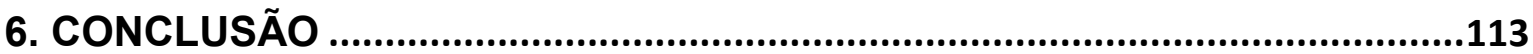

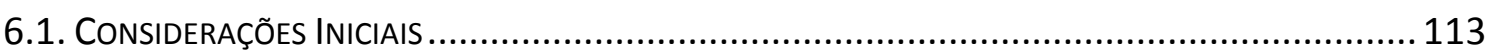

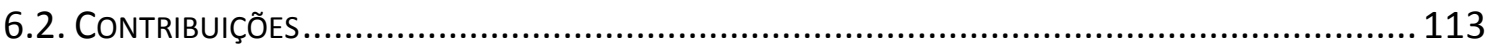

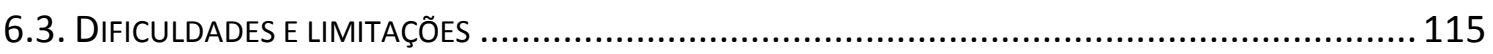

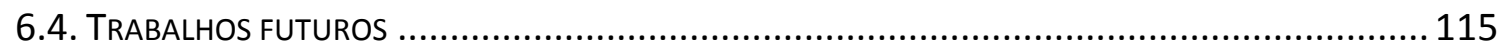

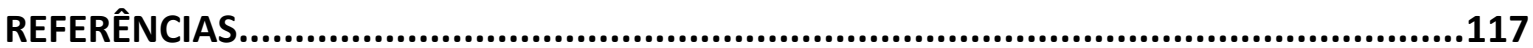

APÊNDICE A - REVISÃO SISTEMÁTICA SOBRE EAI E WEB SERVICES NA INTEGRAÇÃO DE SISTEMAS CORPORATIVOS.........................................................................121

APÊNDICE B - DESCRIÇÃO DAS TAREFAS DO ESTUDO EXPERIMENTAL...........................133

APÊNDICE C - PATTERNS FOR ENTERPRISE APPLICATION INTEGRATION (EAI) ................139

APÊNDICE D - TABELA 1 - VALORES DE T..........................................................157 


\section{Lista de Figuras}

FIGURA 2.1: MODELO DE DESCRIÇÃO DE UMA SOA EM FUNÇÃO DOS SEUS ELEMENTOS (ADAPTADO DE

(KRAFZIG ET AL., 2004)) 29

Figura 2.2: Colaborações EM SOA (TRADUZIDO de (PAPAZOGLOU, 2003)). 30

FIgURA 2.3: PRINCIPAIS TECNOLOGIAS ENVOLVIDAS COM SOA. Fonte: (MERSON ET AL., 2007). 31

FIGURA 2.4: PROCESSO DE SELEÇÃO DAS TECNOLOGIAS, NO CASO DA INTEGRAÇÃO DE APLICAÇÕES EMPRESARIAIS

(ADAPTADO DE (HÄMÄLÄINEN, 2002))

FIGURA 2.5: EXEMPLO DA TRANSFORMAÇÃO DE UMA APLICAÇÃO MONOLÍTICA EM UMA APLICAÇÃO ORIENTADA A SERVIÇOS (KRAFZIG ET AL., 2004) .40

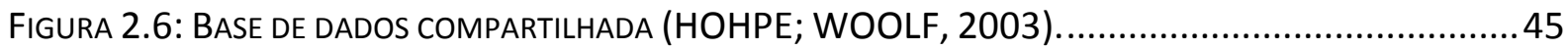

FIGURA 2.7: EMPACOTAMENTO DE WEB SERVICES (WRAPPER) DE SISTEMAS LEGADOS (JIANG, 2008).........46

FIGURA 2.8: EXEMPLO DE REPLICAÇÃO BIDIRECIONAL (NIELSEN ET AL., 2001) ..................................... 47

FIGURA 2.9: EXEMPLO DE TRANSFERÊNCIA DE ARQUIVOS. (HOHPE; WOOLF, 2003)............................ 48

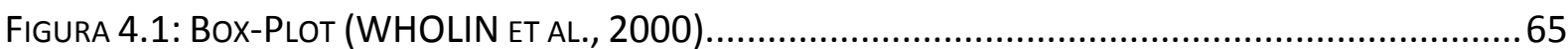

FIGURA 4.2: RELACIONAMENTO DA TABELA AGENDA COM A TABELA CONTATOS. ..................................... 75

FIGURA 4.3: BOXPLOT DO TEMPO GASTO PARA DESENVOLVER A SOLUÇÃO DE INTEGRAÇÃO POR DADOS E POR WS.

FIGURA 4.4: BOXPLOT DO NÚMERO DE LINHAS DE CÓDIGO PARA DESENVOLVER A SOLUÇÃO DE INTEGRAÇÃO POR DADOS E POR WS.

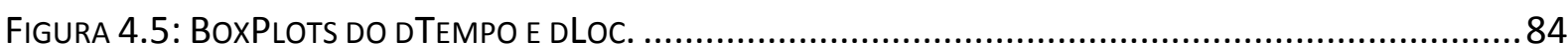

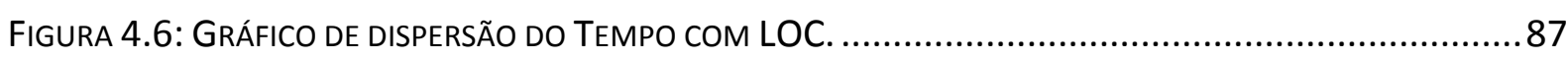

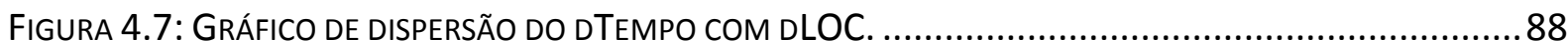

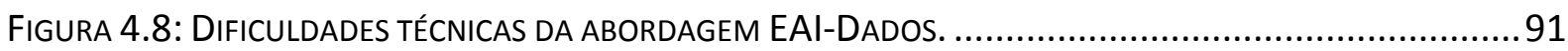

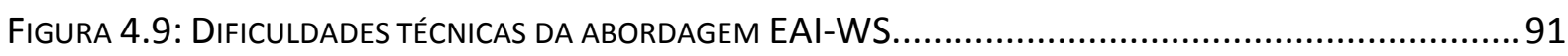

FIGURA 4.10: QUANTITATIVO DA IMPRESSÃO DOS PARTICIPANTES EM RELAÇÃO ÀS ABORDAGENS...................92

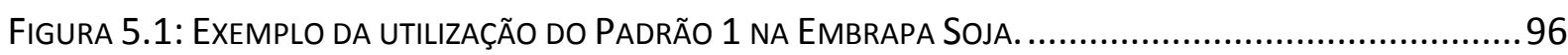

FIGURA 5.2 EXEMPLO DA UTILIZAÇÃO DO PADRÃO 2 NA EMBRAPA SOJA................................................97

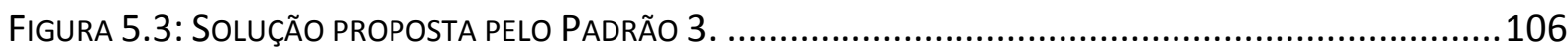

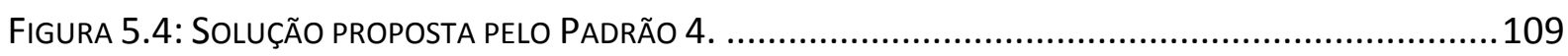




\section{Lista de tabelas}

TABELA 3.1: COMPARAÇÃO ENTRE EAI-WS E EAI-DADOS 51

TABELA 3.2: PONTOS POSITIVOS E NEGATIVOS DAS ABORDAGENS EAI-WS E EAI-

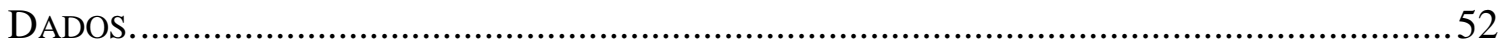

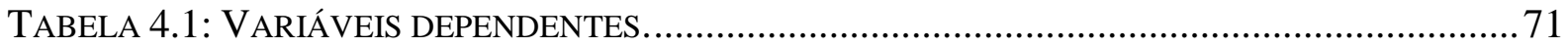

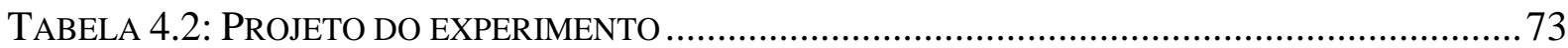

TABELA 4.3: TEMPO GASTO (MINUTOS) E AS LINHAS DE CÓDIGOS ESCRITAS PELOS

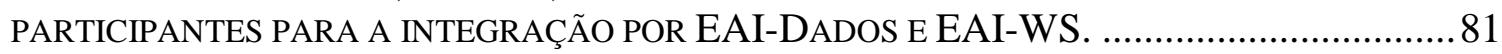

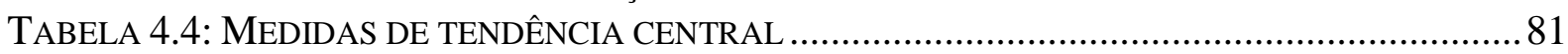

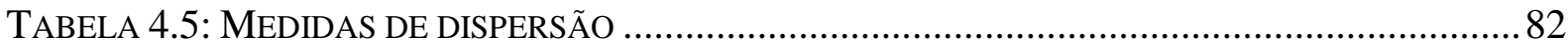

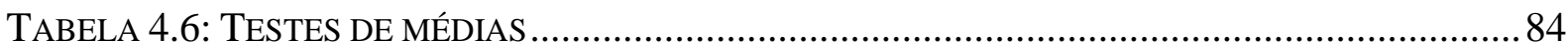

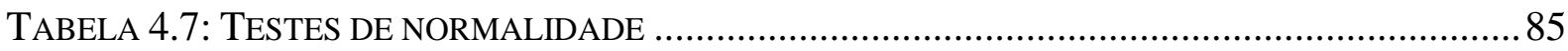

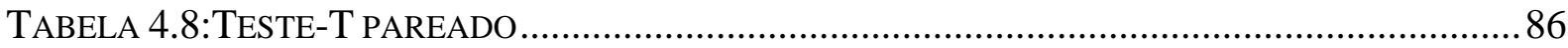

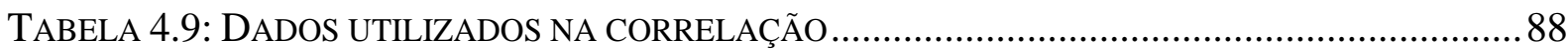

TABELA 4.10: CORRELAÇÃO COM AS VARIÁVEIS DE CONTEXTO …............................................ 89

LISTAGEM 5.1: ARQUIVO PERSISTENCE.XML QUE EFETUA A PERSISTÊNCIA POR MEIO DO JPA DA

TABELA FUNCIONÁRIO DA BASE DE DADOS RH. .............................................................. 97

LISTAGEM 5.2: CLASSE FUNCIONARIO.JAVA QUE FOI GERADA POR MEIO DA PERSISTÊNCIA DA

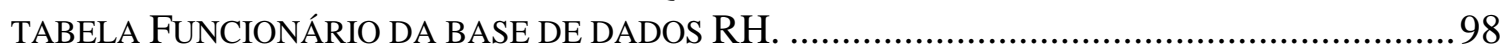

LiSTAGEM 5.3: LÓGICA DO WEB SERVICE WS-BUSCA QUE EFETUA CONSULTAS DA TABELA

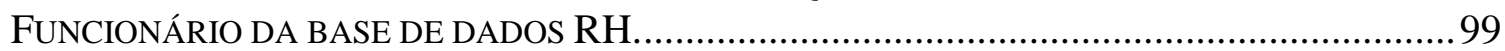

LiSTAGEM 5.4: CONSUMO DO WEB SERVICE WS-CRUD POR MEIO DA LINGUAGEM PHP. ...... 100

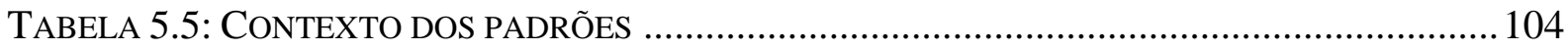


EAI

ERP

HTTP

IBM

ID

JabRef

QP

QS1

QS2

QS3

SLA

SOA

SOAP

TI

UDDI

WS

W3C

WSDL

XML
Enterprise Aplication Integration

Enterprise Resource Planning

Hyper Text Transfer Protocol secure

International Business Machines

Integração de Dados

Gerenciador de Referências Bibliográficas

Questão Primária

Questão Secundária 1

Questão Secundária 2

Questão Secundária 3

Service Leve Agreement

Arquitetura Orientada a Serviços

Simple Object Application Protocol

Tecnologia da Informação

Universal Description, Discovery and Integration

Web Services

World Wide Web Consortium

Web Service Description Language

Extensible Markup Language 
Atualmente a Integração de Aplicações Empresariais (EAI) desempenha um papel fundamental no cenário de integração de sistemas corporativos. Isso pode ser feito de diferentes formas, como por exemplo, por meio do compartilhamento de acesso às bases de dados ou trabalhando-se com Web Services, em que um serviço é disponibilizado por um sistema e pode ser chamado por outro sistema a ser integrado. Essas duas soluções estão sendo empregadas com sucesso, mas ambas apresentam vantagens e desvantagens que devem ser analisadas. Assim, este trabalho tem como objetivo primeiramente efetuar uma comparação entre essas duas abordagens de integração (tomando como base a norma ISO-IEC 9126-1) por meio de uma revisão bibliográfica complementada por uma revisão sistemática e relatos da experiência profissional da autora deste trabalho e da sua orientadora. Com o intuito de validar esta comparação, foi feito um estudo experimental, cujo objetivo do experimento foi avaliar a melhor abordagem para se realizar uma integração de aplicações empresariais: EAI-Dados e EAI-WS no que diz respeito ao esforço necessário para a implantação de cada uma. Assim, a avaliação foi realizada para responder à seguinte questão: Em termos de tempo de desenvolvimento e código produzido, é mais fácil realizar EAI-WS ou EAI-Dados?

Finalmente, foram propostos cinco padrões para EAI, com o objetivo de auxiliar desenvolvedores com problemas similares de integração de aplicações. Esses padrões podem ser reusados em diversos contextos de integração, obedecendo às regras de negócios específicas a serem consideradas no momento da integração, e agilizando a modelagem da solução por meio da instanciação do padrão mais adequado a cada situação. 
Nowadays, Enterprise Applications Integration (EAI) performs a fundamental function in the scenery of enterprise systems integration. This can be done in different forms, for example by sharing the database access or working with Web Services, in which a service is provided by the system and can be called by other systems to be integrated. Those two solutions are being applied successfully, even though both present advantages and disadvantages that must be analyzed. Thus, the goal of this work is first to compare those two integration approaches, (Based on the standard ISO-IEC 9126-1) through a bibliographical review complemented by a systematic review and professional reports from the author of this work and her supervisor. In order to confirm this comparison, an experimental study was done, which resulted in quantitative answers about the best approach to perform systems integration: EAI-Data and EAI-WS which refer to effort required to deploy each. Thus, the assessment was conducted to answer the following question: In terms of development time and code produced, is easier to perform EAI-WS or EAI-Data?

Finally, five patterns were proposed to EAI, which aim to support developers with similar problems of applications integration. These patterns can be reused in many integration contexts, following the rules of specific business to be considered in the moment of integration, and accelerating the modeling of the solution through the instantiation of the most adequate pattern to each situation. 


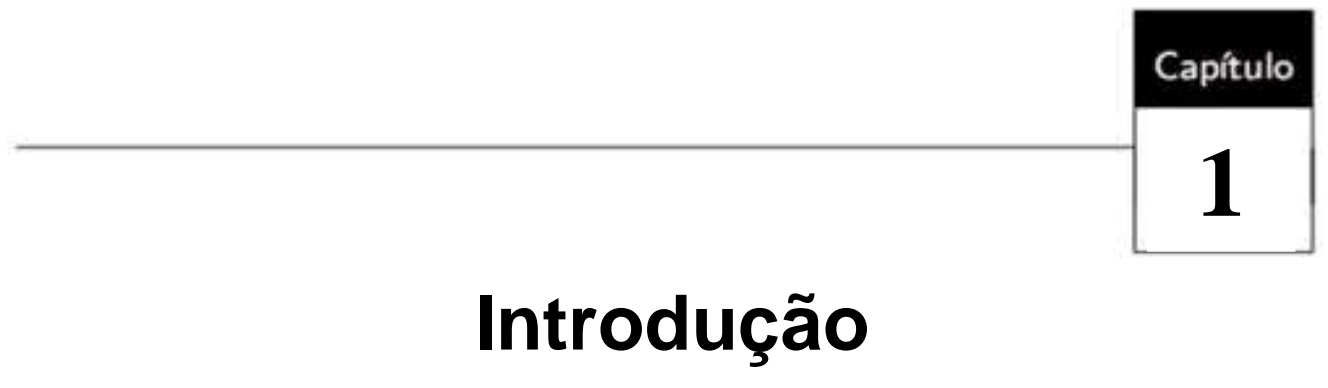

\subsection{Contextualização}

Em função do acelerado desenvolvimento tecnológico, é importante que exista um mecanismo que organize e integre as informações, facilitando a sua consulta de forma rápida e segura em diferentes áreas e setores. Além de agilizar o processo de desenvolvimento de um software a fim de proporcionar maior qualidade, deve-se atender às necessidades dos usuários, evitar a redundância e aproveitar as informações já armazenadas.

A crescente complexidade do software e a exigência cada vez maior dos usuários em termos de qualidade, custos e prazos torna inviável sempre começar a desenvolver um programa a "partir do zero". A reutilização de software é motivada pelo fato que, encontrada uma solução, ela poderia solucionar problemas semelhantes.

No contexto econômico e industrial atual, é desejável que muitos sistemas empresariais sejam reprojetados para atender à demanda do mercado, tanto em razão de mudanças em requisitos funcionais como pela evolução tecnológica. Não se trata apenas de problemas de TI (Tecnologia da Informação), mas antes de tudo, um desafio estratégico e organizacional (CHANNABASAVAIAH et al., 2004).

O grande desafio neste contexto é como conciliar a criação de novos sistemas empresariais com as tecnologias atuais, ao mesmo tempo fazendo com que os sistemas legados se mantenham operantes em novas plataformas ou trabalham em conjunto com novas plataformas, e ainda mantenham alguns sistemas com tecnologias mais antigas. $\mathrm{O}$ problema poderia ser facilmente resolvido se esses sistemas fossem totalmente independentes um do outro. Mas, infelizmente, isso não é verdade. Ao invés disso, cada novo sistema depende das informações que já estão sendo tratadas no sistema legado, e 
a redundância de dados pode não ser interessante em muitos casos. Assim, o conceito de Enterprise Aplication Integration (EAI - Integração de Aplicações Empresarias em português,) está relacionado com os mecanismos utilizados pela empresa na elaboração de soluções que resolvam este problema. Segundo Linthicum (1999), EAI é "o compartilhamento irrestrito de dados e processos de negócios entre todos os aplicativos conectados e fontes de dados na empresa".

Sistemas corporativos podem ser complexos, por isso a sua integração não é uma tarefa trivial, principalmente se o software for de diferentes fornecedores que precisam trabalhar juntos e também, se existem aplicações redundantes ou aplicativos com funções que não podem ser facilmente reutilizadas muitas vezes cada unidade de negócios dentro da organização agiu de forma separada da outra ao desenvolver seus sistemas. Isto leva a problemas de integração, quando se percebe que há informação comum entre os sistemas e que essa informação deve ser disponibilizada a todos eles de uma forma mais flexível. A integração pode ser necessária por várias razões: fusão entre empresas, novas parcerias de negócios ou apenas pela necessidade de interligar os sistemas existentes.

Há vários mecanismos nos quais os sistemas podem ser integrados. Uma possível solução é fazer a integração por meio de um banco de dados compartilhado, ou seja, os dados de um aplicativo são disponibilizados para serem acessados diretamente por outros aplicativos, em que o acesso às informações é feito em um modo somente leitura ou por meio de cópias periódicas das tabelas de banco de dados. Outra forma de integração é por meio de Web Services, em que um serviço é disponibilizado por um sistema e pode ser chamado por outro sistema a ser integrado (KRAFZIG et al., 2004). Essas duas soluções estão sendo empregadas com sucesso, mas ambas apresentam vantagens e desvantagens que devem ser analisadas.

\subsection{Motivação}

Particularmente, a autora do presente trabalho é desenvolvedora de software na Embrapa Soja e vem enfrentando o problema de integração de aplicativos legados com os recém-desenvolvidos nos últimos anos. A solução adotada até agora tem sido a de compartilhar o acesso às bases de dados ou fazer cópias periódicas de algumas tabelas 
que são usadas por várias aplicações. No entanto, esta abordagem apresenta uma série de desvantagens, tais como questões de privacidade, inconsistência de dados, e duplicação de armazenamento. Vale observar que, no caso dos sistemas da Embrapa Soja, a inconsistência de dados é momentânea, uma vez que não é necessário que se tenha os dados atualizados o tempo todo. É importante ressaltar que esta situação não é peculiar somente da Embrapa, ou seja, este mesmo problema ocorre em outras empresas, podendo assim beneficiar-se das soluções apresentadas.

Portanto, o estudo apresentado neste trabalho foi também motivado por este problema concreto, uma vez que, antes de efetuar a utilização concreta de Web Services, desejava-se obter evidências de que esta solução iria resolver o problema de uma forma mais eficiente do que a solução que está sendo aplicada até o momento.

\subsection{Objetivos}

O objetivo principal deste trabalho foi investigar as várias formas de realizar integração de aplicações empresariais e executar a comparação (com base na norma ISO-IEC 9126-1) de dois tipos de integração: (1) integração por dados; e (2) integração por meio de Web Services, apontando as vantagens e desvantagens dessas abordagens de integração. Essa comparação pôde ser feita com base no estudo da literatura sobre o assunto e, para complementar esse estudo, foi feito um experimento com desenvolvedores de software.

Outro objetivo do trabalho foi propor um conjunto de padrões que documentassem as soluções para os tipos mais frequentes de problemas encontrados na integração de aplicações empresariais. Esses padrões poderão ser reutilizados por outros desenvolvedores diante do mesmo problema e em contextos similares.

\subsection{Estrutura da dissertação}

Este trabalho está organizado em seis capítulos. Este capítulo introduziu a área de pesquisa, apresentando a motivação e os objetivos desta dissertação. No Capítulo 2 apresenta-se a fundamentação teórica sobre os assuntos relacionados com o presente trabalho, o que inclui a Arquitetura Orientada a Serviços (SOA), a tecnologia de Web 
Services (WS), a Integração de Aplicações Empresariais, Categorias e abordagens de EAI, os Padrões de software e trabalhos relacionados a Padrões para EAI. No Capítulo 3 é descrita a comparação das duas abordagens de EAI. No Capítulo 4 descreve-se um estudo experimental realizado com alunos e profissionais para comparar a integração de aplicações feita por meio do acesso à base de dados e por meio de WS. No Capítulo 5 são apresentados os padrões para EAI. No Capítulo 6 apresentam-se as conclusões, as contribuições deste trabalho e trabalhos futuros. Por fim, são listadas as referências bibliográficas e os apêndices. 


\section{Fundamentação Teórica}

\subsection{Considerações Iniciais}

Neste capítulo são descritas as tecnologias, métodos e técnicas que foram utilizadas no trabalho de mestrado, tais como a Arquitetura Orientada a Serviços, Web Services, Integração de Aplicações Empresariais, Categorias e abordagens de EAI, Padrões e trabalhos relacionados a padrões para EAI.

O Capítulo está organizado da seguinte forma: é apresentada na Seção 2.2 a Arquitetura Orientada a Serviços com algumas técnicas e abordagens para desenvolvêla, sendo apresentada na Seção 2.3, a tecnologia de Web Services. Em seguida, na Seção 2.4, apresenta-se a abordagem Integração de Aplicações Empresariais. Na Seção 2.5, são apresentadas as categorias de EAI e nas Subseções 2.5.1 e 2.5.2, são apresentadas as abordagens EAI via acesso nativo aos dados e EAI via Web Services, respectivamente. Na Seção 2.6, é apresentada uma visão geral de Padrões e na Seção 2.7, são apresentados os trabalhos relacionados a padrões para EAI. Por fim, na Seção 2.8 são apresentadas as considerações finais deste capítulo.

\subsection{SOA - Arquitetura Orientada a Serviços}

Um serviço é um componente de software que encapsula um conceito de negócio de alto nível e possui significado funcional único e auto-contido (KRAFZIG et al., 2004).

Os serviços são o núcleo de SOA, pois as aplicações são construídas baseadas em serviços. Arquitetura Orientada a Serviços é um padrão arquitetural para a integração de software em que se definem "serviços" comuns a mais de um aplicativo, tanto internos 
como externos em uma organização, tratando-os individualmente e disponibilizando-os em uma rede (DEHNE; DIMARE, 2007).

Mahmoud (2005) define uma SOA como sendo um estilo arquitetural para a construção de aplicações de software que utilizam serviços disponíveis em uma rede como a Web.

Conforme Erl (2005), os princípios fundamentais da arquitetura orientada a serviços são:

- Proporcionam reusabilidade: com a divisão da lógica em serviços, há grande probabilidade de conseguir reutilizá-los;

- São autônomos, auto-suficientes, fracamente acoplados e independentes de plataforma ;

- Compartilham uma interface formal, chamada de contrato (o termo contrato será definido a seguir);

- Abstração: a lógica, com exceção das informações do contrato, é abstrata ao consumidor do serviço;

- Composição: são combináveis, assim, permite-se que a lógica seja representada em diferentes níveis de granularidade; e

- Sem estado (stateless): podem minimizar o armazenamento das informações específicas de uma atividade.

Krafzig et. al. (2004) define uma SOA como sendo um padrão arquitetural baseado nos conceitos-chaves de: (1) aplicação frontend; (2) serviços; (3) repositório de serviços; e (4) barramento de serviços (service bus). Na Figura 2.1 é apresentado o modelo que descreve uma SOA em função de seus elementos. 


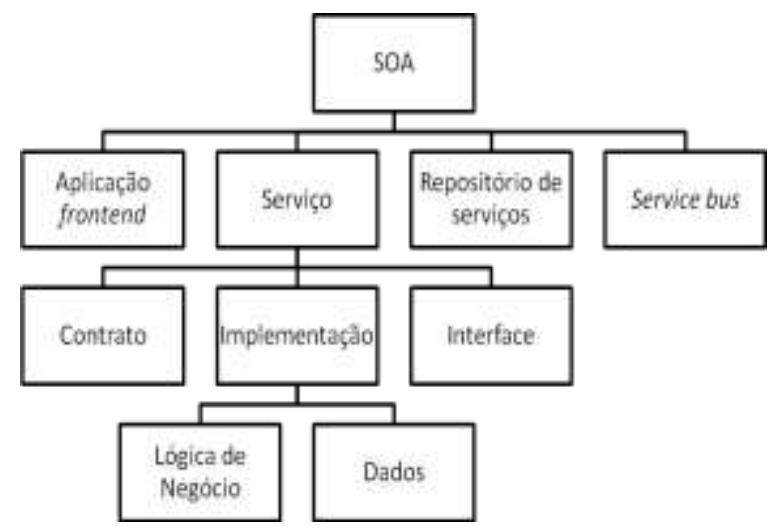

Figura 2.1: Modelo de descrição de uma SOA em função dos seus elementos (adaptado de (KRAFZIG et al., 2004)).

A aplicação frontend é a parte ativa de uma SOA, sendo ela a responsável por iniciar um processo de negócio e receber os resultados. Ela pode interagir diretamente com o usuário final, delegando responsabilidades para um ou mais serviços.

O serviço é composto por três elementos:

- Contrato: pode ser uma especificação informal ou formal do propósito do serviço, apresentando suas funcionalidades, restrições e usos;

- Implementação: provê a lógica de negócios e dados relativos ao serviço; e

- Interface: responsável por expor as funcionalidades do serviço e, fisicamente, consiste na definição de $\operatorname{stubs}^{l}$ de serviço que são incorporados ao cliente (aplicação frontend ou outros serviços).

O repositório de serviços é o responsável por prover facilidades para descobrir e adquirir todas as informações necessárias para usá-los, tais como: contrato de serviço, localização física, termos de uso, limitações técnicas, etc. É importante ressaltar que uma SOA pode ser implementada sem um repositório.

O barramento de serviços é o centro de integração de diferentes tipos de serviço. A integração pode ser feita por meio de mensagens ou manipulação de eventos, e tem por objetivo conectar todos os participantes de uma SOA. Pode ser composto por mais de uma tecnologia, englobando vários conceitos de comunicação e promovendo serviços técnicos como segurança, auditoria, etc (KRAFZIG et al., 2004).

1 Simula o comportamento de uma implementação já existente. 
Vale salientar ainda que uma SOA básica não trata apenas de serviços. Ela é um relacionamento entre três tipos de participantes: o provedor de serviços, o repositório de serviços e o cliente de serviços. As operações envolvem publicação, busca e ligação (PAPAZOGLOU, 2003). Na Figura 2.2 é mostrada a colaboração típica em uma SOA, em que um registro de serviços é o intermediário entre os solicitantes e os provedores de serviços.

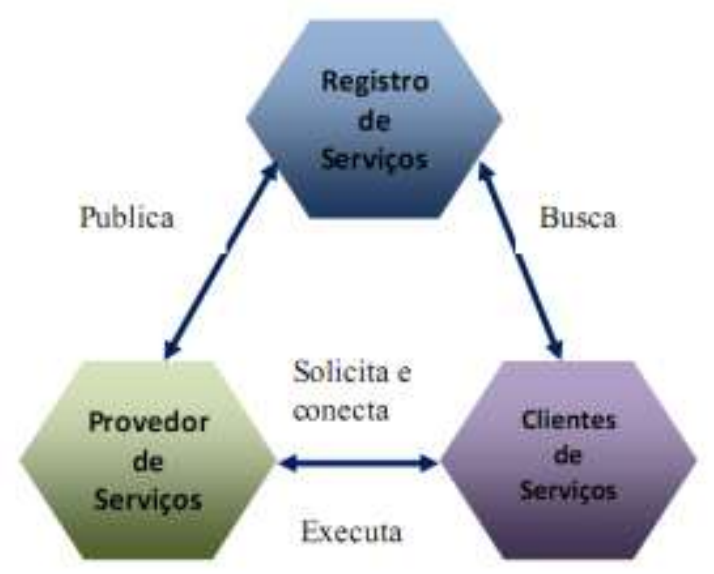

Figura 2.2: Colaborações em SOA (Traduzido de (PAPAZOGLOU, 2003)).

SOA não é um conceito novo (MAHMOUD, 2005). Essa arquitetura foi definida pela SUN no final da década de 90 para descrever o Jini (ambiente para descobertas dinâmicas e uso de serviços por meio de uma rede). Entretanto, atualmente, grande parte das infraestruturas de TI baseia-se no padrão cliente/servidor, em que o ponto central de toda a comunicação é um servidor ou sistema mainframe. Esses sistemas funcionam bem, no entanto, esse tipo de infraestrutura possui algumas dificuldades com relação à inflexibilidade no que diz respeito à extensão e adaptação aos novos modelos organizacionais. Por esse motivo, acredita-se que o uso da SOA seja uma boa solução para se ter uma maior flexibilidade e rapidez na adequação aos novos modelos de negócio dentro de uma empresa (LIEGL, 2007), uma vez que SOA possui uma consolidação de funções empresariais bem definidas por meio de serviços que podem ser compartilhados por inúmeras unidades empresariais. Dessa forma, favorece-se a interoperabilidade e a escalabilidade entre as tecnologias e as aplicações heterogêneas. Isso resulta em uma maior flexibilidade dos aplicativos, que podem evoluir facilmente de acordo com as mudanças nos requisitos, além de facilitar a reusabilidade para 
funcionalidades que já existam fora ou dentro de uma empresa, ao invés de desenvolver novamente um código que reproduza essas funções. Com isso, pode-se obter uma economia de tempo e custo no desenvolvimento dos aplicativos. Funções de um aplicativo ou sistema (incluindo sistemas legados) podem ser acessadas mais facilmente por meio de um serviço em SOA, proporcionando assim, uma integração de sistemas mais simples (MAHMOUD, 2005; ORT, 2005).

No entanto, a SOA possui algumas desvantagens, por exemplo, como os serviços podem invocar outros serviços, todo serviço precisa validar completamente cada parâmetro de entrada, e isto tem implicações no tempo de resposta e no desempenho em geral. Outra desvantagem é que, caso um serviço esteja corrompido, pode existir a propagação e a paralisação de todo o sistema (MAHMOOD, 2007).

Existem diversas tecnologias para a implementação de uma SOA. Na Figura 2.3, são apresentadas as principais delas que são: Web Services, Corba $^{2}$ (Common Object Request Broker Architecture) e Jini.

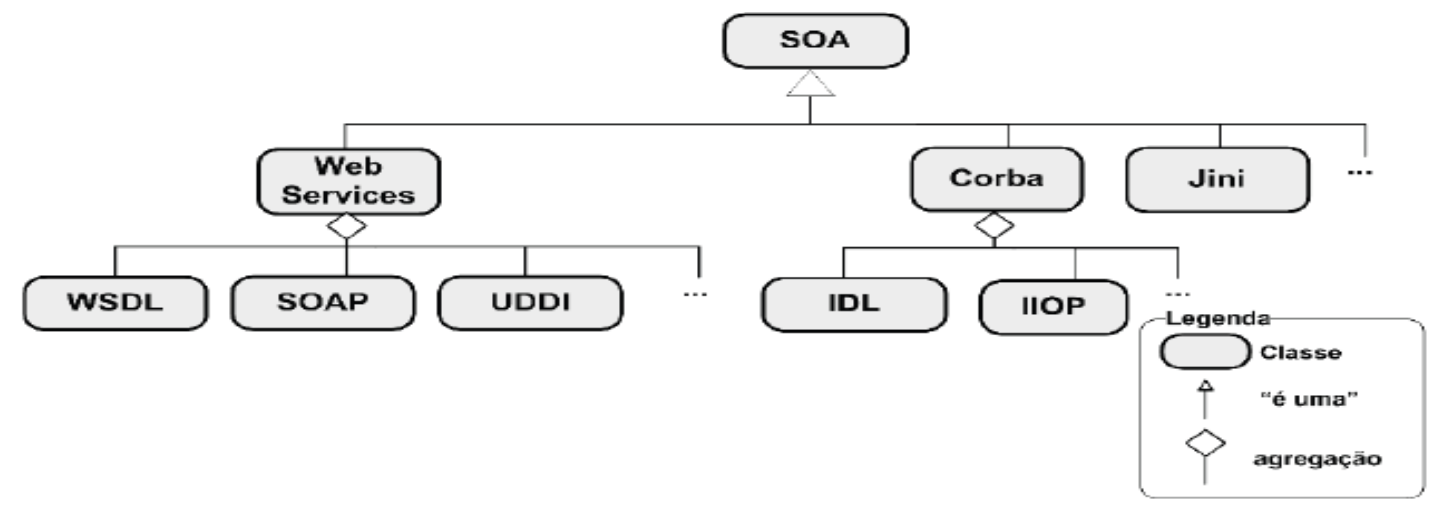

Figura 2.3: Principais tecnologias envolvidas com SOA. Fonte: (MERSON et al., 2007).

É importante ressaltar que SOA e Web Services são conceitos distintos. Enquanto SOA é um estilo arquitetural, Web Service consiste na tecnologia ou uma das tecnologias que implementa este estilo (MAHMOUD, 2005). Como este trabalho pretende utilizar Web Services, por sua ampla aceitação no mercado, na Seção seguinte apresenta-se tal tecnologia com mais detalhes.

2 É a arquitetura padrão criada pelo Object Management Group para estabelecer e simplificar a troca de dados entre sistemas distribuídos heterogêneos. 


\subsection{Web Services}

Web Services são sistemas de software, projetados para apoiar as interações máquinapara-máquina interoperáveis pela rede. Eles possuem uma interface descrita em um formato processável por máquina (especificamente WSDL - Web Services Description Language). Outros sistemas interagem com o Web Service de uma maneira prescrita por sua descrição usando mensagens SOAP (Simple Object Application Protocol), normalmente transmitida por meio de um protocolo HTTP (Hypertext Transfer Protocol), com uma serialização XML (Extensible Markup Language) em conjunto com outros padrões relacionados à web (W3C, 2004).

Além disso, um Web service é composto por duas estruturas: serviço e descrição do serviço, sendo que a última contém os detalhes da interface e da implementação de um serviço, o que inclui os tipos de dados, operações, informação de ligação (binding) e localização de rede. Pode ainda, incluir metadados e informação de categorização para facilitar as atividades de descoberta e utilização por consumidores do serviço. Além disso, essa descrição pode ser publicada em um registro de serviço para tornar o respectivo serviço conhecido em um determinado contexto (W3C, 2004).

Os principais padrões dos Web Services utilizados atualmente são:

- XML: é uma linguagem de marcação de dados baseada em tags, que oferece um padrão para descrever dados estruturados de modo a facilitar a declaração do conteúdo (W3C, 2003).

- SOAP: é um protocolo que define o formato das mensagens que são trocadas entre clientes e fornecedores de serviços. SOAP fornece um formato de mensagem comum para troca de dados entre os consumidores e os serviços. $\mathrm{O}$ item básico de transmissão em SOAP é uma mensagem, que consiste em um envelope (obrigatório), um cabeçalho (opcional), e um corpo (obrigatório). Um envelope funciona como um contêiner para todos os elementos da mensagem e pode especificar (W3C, 2004; W3C, 2007): (1) estilo de codificação que identifica os tipos de dados reconhecidos pela mensagem SOAP; e (2) Namespace (espaço de nomes) XML que especifica os nomes que podem ser usados na mensagem SOAP. Namespaces são projetados para evitar conflitos de 
nome. No entanto, o mesmo nome pode ser usado para diversos itens, desde que os nomes estejam em diferentes espaços;

- WSDL: é uma linguagem utilizada para descrever os Web Services. Ela utiliza XML como base e descreve quatro partes de dados: as interfaces, os tipos de dados, o protocolo de transporte a ser utilizado e o endereço do serviço (W3C, 2001); e

- UDDI (Universal Discovery Description and Integration): é um padrão que define a estrutura e os diretórios de serviços, possibilitando a publicação, descoberta e invocação de serviços nesses diretórios (ORT, 2005). Em outras palavras, UDDI oferece um mecanismo para que os clientes possam encontrar o Web Service.

A seguir são apresentadas duas tecnologias para Web Services: Web Services baseados em SOAP e Web Services Restfull, que são as tecnologias mais utilizadas atualmente, e algumas das suas vantagens e desvantagens.

Os Web Services baseados em SOAP utilizam o formato de mensagem SOAP e WSDL. Uma das suas vantagens é a independência de protocolo. Além disso, usando a WSDL para descrever uma interface de serviço, pode-se abstrair o protocolo de comunicação e os dados de serialização, bem como a plataforma de implementação do serviço. Este tipo de flexibilidade torna-se fundamental quando constroem-se gateways para sistemas legados pré-existentes (PAUTASSO; LEYMANN, 2008).

Os Web Services RESTful aproveitam os padrões já existentes (HTTP, XML, $\mathrm{URIs}^{3}, \mathrm{MIME}^{4}$ ), sendo esse um dos seus pontos fortes. Observa-se que o protocolo HTTP, tanto para clientes quanto para servidores, está disponível para todas as linguagens de programação e principais plataformas de sistema operacional/hardware. Algumas das limitações do RESTful são: (1) dependência do protocolo HTTP, já que é permitida apenas a utilização deste protocolo; e (2) não possui um padrão para a descrição de serviços, ou seja, não há uma linguagem para a descrição de serviços como a WSDL (PAUTASSO; LEYMANN, 2008).

3 Identificador Uniforme de Recursos (Uniform Resource Identifier): é uma cadeia de caracteres compacta usada para identificar ou denominar um recurso na Internet.

4 Extensões Multi função para Mensagens de Internet ( Multipurpose Internet Mail Extensions). 
Atualmente pode-se utilizar a SOA e a tecnologia de Web Services para tornar a EAI mais flexível (DENG et al, 2008), assim a próxima seção aborda o conceito de integração de aplicações empresariais com mais detalhes.

\subsection{EAI - Enterprise Application Integration}

A maior parte das aplicações empresariais tem como um de seus principais objetivos otimizar e facilitar a gestão da informação em grandes bases de dados. Por esse motivo, elas deveriam tirar proveito da TI para atender às necessidades do usuário e, ao mesmo tempo, organizar e integrar essa informação de modo que ela possa ser acessada de forma mais rápida e eficiente por diferentes áreas da organização.

Muitos problemas de negócios da área de TI geralmente são os mesmos desde décadas passadas até hoje (CHANNABASAVAIAH et al., 2004). Na década de 1990, complexos sistemas Enterprise Resource Planning (ERP) ${ }^{5}$ foram se tornando cada vez mais comuns nas grandes empresas e por isso, foram definidas ferramentas que facilitassem a resolução dos problemas de integração, proporcionando assim, uma plataforma para a integração. Foi a partir disso que surgiu o conceito de Enterprise Application Integration (EAI - Integração de Aplicações Empresariais) (DAVIES, 2008).

Integração de aplicações é uma abordagem estratégica para efetuar a ligação dos sistemas de informação que necessitam trabalhar juntos (LINTHICUM, 2003). Conforme Bhosle (2002), EAI pode ser entendida como um processo que direciona sistematicamente uma integração e o seu componente chave é a capacidade de se conectar a diversas fontes heterogêneas de informações.

Gudivada (2005) considera a integração de aplicações empresariais como uma possível solução na integração de sistemas dentro de um ambiente corporativo, em que, ao invés de substituir os sistemas legados, utiliza-se a funcionalidade desses sistemas para a realização de novos requisitos.

A fim de complementar a seção de EAI, na próxima seção são abordadas as categorias e as abordagens de EAI.

5 SIGE (Sistemas Integrados de Gestão Empresarial) 


\subsection{Categorias e abordagens de EAI}

Há dois tipos de integração de EAI: (1) interna: objetiva estabelecer a interoperabilidade entre os sistemas internos de uma empresa; e (2) externa: abrange a interoperabilidade com os sistemas fora da empresa, bem como parceiros, fornecedores e sistemas do cliente (GUDIVADA; NANDIGAM, 2005).

A integração da informação se concentra em fornecer uma visão corporativa e integrada das entidades de dados a fim de promover a integridade dos dados, a semântica e o uso compartilhado, consistente e rápido no desenvolvimento de aplicações. Já a integração de processos de negócios abrange a coordenação e execução de uma sequiência de passos para realizar uma tarefa de negócio. Gudivada et al. (2005) apresenta algumas abordagens para EAI:

- Integração corporativa de dados (EDI): é uma infraestrutura para apoiar a comunicação entre aplicações e serviços genéricos compartilhados, fornecendo assim, uma visão unificada e coerente das entidades de dados críticas, e a conectividade da informação por meio de múltiplas plataformas;

- Comunicação entre aplicativos: é muitas vezes concebida como interfaces de aplicações ponto-a-ponto e isto implica custos de manutenção significativos, especialmente para as grandes organizações; e

- Abordagem de serviços genéricos e compartilhados: visam à realização de EAI por meio de uma matriz de serviços fracamente acoplados, que tenta minimizar as interfaces de aplicações ponto-a-ponto.

Na Figura 2.4 é ilustrada que a primeira tarefa na integração de aplicações empresariais é definir quais são os processos de negócios existentes na organização e também definir quais serão os processos de negócio e os elementos de dados que deverão ser integrados.

A próxima tarefa é decidir as possíveis técnicas de implementação e como a integração será realizada. Conforme Linthicum (1999) a integração pode ser feita em quatro níveis:

- Nível de integração por dados: é aquela integração realizada por meio da troca de dados direta entre depósitos de dados sem envolver alteração na lógica das 
aplicações. Serão descritas mais informações sobre este tipo de integração na subseção 2.5.1.

- Nível de integração pela interface de aplicativos: os desenvolvedores aprimoram essas interfaces para acessar os processos de negócios ou as informações do banco de dados diretamente (forma nativa) ou ambos. Usando essas interfaces, os desenvolvedores são capazes de empacotar várias aplicações, permitindo que elas compartilhem a lógica de negócios e outras informações. As únicas limitações que os desenvolvedores enfrentam são as características e funções específicas das interfaces do aplicativo. Por exemplo, no caso de interfaces desenvolvidas por empresas terceirizadas, como uma interface do SAP;

- Nível de integração por métodos: há o compartilhamento dos processos de negócios ou métodos. Os processos de negócios podem ser compartilhados por servidores de aplicação ou via objetos distribuídos. Para isso, é necessário entender os processos da empresa para escolher a melhor maneira de agir, avaliando os cenários dos processos (regras, lógica, dados e objetos) para que a empresa possa ser integrada por meio de um conjunto de processos interrelacionados. Já os métodos também podem ser compartilhados e posteriormente, integrados à outras aplicações; e

- Nível de integração pela interface com o usuário: geralmente ela é utilizada quando não há outra possibilidade de integração, principalmente, quando se trata de aplicações desenvolvidas por terceiros em que não há disponibilidade de acesso ao banco de dados e ao código fonte da aplicação ou, em outros casos, quando a tecnologia é muito antiga e é inviável por causa do custo/benefício para alteração da aplicação.

A última tarefa na integração de aplicações empresariais é definir a tecnologia que deverá ser utilizada. Na Figura 2.4 são apresentadas algumas possíveis tecnologias, sendo que neste trabalho o foco é no uso de Web Services e middleware de banco de dados que são as tecnologias mais utilizadas atualmente pelas empresas em geral. 


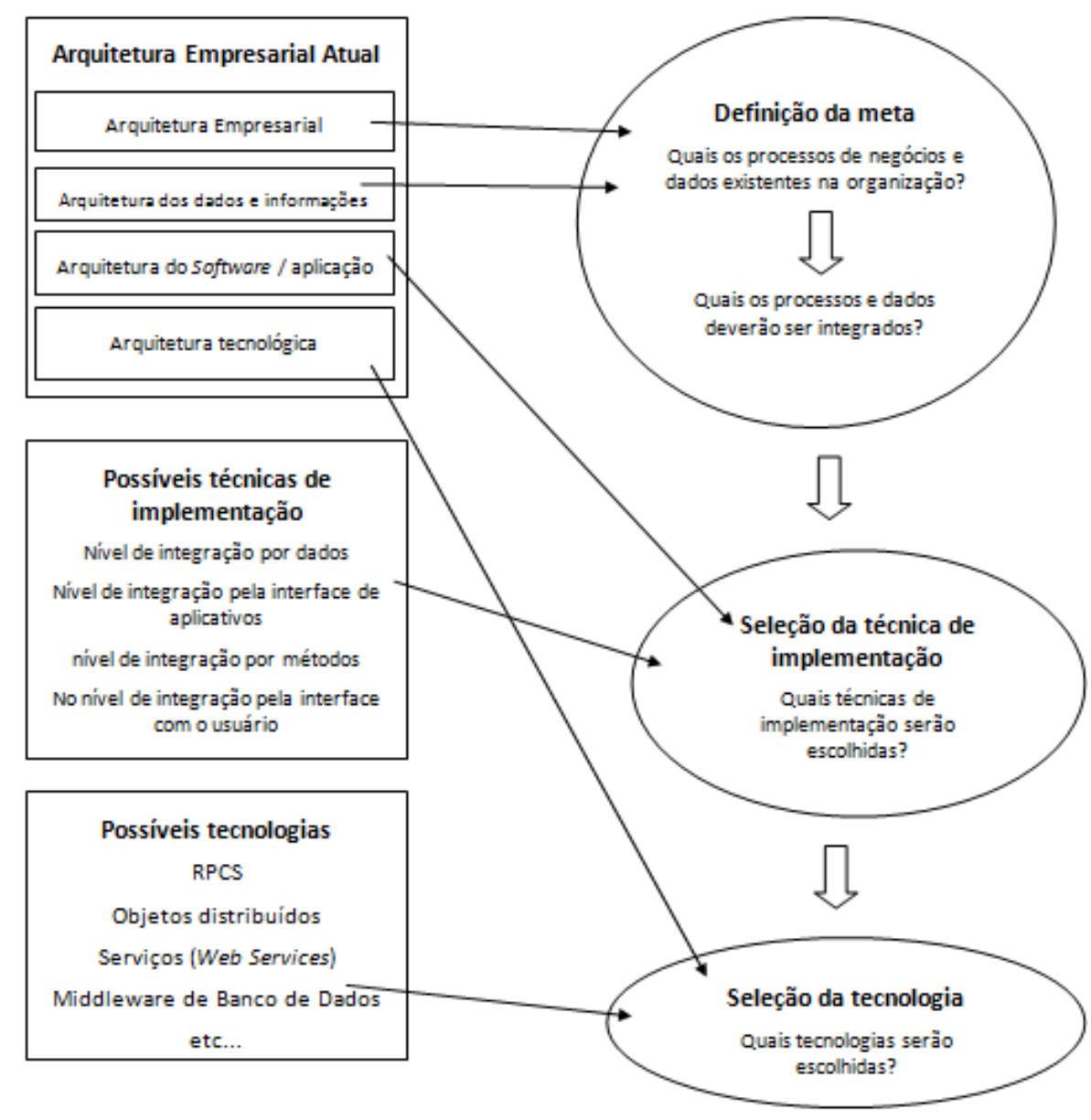

Figura 2.4: Processo de seleção das tecnologias, no caso da integração de aplicações empresariais (adaptado de (HÄMÄLÄINEN, 2002))

Quando se efetua qualquer tipo de integração de sistemas em uma empresa, é importante avaliar cada contexto particular e, assim definir qual integração (por exemplo, via dados ou via WS) é mais conveniente para este contexto.

\subsubsection{EAI via acesso nativo aos dados}

A primeira alternativa de EAI que é usada neste trabalho proporciona o acesso direto às bases de dados das aplicações envolvidas na integração. Segundo Linthicum (2003), esta abordagem consiste no acesso à base para efetuar integração de aplicações, na qual, é fornecido um simples mecanismo para a troca de informações entre dois ou mais sistemas. 
A seguir são apresentados alguns contextos em que a integração via acesso nativo aos dados pode ser uma alternativa viável de integração em uma integração de sistemas em ambientes corporativos: (1) foi desenvolvida uma nova aplicação que substitui a aplicação legada, assim basta migrar os dados para a nova aplicação; (2) os dados são temporariamente integrados, por exemplo, quando se adota uma estratégia de integração incremental. Nesse caso, pode-se projetar soluções em que a cada novo incremento um novo subconjunto dos dados é integrado, até chegar a integração completa; e (3) a integração requer réplicas periódicas de tabelas ou parte delas, por exemplo, quando há atualização dos dados na aplicação legada isso deve ser refletido nas aplicações integradas. As principais vantagens deste tipo de integração são a simplicidade da lógica de implementação e o baixo custo para comprar e instalar a tecnologia necessária.

Durante a integração, ambos os aspectos sintático e semântico dos dados devem ser considerados. O aspecto semântico refere-se ao significado, a integridade e o valor da informação para o negócio. É provável que haja problemas quando a semântica da aplicação de um sistema não for compatível com outros sistemas, ou seja, a semântica é tão diferente que os sistemas não são capazes de entender uns aos outros. Já o aspecto sintático envolve a estrutura de dados e o formato de dados, tanto na aplicação original como na de destino, portanto, uma conversão pode ser necessária (LINTHICUM, 1999; FERNANDEZ, 2004).

EAI via acesso nativo aos dados pode ser a melhor solução em muitas situações. Por exemplo, ela pode ser usada em domínios mais complexos em que existe o problema de transportar dados entre mainframes, bases de dados relacionais para bases de dados orientadas a objetos; bases de dados multidimensionais para bases de dados de mainframe; ou outro tipo de combinação. Assim, para esses domínios, a duplicação do banco de dados pode ser uma boa solução. No entanto, as dificuldades aparecem quando há uma grande variedade de bancos de dados heterogêneos em uma organização. Em vez de tentar resolver a integração em uma única etapa, uma integração gradual poderia ser uma boa alternativa (LINTHICUM, 2003). 


\subsubsection{EAI via Web Services}

Os problemas com a abordagem EAI se manifestaram ao longo do tempo. Como a EAI ganhou popularidade na década de 90 , o primeiro problema foi que a própria arquitetura de EAI (na época) exigia um controle centralizado. No entanto, as empresas tornaramse globalizadas a partir da década de 90 e suas organizações de TI começaram a distribuir as suas funções em várias partes do mundo. Por esse motivo, o controle centralizado de TI tornou-se inviável (DAVIES, 2008).

Atualmente, os ambientes são mais complexos, exige-se a reutilização de sistemas legados, em vez de substituí-los. Além disso, com a evolução da internet criou-se a possibilidade de novos modelos de negócio, em que se exige maior flexibilidade e interoperabilidade nos sistemas. Em um ambiente de tal complexidade, é necessário desenvolver sistemas que incorporem a heterogeneidade como uma parte fundamental de seu ambiente de TI, de modo que se possa acomodar uma grande variedade de hardware, sistemas operacionais, middleware e armazenamentos de dados (CHANNABASAVAIAH et al., 2004).

Com o advento dos Web Services e SOA, ficou mais fácil realizar a EAI e executar a informatização de integrações interempresariais, uma vez que se pode oferecer serviços nas aplicações já existentes. Do ponto de vista empresarial, EAI pode ser introduzida para simplificar a infraestrutura da aplicação e ajudar a promover a reutilização, proporcionando assim, uma boa motivação para a criação de uma SOA (KRAFZIG et al., 2004). Uma forma de alcançar esse objetivo é utilizando um aplicativo de integração empresarial baseado em SOA e Web services (DENG et al., 2008).

A fim de proporcionar a funcionalidade de EAI em um ambiente orientado a serviços, a tarefa mais comum é a ativação do serviço. Essa ativação é o processo que cria um serviço para encapsular a funcionalidade fornecida por uma aplicação existente. Por exemplo, essa aplicação pode ser alguma função de um aplicativo monolítico de um mainframe que é empacotada e distribuída como serviço. Na Figura 2.5 é apresentado um exemplo da transformação de uma aplicação monolítica em uma aplicação orientada a serviços (KRAFZIG et al., 2004) em que: (a) inicia-se a transformação da aplicação monolítica em uma aplicação SOA; (b) é feita a separação da parte visual da parte não visual; (c) é incluído um barramento para dar suporte às diferentes interfaces; (d) o 
modelo é cortado e separado em dois sub modelos; e (e) há a transformação da aplicação em uma infraestrutura de serviços desacoplados.

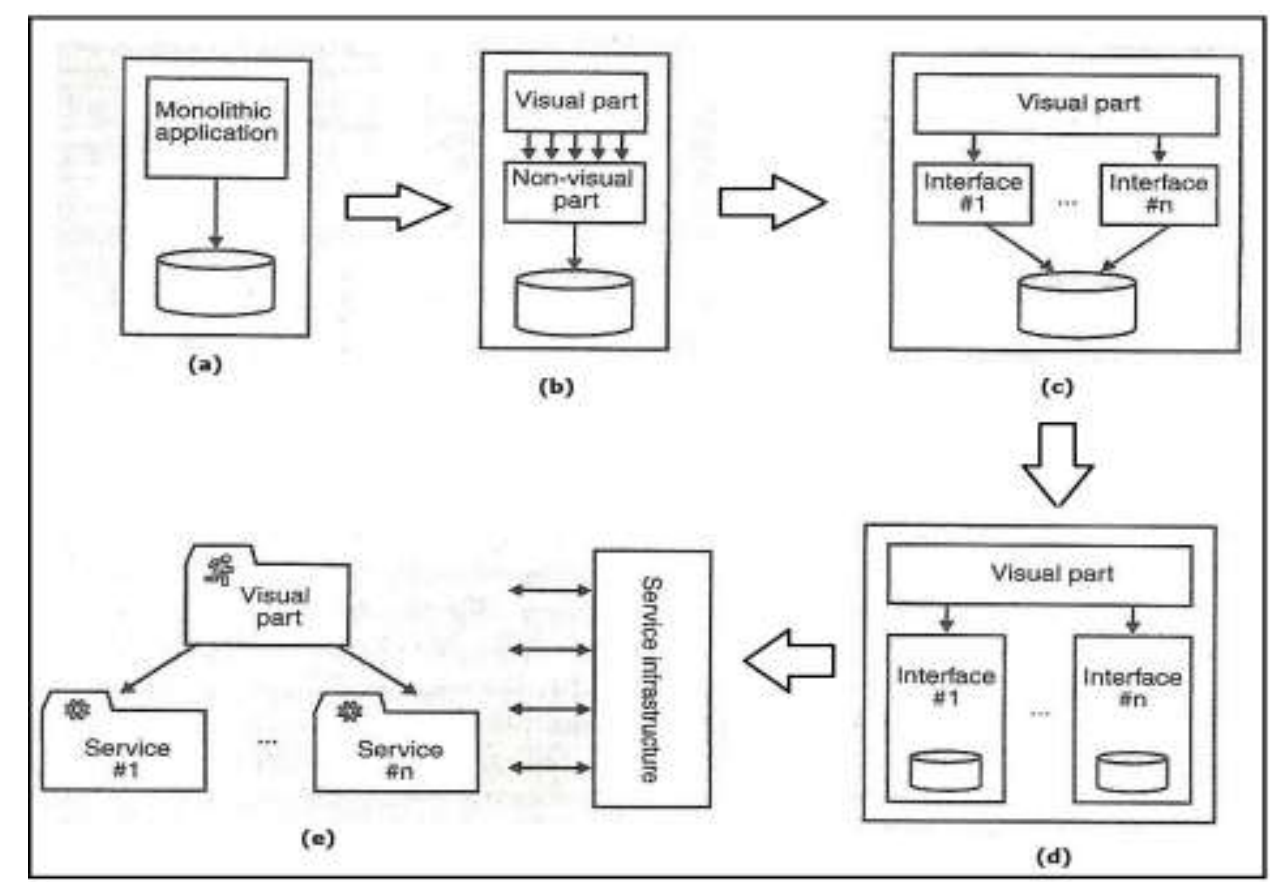

Figura 2.5: Exemplo da transformação de uma aplicação monolítica em uma aplicação orientada a serviços (KRAFZIG et al., 2004)

O acesso à camada não visual é definido por uma ou mais interfaces. Se possível, a implementação das interfaces e dos dados persistentes também pode ser separada. Para finalizar, a aplicação é movida para uma infraestrutura de serviços (KRAFZIG et al., 2004).

Na próxima seção, são apresentados de forma sucinta os conceitos sobre padrões de software, que fornecem subsídios para o Capítulo 5 que trata do assunto de Padrões para a integração de aplicações empresariais.

\subsection{Padrões}

Conforme Buschmann (1996), um padrão descreve uma solução para um problema que ocorre com frequência durante o desenvolvimento de software, podendo ser considerado como um par "problema/solução".

Também, pode-se considerar que um padrão é um conjunto de informações instrutivas que possui um nome e que capta a estrutura essencial e o raciocínio de uma 
família de soluções comprovadamente bem sucedidas para um problema repetido que ocorre sob um determinado contexto e um conjunto de repercussões (APPLETON, 1997).

Um fator importante, conforme Gamma (1995), é que projetistas familiarizados com certos padrões podem aplicá-los imediatamente a problemas de projeto, sem ter que redescobri-los. O uso de padrões proporciona um vocabulário comum para a comunicação entre projetistas. Além disso, eles atuam como blocos construtivos a partir dos quais projetos mais complexos podem ser construídos.

\subsubsection{Componentes de um padrão}

Existem componentes essenciais que devem ser claramente identificáveis quando se faz a leitura de um padrão, conforme Appleton (1997), que são definidos a seguir:

- Nome: todo padrão deve ter um nome significativo. Pode ser uma única palavra ou frase curta que se refira ao padrão e ao conhecimento ou estrutura descritos por ele. Se o padrão possuir mais do que um nome comumente usado ou reconhecível na literatura, subseções "Aliases" ou "Also know as" devem ser criadas;

- Problema: estabelece o problema a ser resolvido pelo padrão, descreve a intenção e objetivos do padrão perante o contexto e as forças específicas;

- Contexto: são pré-condições dentro das quais o problema e sua solução costumam ocorrer e para as quais a solução é desejável, o que reflete a aplicabilidade do padrão. Pode também ser considerado como a configuração inicial do sistema antes da aplicação do padrão;

- Forças: trata-se da descrição dos impactos, influências e restrições relevantes para o problema e de como eles interagem ou são conflitantes entre si e com os objetivos a alcançar;

- Solução: são relacionamentos estáticos e regras dinâmicas que descrevem como obter o resultado desejado. Equivale a dar instruções que descrevem como o problema é resolvido, podendo para isso utilizar texto, diagramas e figuras. São possíveis as seguintes subseções: 
○ Estrutura: descreve a forma e a organização estática do padrão;

○ Participantes: descreve cada um desses componentes;

o Dinâmicas: exibe o comportamento dinâmico do padrão;

○ Implementação: mostra os detalhes de implementação do padrão; e

- Variações: discute as possíveis variações e especializações da solução.

- Exemplos: são uma ou mais aplicações do padrão que ilustram, num contexto inicial específico, como o padrão é aplicado e transforma aquele contexto em um contexto final;

- Contexto Resultante: é o estado ou configuração do sistema após a aplicação do padrão, podendo ter uma subseção "Conseqüências" (tanto boas quanto ruins). Descreve as pós-condições e efeitos colaterais do padrão;

- Raciocínio (do inglês Rationale): é uma explicação das regras ou passos do padrão que explicam como e porque ele trata suas influências contrárias, definidas em 'Forças', para alcançar os objetivos, princípios e filosofia propostos. Em suma, é dito como o padrão funciona, porque funciona e porque ele é bom;

- Padrões relacionados: são os relacionamentos estáticos e dinâmicos desse padrão com outros dentro da mesma linguagem ou sistema de padrões. Padrões relacionados geralmente compartilham as mesmas influências, sendo possíveis os seguintes tipos de padrões relacionados:

○ Padrões predecessores, cuja aplicação conduza a esse padrão;

○ Padrões sucessores, que devem ser aplicados após esse;

○ Padrões alternativos, que descrevem uma solução diferente para o mesmo problema mas diante de influências e restrições diferentes; e

○ Padrões codependentes, que podem (ou devem) ser aplicados simultaneamente com esse padrão.

- Usos conhecidos: descreve as ocorrências conhecidas do padrão e sua aplicação em sistemas existentes. Isso ajuda a validar o padrão, verificando se ele é realmente uma solução provada para um problema recorrente. 


\subsubsection{Classificação de padrões}

Padrões de software abrangem diferentes níveis de abstração, podendo portanto ser classificados em diversas categorias de modo a facilitar sua recuperação e uso. Porém, essa classificação não é rigorosa, podendo haver padrões que se encaixem em mais do que uma categoria (APPLETON, 1997). A seguir resumem-se algumas categorias importantes de padrões segundo o autor.

- Padrões de processo: definem soluções para os problemas encontrados nos processos envolvidos na engenharia de software: desenvolvimento, controle de configuração, testes, etc;

- Padrões arquiteturais: expressam o esquema ou organização estrutural fundamental de sistemas de software ou hardware;

- Padrões de padrão (em inglês, patterns on patterns): são padrões descrevendo como um padrão deve ser escrito, ou seja, que padronizam a forma com que os padrões são apresentados aos seus usuários;

- Padrões de análise: descrevem soluções para problemas de análise de sistemas, embutindo conhecimento sobre o domínio de aplicação específico;

- Padrões de projeto: definem soluções para problemas de projeto de software;

- Padrões de interface: definem soluções para problemas comuns no projeto da interface de sistemas. É um caso particular dos padrões de projeto;

- Padrões de programação: descrevem soluções de programação particulares de uma determinada linguagem ou regras gerais de estilo de programação;

- Padrões de Persistência: descrevem soluções para problemas de armazenamento de informações em arquivos ou bancos de dados;

- Padrões para Hipertexto: descrevem soluções para problemas encontrados no projeto de hipertextos; e

- Padrões para Hipermídia: descrevem soluções para problemas encontrados no desenvolvimento de aplicações hipermídia. 


\subsubsection{Regras para derivação de novos padrões}

Algumas regras para derivação de novos padrões ("Pattern mining") são sugeridas por BUSCHMANN et al. (1996). São elas:

- Encontre pelo menos três exemplos nos quais um problema é resolvido efetivamente usando a mesma solução;

- Extraia a solução, o problema e as influências;

- Declare a solução como candidata a padrão;

- Execute um “writer's workshop" para melhorar a descrição do candidato e compartilhá-lo com outros;

- Aplique o candidato a padrão em um outro projeto de desenvolvimento de Software; e

- Declare o candidato a padrão como padrão se sua aplicação for bem sucedida. Caso contrário tente procurar uma solução melhor.

\subsection{Trabalhos relacionados a padrões para EAI}

A seguir são descritos trabalhos relacionados a padrões para integração de aplicações empresariais encontrados na literatura. Deve-se observar que esses padrões possuem uma abordagem mais técnica e são mais voltados a aspectos de implementação, enquanto os padrões propostos neste trabalho (Capítulo 5) focam na perspectiva das regras de negócios estabelecidas pelas organizações ao considerar um projeto de integração de aplicações.

Os padrões descritos a seguir possuem algum tipo de relacionamento com um ou mais padrões propostos neste trabalho, sendo que isso é descrito na seção "Padrões relacionados" de cada um dos padrões (Capítulo 5 e Apêndice C). 


\subsubsection{Shared database (base de dados compartilhada)}

O padrão Base de dados compartilhada, de Hohpe et al. (2003), relativo ao compartilhamento de informações por diferentes aplicações usa uma abordagem que permite acesso livre aos dados compartilhados (como se pode visualizar na Figura 2.6).

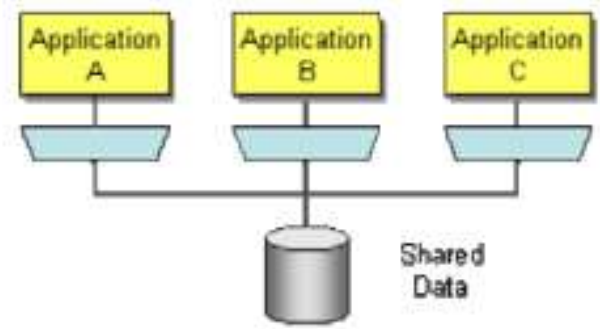

Figura 2.6: Base de dados compartilhada (HOHPE; WOOLF, 2003).

\subsubsection{Remote Procedure Invocation (Chamadas de procedimentos remotos)}

Padrões existentes na literatura que utilizam chamadas a procedimentos remotos também estão relacionados aos padrões propostos neste trabalho, principalmente aos padrões que utilizam Web Services. Isso muitas vezes é feito abstraindo aspectos de independência de plataforma e linguagem de programação, segundo Hohpe et al. (2003), com a popularização de SOA, este padrão passou a ser utilizado por muitas empresas para realizar a integração de sistemas empresariais, principalmente considerando sistemas legados em diferentes plataformas. Também na literatura foram encontrados alguns exemplos são eles: (1) o framework proposto por Deng et al. (2008), que combina EAI com a tecnologia de Web Services, podendo trabalhar com dados de diferentes fontes ou até mesmo de sistemas heterogêneos; e o trabalho de Gudivada et al. (2005), que descreve uma abordagem para EAI utilizando os Web Services extensíveis a fim de integrar várias aplicações legadas; (2) foi apresentada no artigo de Jiang (2008), uma discussão de algumas técnicas fundamentais para a integração de aplicativos em ambientes heterogêneos. A técnica trabalha com a decomposição das funcionalidades de um sistema legado e depois, executa-se o seu empacotamento por meio de um wrapper e por último, são disponibilizadas em Web Services, como se pode ver na Figura 2.7 ilustrada a seguir; e (3) no livro de Hohpe et al. (2003), aborda-se o tema de integração por meio de uma arquitetura orientada a serviços em que cada aplicação pode "negociar" um contrato de comunicação com o serviço. Essas duas 
funções, serviço de descoberta e de negociação, são os principais elementos que compõem uma arquitetura orientada a serviço. Um novo aplicativo pode ser desenvolvido usando serviços remotos que podem ser fornecidos por outros aplicativos. Portanto, chamar um serviço pode ser considerado uma integração entre duas ou mais aplicações;

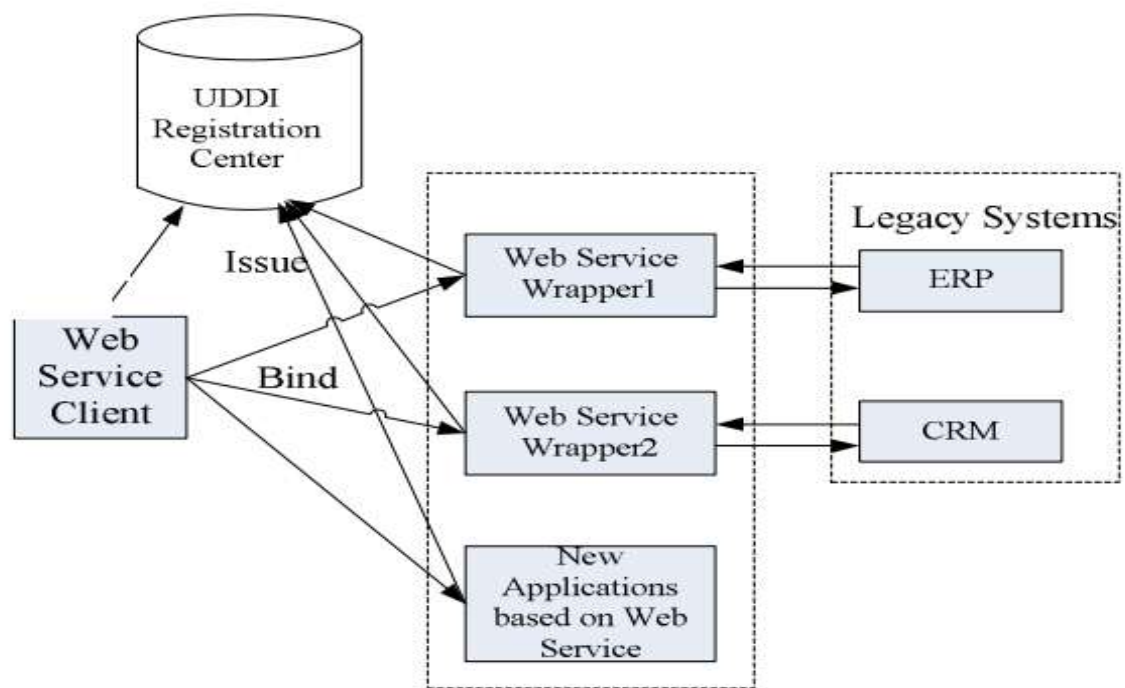

Figura 2.7: Empacotamento de Web Services (wrapper) de sistemas legados (JIANG, 2008).

O padrão Remote Procedure Invocation (Chamadas de procedimentos remotos) segundo Hohpe et al. (2003), aplica o princípio de encapsulamento para integração de aplicativos. Se uma aplicação necessita de alguma informação que é propriedade de outro aplicativo, ela pode efetuar o seu pedido à aplicação diretamente. Se um aplicativo precisa modificar os dados de outro, ele pode executar uma chamada para o outro aplicativo e, dessa forma, cada aplicação mantém a sua integridade de dados, sendo que cada aplicação pode alterar seus dados internos, sem afetar os outros aplicativos. Há um grande número de abordagens de chamada de procedimento remoto (RPC) tais como: CORBA, COM, .NET Remoting, Java RMI, etc. Atualmente, os Web Services são os mais utilizados e uma de suas características é que eles funcionam facilmente com HTTP (não há problemas com os firewalls).

\subsubsection{File Transfer (Transferência de dados)}

Uma outra categoria de padrões existentes relacionados aos padrões propostos refere-se a duplicação de dados, que é uma solução adotada quando muitos sistemas empresariais 
precisam acessar os mesmos dados (HOHPE; WOOLF, 2003). Uma das formas de implementar isso é por meio do banco de dados, em que muitos fornecedores possuem ferramentas que efetuam as operações de replicações no banco de dados, podendo assim, exportar os dados em arquivos e re-importá-los para o outro sistema. A Figura 2.8 ilustra o padrão "Data replication" da IBM de Nielsen et al. (2001), que, apesar de não seguir o formato convencional dos padrões, representa um tipo de replicação bidirecional. Neste padrão, a replicação de dados fornece a replicação bidirecional de dados entre dois nós. Isto pode ser usado para proporcionar redundância, bem como benefícios de desempenho para aplicações que utilizam o mesmo banco de dados, mas estão dispersos geograficamente. Ao contrário do caso de propagação de dados, a replicação assume que os esquemas das duas bases de dados são compatíveis, por isso não há necessidade de transformação de dados.

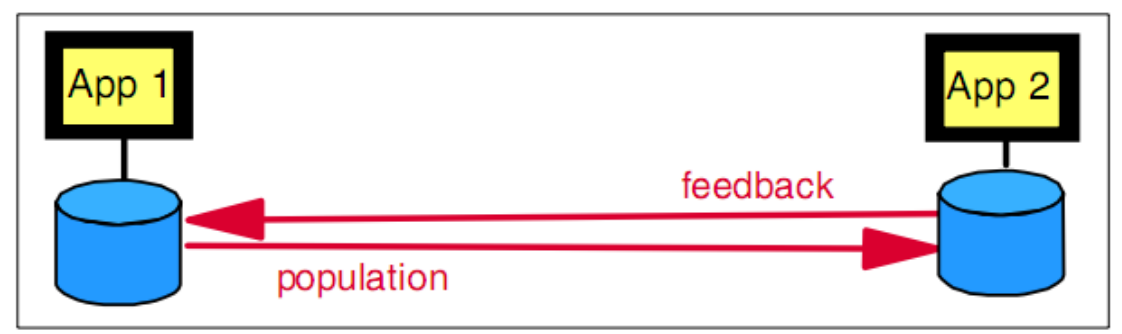

Figura 2.8: Exemplo de replicação bidirecional (NIELSEN et al., 2001).

Hohpe et al. (2003) aborda o tema de transferência de arquivos, que pode ser utilizado quando uma empresa possui vários aplicativos que foram construídos de forma independente e com diferentes linguagens e plataformas, uma vez que os arquivos são mecanismos de armazenamento universal e estão disponíveis a partir de qualquer linguagem empresarial. Provavelmente a abordagem mais simples seria de alguma forma integrar as aplicações usando arquivos. Neste caso, é importante que cada arquivo produza aplicativos que contenham informações que outras aplicações precisam consumir. A parte integradora deve assumir a responsabilidade de transformar arquivos em diferentes formatos. A Figura 2.9 ilustra um exemplo de transferência de arquivos. Além disso, deve-se tomar uma decisão importante em relação ao formato do arquivo, a fim de que a aplicação que for consumir este arquivo possa reconhecer os dados para efetuar a importação sem problemas. 


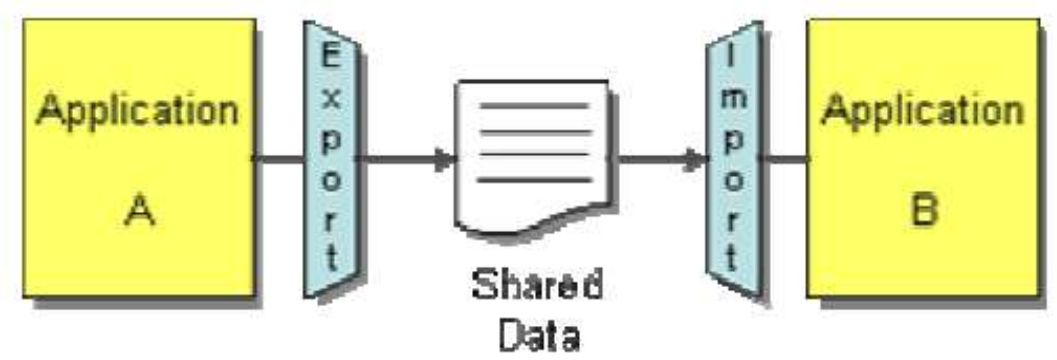

Figura 2.9: Exemplo de transferência de arquivos. (HOHPE; WOOLF, 2003).

\subsubsection{Discussão}

A maioria dos padrões mencionados (e também outros padrões indiretamente relacionados a este trabalho) foi escrita sem usar um dos formatos de padrões de software, além de estarem espalhados em diversos livros, artigos científicos e sites da Web, dificultando assim, seu uso. Também, conforme mencionado anteriormente, eles têm um enfoque mais técnico de implementação, sendo difícil aplicá-los levando em conta o contexto de integração da empresa. Essa é uma das motivações para a proposta de padrões feita neste trabalho (Capítulo 5).

\subsection{Considerações Finais}

Neste capítulo apresentou-se uma visão geral da abordagem Integração de Aplicações Empresariais e também da Arquitetura Orientada a Serviços, com ênfase na tecnologia de Web Services. Também foram apresentadas, conforme o escopo deste trabalho, duas abordagens de integração: (1) EAI via acesso nativo aos dados e (2) EAI via Web Services. Por último, foi apresentada uma visão geral de Padrões de software e uma breve descrição de trabalhos relacionados a padrões para EAI. No próximo capítulo é realizada uma comparação das duas abordagens de integração citadas anteriormente. 


\section{Capítulo \\ 3 \\ Comparação das abordagens EAI via WS X EAI via dados}

\subsection{Considerações Iniciais}

Nesta seção apresenta-se uma comparação entre as abordagens de integração de aplicações empresariais feitas por meio de Web Services e acesso nativo ao banco de dados. A fim de facilitar a discussão, a partir de agora as abordagens serão chamadas de EAI-WS e EAI-Dados, respectivamente.

O Capítulo está organizado da seguinte forma: é apresentada na Seção 3.2 a Comparação entre EAI-Dados e EAI-WS. Na Seção 3.3 são apresentadas as considerações finais deste capítulo.

\subsection{Comparação entre EAI-Dados e EAI-WS}

A norma da ISO-IEC 9126 contém características e subcaracterísticas que definem um produto de qualidade. Foram criadas divisões nessa norma, após sucessivas melhoras surgindo a norma ISO-IEC 9126-1 (ISO/IEC 9126-1, 2000) que apresenta um conjunto de características que definem um modelo de qualidade que podem ser aplicadas a qualquer produto de software.

Neste trabalho, a comparação foi baseada na Revisão Sistemática realizada (ver Apêndice A) e no conhecimento prático sobre a execução de EAI-WS e EAI-Dados pela autora e pela orientadora.

A seguir são detalhadas as características e as subcaracterísticas utilizadas na Tabela 3.1, que resume a comparação tomando como base a norma ISO-IEC 9126-1.

- Eficiência: é constituída por um conjunto de atributos que verifica o relacionamento entre o nível de desempenho de software e a quantidade de 
recursos utilizados, mediante condições estabelecidas. Suas subcaracterísticas são:

○ Comportamento em relação aos recursos: são atributos de software que evidenciam a quantidade de recursos usados e a duração de seu uso na execução de suas funções; e

○ Comportamento em relação ao tempo: atributos do software que tratam o seu tempo de resposta, tempo de processamento e velocidade na execução de suas funções.

- Funcionalidade: descreve um conjunto de atributos que evidenciam a existência de um conjunto de funções que satisfazem às necessidades implícitas e explícitas, além das suas propriedades específicas. Suas subcaracterísticas utilizadas neste trabalho são:

- Acurácia: Evidencia a geração de resultados ou efeitos corretos ou conforme acordados;

○ Interoperabilidade: Evidencia sua capacidade de interagir com sistemas específicos; e

- Segurança de acesso: Evidencia sua capacidade de evitar acesso não autorizado, acidental ou deliberado, a programas e aos dados.

- Manutenibilidade: Mostra os atributos que avaliam o esforço necessário para fazer modificações específicas no software. A subcaracterística utilizada neste trabalho é:

- Modificabilidade (neste caso em relação à integração de duas aplicações): evidencia o esforço necessário para modificar, remover defeitos ou adaptar a mudanças ambientais; e

- Foi acrescentada uma subcaracterística específica para tratar do reúso, que é um aspecto importante a ser considerado em EAI, denotando a facilidade em reutilizar código durante a integração.

- Portabilidade: capacidade do software de ser transferido de um ambiente para outro. As subcaracterísticas utilizadas foram:

- Adaptabilidade: evidencia a capacidade de se adaptar a ambientes diferentes, sem a necessidade da aplicação de outras ações ou meios além daqueles fornecidos para essa finalidade; e 
- Facilidade de Instalação: atributos do software que o tornam consonante com os padrões ou as convenções relacionadas à portabilidade.

- Confiabilidade: possui um conjunto de atributos que evidenciam a capacidade do software de manter seu nível de desempenho sob condições estabelecidas durante um período de tempo estabelecido. A subcaracterística é:

- Recuperabilidade: evidenciam sua capacidade de restabelecer seu nível de desempenho e recuperar dados diretamente afetados, em caso de falha, e no tempo e esforço necessário para isso.

- Usabilidade: evidencia o esforço necessário para se poder utilizar o software. As subcaracterísticas utilizadas neste trabalho são:

○ Facilidade de aprendizagem: evidenciam o esforço do usuário para aprender como utilizar a aplicação; e

○ Inteligibilidade: evidencia o esforço do usuário para reconhecer o conceito lógico e sua aplicabilidade.

Tabela 3.1: Comparação entre EAI-WS e EAI-Dados.

\begin{tabular}{|l|l|}
\hline \multicolumn{1}{|c|}{ Característica/Sub-característica } & Fator \\
\hline Eficiência -> Comportamento em relação aos recursos & 1 \\
\hline Eficiência -> Comportamento em relação ao tempo & 2 \\
\hline Funcionalidade -> Acurácia & 3 \\
\hline Funcionalidade ->Interoperabilidade & 4 \\
\hline Funcionalidade -> Segurança de acesso & 5 \\
\hline Manutenibilidade -> Modificabilidade - Reúso & 6 \\
\hline Manutenibilidade -> Modificabilidade (Integração de duas aplicações) & 7 \\
\hline Portabilidade -> Adaptabilidade & 8 \\
\hline Portabilidade -> Facilidade de Instalação & 9 \\
\hline Confiabilidade -> Recuperabilidade & 10 \\
\hline Usabilidade -> Facilidade de aprendizagem & 11 \\
\hline Usabilidade ->Inteligibilidade & 12 \\
\hline
\end{tabular}

Na Tabela 3.2 são apresentados os pontos positivos e negativos das abordagens EAI-WS e EAI-Dados utilizando as características e sub características da Tabela 3.1. 
Tabela 3.2: Pontos positivos e negativos das abordagens EAI-WS e EAI-Dados.

\begin{tabular}{|c|c|c|}
\hline Fator & EAI-WS & EAI-Dados \\
\hline 1 & $\begin{array}{l}\text { + Não há espaço desperdiçado com informações } \\
\text { redundantes, a menos que a aplicação que invoca o } \\
\text { serviço armazene uma cópia dos dados obtidos. }\end{array}$ & $\begin{array}{l}\text { - Dependendo da estratégia adotada para realizar } \\
\text { a integração, mais espaço será necessário para } \\
\text { armazenar as cópias do banco de dados ou a } \\
\text { tabela em cada aplicação (SILBERSCHATZ et } \\
\text { al., 1999). }\end{array}$ \\
\hline 2 & $\begin{array}{l}\text { - O desempenho pode ser afetado quando existem } \\
\text { serviços invocando outros serviços, e também, quando } \\
\text { precisa-se executar a validação dos parâmetros de } \\
\text { entrada. Além disso, caso um Web Service esteja } \\
\text { danificado, uma propagação do erro poderá ocorrer, } \\
\text { afetando ou até mesmo paralisando todo o sistema } \\
\text { (MAHMOOD, 2007). } \\
+ \text { Uma vantagem de EAI-WS é que várias } \\
\text { alternativas de WS podem ser implementadas para o } \\
\text { mesmo serviço, com diferentes atributos de qualidade. } \\
\text { Assim, o aplicativo cliente pode escolher o serviço } \\
\text { que melhor se adapta às suas necessidades em termos } \\
\text { de desempenho. }\end{array}$ & $\begin{array}{l}\boldsymbol{+} \text { - Se outro banco de dados for acessado } \\
\text { diretamente, o desempenho depende do volume } \\
\text { de dados a ser integrado e as conversões } \\
\text { necessárias, uma vez que se pode optar por fazer } \\
\text { cópias temporárias de banco de dados (ou parte } \\
\text { dele) de uma aplicação para outra. } \\
\text { + - Problemas de desempenho podem ser } \\
\text { resolvidos no lado do cliente, mas isso levanta o } \\
\text { problema de inconsistência. } \\
\text { + Por outro lado, se houver várias cópias da } \\
\text { mesma tabela ou base de dados, o aplicativo } \\
\text { cliente pode escolher aquela cópia que oferece o } \\
\text { melhor tempo de acesso (SILBERSCHATZ et } \\
\text { al., 1999). }\end{array}$ \\
\hline 3 & $\begin{array}{l}\text { + Uma vez que um Web Service esteja bem projetado } \\
\text { para executar uma tarefa de integração, a consistência } \\
\text { das informações é garantida. } \\
\text { - Um projeto ruim do modelo de negócios pode levar } \\
\text { à inconsistência de informações. Por exemplo, se um } \\
\text { WS retorna dados sobre um paciente em um hospital e } \\
\text { esses dados são armazenados localmente por um } \\
\text { médico em seu consultório particular, que procede } \\
\text { com as modificações sem devolvê-las ao hospital, }\end{array}$ & $\begin{array}{l}\text { - A manutenção de uma ou mais cópias de uma } \\
\text { base de dados ou tabela em locais diferentes } \\
\text { podem gerar inconsistências. } \\
\text { + Se houver uma política de sincronização }\end{array}$ \\
\hline
\end{tabular}




\begin{tabular}{|c|c|c|}
\hline & $\begin{array}{l}\text { haverá inconsistência entre as duas aplicações. Seria } \\
\text { necessário neste caso, garantir que quaisquer } \\
\text { alterações feitas localmente sejam enviadas de volta } \\
\text { para o outro aplicativo. }\end{array}$ & $\begin{array}{l}\text { pode-se evitar ou amenizar os problemas citados } \\
\text { anteriormente. } \\
\text { + A duplicação de dados tem um aspecto } \\
\text { positivo, em que a falha permanente de um } \\
\text { banco de dados é amenizada, porque os dados } \\
\text { estão preservados nas outras cópias } \\
\text { (SILBERSCHATZ et al., 1999). }\end{array}$ \\
\hline 4 & $\begin{array}{l}\text { + Web Services são independentes de linguagem de } \\
\text { programação (ENDREI et al., 2004). } \\
\text { + Um Web Service pode ser agregado com outro WS } \\
\text { (ENDREI et al., 2004). Isso facilita a divisão de um } \\
\text { problema complexo em vários serviços e, dessa forma, } \\
\text { melhora-se a reutilização dos serviços de baixa } \\
\text { granularidade. }\end{array}$ & $\begin{array}{l}\text { - Os problemas surgem quando é necessário } \\
\text { executar a conversão de dados ou quando o } \\
\text { esquema do banco é muito complexo e não há } \\
\text { uma boa documentação. } \\
\text { + Existe grande número de tecnologias que } \\
\text { podem dar suporte ao acesso às bases de dados. } \\
\text { - A composição é mais difícil, uma vez que cada } \\
\text { integração é feita de acordo com exigências } \\
\text { particulares de cada caso. Por exemplo, no } \\
\text { exemplo de uma agência de turismo, seria } \\
\text { necessário ter acesso às bases de dados de } \\
\text { diferentes aplicações e de diferentes prestadores } \\
\text { de serviços para executar o processo de } \\
\text { negócios. Algumas das aplicações podem ser } \\
\text { fechadas, ou seja, implementadas por terceiros, e } \\
\text { isso iria dificultar o acesso direto à base de } \\
\text { dados, tornando assim, impossível a integração. }\end{array}$ \\
\hline 5 & $\begin{array}{l}\text { + Aplicativos clientes devem seguir as políticas de } \\
\text { segurança da empresa, de modo que seja garantido } \\
\text { que apenas as aplicações com os direitos apropriados } \\
\text { sejam autorizadas a acessar as informações. } \\
\text { + Facilidade em implementar políticas. } \\
\text { - WS quando usado sozinho, não oferece uma }\end{array}$ & $\begin{array}{l}\text { + - Acesso ao BD possibilita uso indevido por } \\
\text { causa do acesso total ou parcial ao banco de } \\
\text { dados por parte dos desenvolvedores. No } \\
\text { entanto, isso pode acarretar alguns problemas de } \\
\text { segurança, especialmente quando as aplicações } \\
\text { pertencentes a diferentes empresas estão sendo } \\
\text { integradas. Uma alternativa para tentar amenizar }\end{array}$ \\
\hline
\end{tabular}




\begin{tabular}{|c|c|c|}
\hline & $\begin{array}{l}\text { quantidade certa de segurança exigida por projetos de } \\
\text { EAI, sendo necessário, entre outras atividades, efetuar } \\
\text { a validação do remetente da mensagem. Isto implica } \\
\text { que outras soluções devem ser utilizadas em conjunto } \\
\text { com o WS para melhorar a segurança. } \\
\text { + Soluções utilizadas em conjunto com o WS } \\
\text { melhoram a segurança. Por exemplo, WS-Security } \\
\text { (Web Services Security). é uma especificação que } \\
\text { fornece um protocolo de comunicação para lidar com } \\
\text { a segurança durante a troca de mensagens entre o WS } \\
\text { SOAP. Neste caso, usa-se um elemento de cabeçalho } \\
\text { de mensagens SOAP para anexar as informações de } \\
\text { segurança às mensagens, tornando possível o } \\
\text { intercâmbio de diferentes tipos de solicitações, tais } \\
\text { como nomes, identidades, chaves, grupos, privilégios, } \\
\text { recursos, etc, assim como informações sobre } \\
\text { criptografia e assinatura digital (SOSNOSKI, 2011). } \\
\text { - Se serviços muito específicos estão disponíveis, } \\
\text { cada projeto novo de integração pode implicar no } \\
\text { desenvolvimento de serviços adicionais para cumprir } \\
\text { cada requisito de segurança mais peculiar. Por } \\
\text { exemplo, se um serviço CRUD está disponível para } \\
\text { uma tabela de banco de dados, qualquer aplicação que } \\
\text { tenha acesso a esse serviço poderá ser capaz de } \\
\text { incluir, atualizar e excluir registros, no entanto, é } \\
\text { perigosa, caso não se adote políticas de segurança } \\
\text { corretas. }\end{array}$ & $\begin{array}{l}\text { esse problema, é fazer com que o aplicativo do } \\
\text { servidor ofereça views, procedures ou até mesmo } \\
\text { efetuar uma cópia somente das informações e de } \\
\text { dados que sejam específicos. No entanto, essa } \\
\text { alternativa pode ter algumas consequências } \\
\text { negativas, tais como inconsistência, baixa } \\
\text { flexibilidade e desperdício de espaço no } \\
\text { armazenamento das informações. }\end{array}$ \\
\hline 6 & $\begin{array}{l}\text { + Possuem funções empresariais bem definidas que } \\
\text { estão disponíveis e podem ser reutilizadas facilmente } \\
\text { por outras aplicações (ENDREI et al., 2004). Ao } \\
\text { conhecer as interfaces fornecidas e solicitadas, } \\
\text { qualquer aplicativo é capaz de efetuar a integração, } \\
\text { uma vez que não há necessidade de se conhecer a }\end{array}$ & $\begin{array}{l}\text { - Quando a informação é acessada diretamente } \\
\text { da base de dados, muitas vezes exige-se soluções } \\
\text { que são muito específicas de cada problema de } \\
\text { integração, sendo possível a reutilização, mas em } \\
\text { um nível mais baixo. }\end{array}$ \\
\hline
\end{tabular}




\begin{tabular}{|c|c|c|}
\hline & $\begin{array}{l}\text { lógica interna do WS, assim, a reutilização se torna } \\
\text { mais fácil. Por exemplo, a autora trabalhou } \\
\text { recentemente na implementação de alguns padrões } \\
\text { EAI usando WS, em que há a implementação de dois } \\
\text { WS. O primeiro efetua uma busca no banco de dados } \\
\text { Interbase para retornar um determinado funcionário. } \\
\text { Já o segundo faz inclusão, alteração ou exclusão de } \\
\text { funcionários no mesmo banco de dados. Os dois Web } \\
\text { Services podem ser reutilizados por outros padrões } \\
\text { que já foram implementados anteriormente, bem como } \\
\text { por outras aplicações que podem ser integradas de } \\
\text { acordo com as necessidades da organização. }\end{array}$ & \\
\hline & $\begin{array}{l}\text { + - Executar o projeto de Web Services requer } \\
\text { conhecimento sobre os aplicativos e como eles podem } \\
\text { ser integrados. Neste caso, uma análise mais apurada } \\
\text { dos requisitos é necessária para prover os serviços } \\
\text { adequados com o nível de granularidade correta. }\end{array}$ & $\begin{array}{l}\text { - A maior dificuldade está em entender o } \\
\text { esquema de banco de dados e como as } \\
\text { informações podem ser integradas. Esta é uma } \\
\text { tarefa onerosa, que envolve altos custos, esforços } \\
\text { por parte do projetista e tempo para serem } \\
\text { executados. }\end{array}$ \\
\hline & $\begin{array}{l}\text { + Um serviço com alta coesão é mais fácil de } \\
\text { compreender e reutilizar. } \\
\text { - As tentativas de implementar serviços com } \\
\text { propósito geral pode tornar o sistema ineficiente. }\end{array}$ & $\begin{array}{l}\text { - A interpretação dos dados é um risco que pode } \\
\text { acarretar falhas no projeto. Tanto o } \\
\text { conhecimento sintático como o semântico dos } \\
\text { dados é importante, e isso depende de uma boa } \\
\text { documentação do banco de dados. }\end{array}$ \\
\hline & $\begin{array}{l}\text { + - Quando se faz uma manutenção é necessário } \\
\text { analisar o código-fonte para detectar possíveis } \\
\text { dependências com as aplicações que foram alteradas } \\
\text { (LÄMMER, 2008). Ou seja, se uma alteração na } \\
\text { interface do WS é necessária, em seguida, todas as } \\
\text { aplicações que invocam esse Web Service devem ser } \\
\text { analisadas e, possivelmente, alteradas para se adequar } \\
\text { à nova interface. }\end{array}$ & $\begin{array}{l}\text { - Em uma integração de aplicativos } \\
\text { desenvolvidos por fornecedores externos, pode } \\
\text { ser um risco, quando o projetista de integração } \\
\text { não está familiarizado com um ou mais sistemas } \\
\text { que estão sendo integrados e a documentação } \\
\text { não está muito completa (LINTHICUM, 1999). }\end{array}$ \\
\hline & $+\quad \mathrm{Se}$ as mudanças são feitas apenas na & $\begin{array}{l}\text { - Qualquer alteração feita em um esquema de } \\
\text { banco de dados precisa ser analisada com }\end{array}$ \\
\hline
\end{tabular}




\begin{tabular}{|c|c|c|}
\hline & $\begin{array}{l}\text { implementação interna do WS, então há vantagem em } \\
\text { usar WS, pois os aplicativos clientes não precisam ter } \\
\text { conhecimento dessa mudança. }\end{array}$ & $\begin{array}{l}\text { cautela, olhando para todos os projetos de } \\
\text { integração que envolvem tabelas deste banco de } \\
\text { dados. Por exemplo, se as cópias de uma ou mais } \\
\text { tabelas do banco de dados é feita, elas precisam } \\
\text { ser mudadas também (SILBERSCHATZ et al., } \\
\text { 1999). Vale salientar que scripts e triggers } \\
\text { também estão sujeitos a alterações. }\end{array}$ \\
\hline 8 & $\begin{array}{l}\text { + Escalabilidade não é geralmente um problema de } \\
\text { integração baseada em Web Services uma vez que eles } \\
\text { permitem interfaces bem definidas para os serviços, e } \\
\text { estes são definidos durante o projeto, } \\
\text { independentemente da quantidade de dados } \\
\text { gerenciados pelo aplicativo (MAHMOUD, 2005; } \\
\text { ORT, 2005). } \\
\text { - Problemas poderiam surgir se o serviço retornasse } \\
\text { um número variável de objetos, o que poderia afetar o } \\
\text { desempenho quando a aplicação cresce. }\end{array}$ & $\begin{array}{l}\text { - Se a organização trabalha com várias } \\
\text { tecnologias de banco de dados diferentes ou se o } \\
\text { esquema do banco é complexo, este tipo de } \\
\text { integração poderá ser proporcionalmente mais } \\
\text { difícil de realizar (LINTHICUM, 1999, 2003). }\end{array}$ \\
\hline 9 & $\begin{array}{l}\text { - Para desenvolver um projeto EAI usando Web } \\
\text { Services é necessário instalar um servidor de aplicação } \\
\text { (por exemplo, Glassfish, Tomcat, etc) para } \\
\text { implementar e disponibilizar os serviços que irão } \\
\text { satisfazer cada exigência de integração. Isso pode ser } \\
\text { bastante complexo se as pessoas envolvidas não } \\
\text { estiverem familiarizadas com WS. } \\
\text { + A recompensa será aparente quando o Web Service } \\
\text { já estiver implementado, } \\
\text { desenvolvimento dos próximos projetos de integração } \\
\text { em razão da reutilização desses WS. } \\
\text { - Em muitos casos, as organizações possuem sistemas }\end{array}$ & $\begin{array}{l}\text { + A integração com dados é uma atividade na } \\
\text { qual o mercado oferece muitas ferramentas e } \\
\text { técnicas para acesso seguro aos bancos de dados. } \\
\text { + Este tipo de integração tem sido feito há } \\
\text { muitas décadas e a maior parte dos profissionais } \\
\text { de TI está muito familiarizada com esta } \\
\text { integração. }\end{array}$ \\
\hline
\end{tabular}




\begin{tabular}{|c|c|c|}
\hline & $\begin{array}{l}\text { que foram criados antes da implantação do WS, então } \\
\text { neste caso, esses sistemas devem ser alterados ou, em } \\
\text { casos extremos, reconstruídos a partir do zero. } \\
\text { Entretanto, mudar os sistemas implica novos testes, } \\
\text { integração e implantação, que podem causar altos } \\
\text { custos (LINTHICUM, 2003). Assim, antes de decidir } \\
\text { integrar usando WS, esses fatores devem ser } \\
\text { analisados. }\end{array}$ & \\
\hline 10 & $\begin{array}{l}\text { + - Serviços alternativos podem ser implementados } \\
\text { para fornecer uma função que melhore a } \\
\text { disponibilidade do sistema. No entanto, quando isso } \\
\text { não for possível, a falha do servidor web pode fazer o } \\
\text { aplicativo cliente falhar, além de afetar o desempenho, } \\
\text { a disponibilidade de um serviço pode também ser } \\
\text { comprometida quando um WS é corrompido, levando } \\
\text { à propagação do erro para todo o sistema } \\
\text { (MAHMOOD, 2007). }\end{array}$ & $\begin{array}{l}\text { - Se a informação está concentrada em um só } \\
\text { aplicativo e os outros são integrados por meio do } \\
\text { acesso somente leitura, o mau desempenho desta } \\
\text { aplicação pode causar problemas para todos os } \\
\text { outros. } \\
\text { + Considerando que as cópias locais são } \\
\text { mantidas por outras aplicações, caso um desses } \\
\text { bancos se tornem indisponíveis, os outros bancos } \\
\text { podem ser utilizados para prosseguir com a } \\
\text { operação que estava sendo realizada } \\
\text { (SILBERSCHATZ et al., 1999). }\end{array}$ \\
\hline 11 & $\begin{array}{l}\text { + Web Services são auto suficientes e auto descritos } \\
\text { (ENDREI et al., 2004), por esse motivo, eles podem } \\
\text { ser usados e o que precisa ter conhecimento é do seu } \\
\text { propósito e o formato das mensagens. Portanto, não é } \\
\text { necessário compreender a sua estrutura interna. }\end{array}$ & $\begin{array}{l}\text { - Quando a integração é feita por meio do acesso } \\
\text { aos dados, a compreensão de como esta } \\
\text { integração é feita depende do entendimento de } \\
\text { todos os detalhes de implementação e do projeto } \\
\text { do banco de dados, incluindo restrições de } \\
\text { integridade de negócios que podem ser } \\
\text { específicas para determinadas operações ou } \\
\text { subtipos de dados. } \\
\text { + Quando as informações são conhecidas pelo } \\
\text { integrador, a integração se torna mais fácil de } \\
\text { compreender e utilizar (LINTHICUM, 2003). }\end{array}$ \\
\hline 12 & - Quando se implementa um Web Service no lado do & + Se o aplicativo cliente tem acesso garantido \\
\hline
\end{tabular}




\begin{tabular}{|l|l|l|}
\hline servidor, pode ser preciso alterar a aplicação do & ao banco de dados, não é necessário mudar a \\
servidor, de modo que ela forneça um serviço de & lógica da aplicação no lado do servidor, de modo \\
acordo com a interface apropriada. Isto pode exigir o & que ele não precisa ter conhecimento do que está \\
acesso à aplicação ou, pelo menos, à base de dados, & sendo acessado pelo cliente. \\
como ocorre em EAI-Dados. É importante ressaltar & \\
que isso pode ser um problema em aplicações & \\
fechadas como ERPs, por causa da elevada \\
dependência do fornecedor do produto, que muitas \\
vezes não disponibiliza o acesso direto à base de \\
dados a fim de modificar algumas regras de negócio.
\end{tabular}

\subsection{Considerações Finais}

Embora os resultados indiquem que EAI-WS é melhor do que EAI-Dados na grande maioria dos fatores de comparação, para apoiar a decisão de um desenvolvedor ao realizar EAI é recomendado que todos os aspectos envolvidos no projeto de integração sejam cuidadosamente analisados. Por exemplo:

- No fator 7, é importante ressaltar que muitos dos problemas com o esforço para projetar a integração acontecem tanto na integração via dados como via WS, uma vez que o projeto da lógica de Web Services também envolve a compreensão de como os aplicativos estão sendo integrados;

- No fator 8, caso a quantidade de informações a ser integrada seja muito grande, podem existir problemas de escalabilidade e desempenho tanto na a abordagem EAI-Dados como na abordagem EAI-WS;

- No fator 9, os esforços para implementar a integração, é um fator em que EAIDados geralmente é melhor do que EAI-WS. No entanto, como a área de TI evolui rapidamente, por exemplo, com a popularização da computação em nuvem (RHOTON, 2010), este cenário tende a mudar nos próximos anos. Por exemplo, com a possibilidade de usar infraestrutura como um serviço e software como um serviço, que são os pilares da computação em nuvem, as tecnologias de bases de dados poderão ficar sob responsabilidade do provedor, e as aplicações cliente não precisão estar a par dos detalhes técnicos. 
- No fator 12, fala da dependência da aplicação lógica, como se pode ver na Tabela 3.1, é outro fator em que EAI-Dados geralmente é melhor que EAI-WS.

É importante ressaltar também, que no fator 6, que se refere ao reúso, é um item que não consta na norma da ISO-IEC 9126-1.

Pode-se concluir que há situações em que EAI-Dados é a abordagem mais apropriada do que EAI-WS, ou vice-versa. Portanto, a decisão deve ser feita com base no contexto particular em que a integração está ocorrendo, considerando assim, todas as variações possíveis das características analisadas.

A fim de complementar e validar esta comparação, obtendo alguns dados numéricos sobre o uso de EAI-dados e EAI-WS, foi feito um estudo experimental que é apresentado no próximo capítulo. 


\section{Estudo Experimental}

\subsection{Considerações Iniciais}

O experimento controlado (ou estudo empírico) apresentado neste capítulo teve por objetivo obter dados quantitativos relacionados à integração de aplicações usando WS e acesso direto aos dados. O experimento foi construído com base nos conceitos definidos por Wholin et al. (2000).

Inicialmente, na Seção 4.2 é apresentada a metodologia utilizada em que é descrita a parte teórica deste estudo experimental. Já na Seção 4.3, apresentam-se a definição e o planejamento do experimento, que são de suma importância para as próximas etapas: a fase de execução (Seção 4.4) e a fase de análise do estudo experimental e das hipóteses (Seção 4.5). Na Seção 4.6 discutem-se os resultados do estudo experimental e, finalmente, na Seção 4.7 apresentam-se as considerações finais deste capítulo.

\subsection{Metodologia do estudo experimental}

A fase inicial do estudo experimental é a sua definição, em que foi determinado o objeto de estudo do experimento, o propósito, o foco quantitativo e qualitativo, a perspectiva e o contexto.

\subsubsection{Definição do Estudo Experimental}

Nesta etapa de definição, o estudo experimental é expresso em termos de problemas e objetivos. Além disso, são descritas as principais questões que deram origem ao experimento e é a partir delas, que é definido e planejado o escopo do experimento e as hipóteses são formuladas (TRAVASSOS, 2002). 


\section{Metas do experimento}

A seguir são definidas as metas do experimento conforme Wholin et al. (2000).

- Objeto de estudo: entidade que é estudada no experimento;

- Propósito: define qual a intenção do experimento. Pode ser a avaliação do impacto de duas técnicas diferentes ou para caracterizar a curva de aprendizado de uma organização;

- Foco: define qual a propriedade ou a qualidade que será estudada;

- Perspectiva: mostra o ponto de vista do qual os resultados do experimento são interpretados. Exemplo: desenvolvedores, gerentes de projetos, clientes e pesquisadores; e

- Contexto: o ambiente no qual se roda um experimento.

A próxima fase é efetuar o planejamento com o objetivo de preparar a fase de operação do estudo experimental.

\subsubsection{Planejamento do Experimento}

Nesta fase, são definidos o contexto, as hipóteses, as variáveis, os participantes, o projeto do experimento, a instrumentação e por fim a avaliação de validade do estudo.

\section{Definição das Hipóteses}

Nesta fase, a definição do experimento é formada por duas hipóteses que são descritas a seguir.

\section{Hipóteses nulas}

Conforme Wohlin et al. (2000), essas hipóteses são aquelas em que o pesquisador deseja rejeitar com um nível alto de significância, ou seja, é basicamente a negação do que se deseja provar. 


\section{Hipóteses alternativas}

Essas são as hipóteses em favor da qual a hipótese nula é rejeitada, ou seja, geralmente é a própria hipótese da pesquisa (WHOLIN et al., 2000).

\section{Seleção das variáveis}

Nesta seção, foram definidas as seguintes variáveis: (1) variáveis independentes; (2) variáveis dependentes; e (3) variáveis de contexto.

\section{Variáveis independentes}

Wohlin et al. (2000), definem as variáveis independentes como aquelas variáveis que podem ser manipuladas ou controladas em um estudo experimental.

\section{Variáveis dependentes}

Conforme Wohlin et al. (2000), variáveis dependentes são aquelas em que são observados os resultados da manipulação de variáveis independentes.

\section{Seleção dos sujeitos}

A seleção de sujeitos também é chamada de uma amostra da população (WHOLIN et al., 2000).

\subsubsection{Execução do estudo experimental e validação dos dados}

Após efetuadas as fases de definição e planejamento, a próxima fase foi a de execução do estudo experimental. São descritos os processos de preparação do estudo experimental, os participantes, a execução e, por fim a validação dos dados. 


\subsubsection{Análise dos resultados e avaliação das hipóteses do estudo experimental}

Após coletar os dados do experimento, o próximo passo foi efetuar a análise dos resultados por meio da avaliação e comparação da relação entre as métricas e, por fim efetuar a avaliação das hipóteses.

Durante a análise dos dados foi utilizada a estatística descritiva, na qual foram feitas o cálculo da média, desvio padrão, variâncias, mediana, coeficientes de assimetria e curtose, as correlações entre as abordagens utilizadas, teste de normalidade, e por fim, teste das hipóteses.

\section{Estatística descritiva}

A Estatística Descritiva lida com as formas de obter informações úteis a partir de um conjunto de dados, podendo ser descrita e também, representada graficamente, a fim de facilitar a resolução de problemas (WHOLIN et al., 2000).

\section{Medidas de tendência central}

A maior parte dos dados apresenta uma tendência de se concentrar em torno de um ponto central, mas, é possível selecionar um valor que melhor descreva o conjunto. Este valor é uma medida de tendência central, tais como a média, a mediana e a moda (WHOLIN et al., 2000).

\section{Medidas de dispersão}

Essas medidas mostram a dispersão dos dados em torno da tendência central, tais como o valor mínimo e máximo, a amplitude, o quartil, o desvio padrão, o erro padrão da média, a variância e o coeficiente de variação (WHOLIN et al., 2000).

\section{Box-plots}

O box-plot permite avaliar a simetria dos dados, sua dispersão e a existência ou não de outliers também chamados de dados discrepantes, nos mesmos. Na Figura 4.1, a barra do meio no box é a mediana (m), a parte inferior da caixa é delimitada pelo quartil inferior (lq) e a parte superior pelo quartil superior (uq). As hastes inferiores e 
superiores se estendem, respectivamente, do quartil inferior até o menor valor não inferior a (lq $\left.-1.5^{*} \mathrm{~d}\right)$ e do quartil superior até o maior valor não superior a (uq $+1.5^{*} \mathrm{~d}$ ). Os valores inferiores a $\left(\mathrm{lq}-1.5^{*} \mathrm{~d}\right)$ e superiores a $\left(\mathrm{uq}+1.5^{*} \mathrm{~d}\right)$ são caracterizados como outliers (WHOLIN et al., 2000).

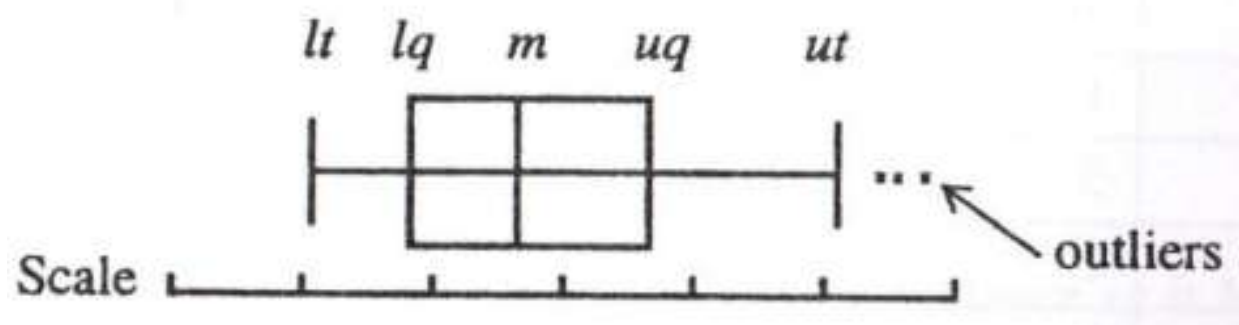

Figura 4.1: Box-Plot (WHOLIN et al., 2000).

\section{Testes que auxiliam no entendimento da ausência de normalidade}

A seguir são descritos os testes de normalidades utilizados neste estudo experimental.

\section{Coeficientes de curtose (Kurtosis)}

Em estatística, é uma medida de dispersão que caracteriza o "achatamento" da curva da função de distribuição (SPIEGEL, 1985). Portanto:

- Se o valor da curtose for $=0$, então existe o mesmo achatamento que a distribuição normal também chamada de achatamento mesocúrtico;

- Se o valor é > 0 então a distribuição em questão é mais alta (afunilada) e concentrada que a distribuição normal e esse achatamento é definido como leptocúrtico; e

- Se o valor é < 0 então a função de distribuição é mais "achatada" que a distribuição normal também definido como achamento platicúrtico.

\section{Coeficientes de assimetria (Skewness)}

É uma medida da assimetria de uma determinada distribuição de frequência, ou seja, é o grau de desvio, ou afastamento da simetria de uma distribuição. A obliquidade mede a assimetria das caudas da distribuição (v). Nota-se que as distribuições assimétricas que têm uma cauda mais "pesada" que a outra apresenta obliquidade. Distribuições simétricas têm obliquidade zero (SPIEGEL, 1985). Assim: 
- Se $\mathrm{v}>0$, então a distribuição tem uma cauda direita (valores acima da média) mais pesada;

- Se $\mathrm{v}<0$, então a distribuição tem uma cauda esquerda (valores abaixo da média) mais pesada;

- Se v=0, então a distribuição é aproximadamente simétrica (na terceira potência do desvio em relação à média).

\section{Teste de normalidade de Shapiro-Wilk}

É baseado na estatística $W$, em que $\mathrm{x}_{\mathrm{i}}$ são os valores da amostra ordenados em que $\mathrm{x}_{(1)}$ é o menor valor. Trata-se de um teste padrão para pequenas amostras (SHAPIRO; WILK, 1965). Para realizar o teste de Shapiro-Wilk, deve-se:

- Efetuar a formulação da hipótese:

$\mathrm{H}_{0}$ : A amostra provém de uma população Normal

$\mathrm{H}_{1}$ : A amostra não provém de uma população Normal

- Estabelecer o nível de significância do teste $(\alpha)$, normalmente 0,05 ;

- Calcular a estatística deste teste (programas estatísticos efetuam essas tarefas); e

- Tomar a decisão: rejeitar $\mathrm{H}_{0}$ ao nível de significância $\alpha$ se $\mathrm{W}_{\text {calculado }}<\mathrm{W}_{\alpha}$ ou não rejeitar.

Há casos em que as distribuições não seguem a normalidade por causa dos valores discrepantes (outliers) necessitando assim, de uma transformação nos dados para estabilizar a variância e normalizar os dados. Em geral, quando são detectados os valores discrepantes, surgem também valores muito grandes para os coeficientes de assimetria e curtose. Convém salientar que deve-se ter cuidado em avaliar se um outlier não é o valor que se deseja encontrar numa pesquisa, nem sempre esse valor é ruim.

\section{Testes de Médias}

$\mathrm{Na}$ pesquisa científica todo método estatístico tem como premissa avaliar a média e a variância dos tratamentos em cada variável mensurada. Sendo assim, para verificar se houve resposta em favor das hipóteses formuladas (sub seção 4.2.2) foram consideradas duas amostras representativas de duas populações. 
É necessário que as duas populações sejam independentes. Porém, na prática, há algumas situações em que as populações não são independentes. Considere duas amostras dependentes $\mathrm{X}_{1}, \ldots, \mathrm{X}_{\mathrm{n}} \mathrm{e} \mathrm{Y}_{1}, \ldots, \mathrm{Yn}$. Neste caso, são consideradas observações pareadas, isto é, pode-se considerar que há na realidade uma amostra de pares, por exemplo, $\left(\mathrm{X}_{1}, \mathrm{Y}_{1}\right), \ldots,\left(\mathrm{X}_{\mathrm{n}}, \mathrm{Y}_{\mathrm{n}}\right)$.

Pode-se definir $D_{i}=X_{i}-Y_{i}$, para $i=1,2, \ldots, n$. Assim pode-se obter a amostra $\mathrm{D}_{1}, \ldots, \mathrm{D}_{\mathrm{n}}$, resultante das diferenças entre os valores de cada par. Aqui, apesar das amostras serem dependentes, pode-se considerar $\mathrm{D}_{\mathrm{i}} \sim \mathrm{N}(\mu \mathrm{D}, \sigma \mathrm{D} 2)$, em que, as diferenças dos indivíduos são aproximadamente normais.

É importante ressaltar que o teste de comparações de médias deve ser realizado somente quando verificado todas as pressuposições da análise de variação, quais sejam: normalidade e independência dos dados, e afastamento do valor médio. Para essa avaliação usam-se estatísticas clássicas, descritivas e gráficas como os coeficientes de assimetria e curtose, o teste de Shapiro-Wilk e o Box-plot.

\section{Teste de Hipóteses}

De acordo com as recomendações de Wholin et al. (2000) e também, por causa do resultado dos testes de normalidade, foi utilizado o teste $\mathrm{T}$ pareado para testar as hipóteses.

\section{Teste T Pareado}

Conforme definido no planejamento, foi selecionado o teste paramétrico Teste $\mathrm{T}$ pareado que é utilizado quando duas amostras resultantes de medidas com repetições são comparadas (WHOLIN et al., 2000).

Numa situação de comparação inter laboratorial em que dois laboratórios medem a mesma peça, por exemplo, as medidas entre os laboratórios não são independentes, é utilizado o teste $\mathrm{T}$ pareado. Para realizar o teste $\mathrm{T}$ pareado deve-se primeiramente estabelecer uma das hipóteses.

\subsection{Definição e planejamento do estudo experimental}

Nesta seção são apresentados a definição e o planejamento do estudo experimental. 


\subsubsection{Definição do Estudo Experimental}

Na definição do estudo experimental são apresentados o objetivo e as metas em que são definidos o objeto de estudo, propósito, foco quantitativo, foco qualitativo, perspectiva e o contexto.

\section{Objetivo do experimento}

O objetivo do experimento foi avaliar a melhor abordagem para se realizar uma integração de aplicações empresariais: EAI-Dados e EAI-WS no que diz respeito ao esforço necessário para a implantação de cada uma. Assim, a avaliação foi realizada para responder à seguinte questão:

- Em termos de tempo de desenvolvimento e código produzido, é mais fácil realizar EAI-WS ou EAI-Dados?

\section{Metas do experimento}

A seguir, são apresentadas as principais metas do estudo experimental:

- Objeto de estudo: abordagem de integração de software;

- Propósito: avaliar a utilização de Web Services (WS) na Integração de Aplicações Empresariais, comparando com a integração utilizando dados. Conforme visto no Capítulo 2, EAI-Dados pressupõe executar a integração por meio da troca de dados direta entre depósitos de dados sem envolver alteração na lógica das aplicações (LINTHICUM, 1999). Já EAI-WS é a utilização de Web Services como meio de realizar a integração. Esses WS são implementados em um servidor de aplicação e podem ser consumidos por outra ou outras aplicações que necessitem da informação;

- Foco quantitativo: o foco é medir o esforço necessário para realizar uma atividade de EAI segundo as duas diferentes abordagens;

- Foco qualitativo: o foco primário é identificar as dificuldades do desenvolvedor para realizar a integração nas abordagens EAI-Dados e EAI-WS. O foco secundário é identificar as dificuldades do desenvolvedor em lidar com a 
tecnologia em ambas as abordagens;

- Perspectiva: desenvolvedor(es) envolvido(s) na integração de aplicações empresariais;

- Contexto: o estudo experimental foi realizado por alunos de pós-graduação do ICMC-USP e profissionais de informática da Embrapa Pecuária Sudeste de São Carlos. Os participantes possuíam conhecimentos prévios em banco de dados e programação e alguns deles possuíam ou não experiência com PHP e WS. O estudo durou no máximo dois dias, com duas etapas, uma para EAI-Dados e outra para EAI-WS. Os participantes não puderam trocar informações sobre o experimento durante o seu período de execução, receberam treinamento adequado para cada uma das tarefas e não foram supervisionados em suas atividades.

\subsubsection{Planejamento do Experimento}

A seguir são descritas as fases do planejamento.

\section{Seleção do contexto}

Cada participante trabalhou com os dois tipos de integração, ou seja, EAI-Dados e EAIWS, sendo que todos os participantes iniciaram pela integração EAI-Dados.

\section{Definição das Hipóteses}

Para realizar a análise e verificar a validade das hipóteses foram considerados os tempos em cada abordagem, ou seja, para EAI-dados foi considerado $T_{D-E A I-D a d o s}=T_{E 1}+T_{P 1}+T_{I 1}$ + $\mathrm{T}_{\text {IT1 }}$, que é o tempo (em minutos) gasto para desenvolver a solução de integração por dados, sendo que:

- $\mathrm{T}_{\mathrm{E} 1}$ : Tempo gasto em estudo ou revisão conceitos sobre BD ou sobre o banco específico (exceto o tempo gasto no treinamento);

- $\mathrm{T}_{\mathrm{P} 1}$ : Tempo gasto para projetar a solução de integração;

- $\mathrm{T}_{\mathrm{I} 1}$ : Tempo gasto na implementação da integração; e

- $\mathrm{T}_{\text {Iт1 }}$ : Tempo para implantar/testar a solução. 
Para EAI-WS foi considerado $\mathrm{T}_{\mathrm{D}-\mathrm{EAI}-\mathrm{WS}}=\mathrm{T}_{\mathrm{E} 2}+\mathrm{T}_{\mathrm{P} 2}+\mathrm{T}_{\mathrm{IS} 2+} \mathrm{T}_{\mathrm{IC} 2+} \mathrm{T}_{\mathrm{ITS} 2+} \mathrm{T}_{\mathrm{ITC} 2}$, que é o tempo (em minutos) gasto para desenvolver a solução de integração por WS, sendo que:

- $\mathrm{T}_{\mathrm{E} 2}$ : Tempo gasto em estudo ou revisão de conceitos sobre WS ou outros conceitos necessários para implementar a solução (exceto o tempo gasto no treinamento);

- $\mathrm{T}_{\mathrm{P} 2}$ : Tempo gasto para projetar a solução de integração (definição do serviço e cliente);

- $\mathrm{T}_{\text {IS2 }}$ : Tempo gasto na implementação do WS;

- $\mathrm{T}_{\mathrm{IC} 2}$ : Tempo gasto na implementação do cliente do WS;

- $\mathrm{T}_{\text {ITs2 }}$ : Tempo gasto no teste e implantação do WS; e

- $\mathrm{T}_{\text {Iтc2 }}$ : Tempo para implantar e testar o cliente.

A fim de realizar a análise e validar as hipóteses foi considerado o número de linhas de código produzidas em cada abordagem, ou seja, para EAI-dados considerou-se

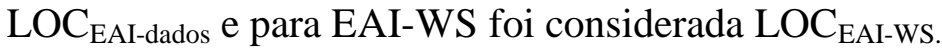

As hipóteses deste estudo foram: (1) gasta-se mais tempo para desenvolver a solução de integração por WS (EAI-WS) do que a integração por dados (EAI-Dados); e (2) o número de linhas de códigos escritas utilizando a EAI-Dados é menor que a EAIWS.

\section{Hipóteses nulas}

A seguir são apresentadas as hipóteses nulas deste estudo experimental:

- HN1 - Seja $\mathrm{T}_{\mathrm{D} \text {-EAI-Dados }}$ o tempo gasto para desenvolver a solução de integração por dados e $T_{D-E A I-W S}$ o tempo gasto para desenvolver a solução de integração por WS, então $\mathrm{T}_{\mathrm{D}-\mathrm{EAI}-\mathrm{Dados}}>=\mathrm{T}_{\mathrm{D}-\mathrm{EAI}-W S} ; \mathrm{e}$

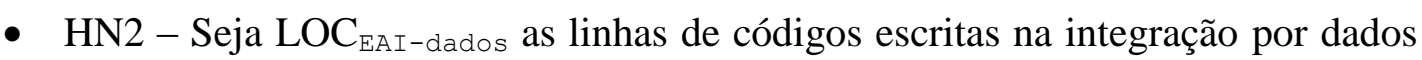
e $\mathrm{LOC}_{\mathrm{EAI}-W S}$ as linhas de códigos escritas na integração por WS, então $\mathrm{LOC}_{\mathrm{EAI}-}$ dados $>=\mathrm{LOC}_{\mathrm{EAI}-\mathrm{WS}}$. 


\section{Hipóteses alternativas}

As hipóteses alternativas deste experimento são:

- HA1 - Seja $\mathrm{T}_{\text {D-EAI-Dados }}$ o tempo gasto para desenvolver a solução de integração por dados e $\mathrm{T}_{\mathrm{D} \text {-EAI-WS }}$ o tempo gasto para desenvolver a solução de integração por WS, então $\mathrm{T}_{\mathrm{D}-\mathrm{EAI} \text {-Dados }}<\mathrm{T}_{\mathrm{D}-\mathrm{EAI}-W \mathrm{~S}}$; $\mathrm{e}$

- HA2 - Seja LOC $\mathrm{EAI}_{\text {Edados }}$ as linhas de códigos escritas na integração por dados e $\mathrm{LOC}_{\mathrm{EAI}-W S}$ as linhas de códigos escritas na integração por WS, então $\mathrm{LOC}_{\mathrm{EAI}-}$ dados $<\mathrm{LOC}_{\text {EAI-WS }}$.

\section{Seleção das variáveis}

Trabalhou-se com três tipos de variáveis: (1) variáveis independentes; (2) variáveis dependentes; e (3) variáveis de contexto.

\section{Variáveis independentes}

As variáveis independentes definidas neste estudo experimental foram:

- Mecanismo de integração: Dois mecanismos de integração (EAI-Dados e EAIWS) foram utilizados para fazer a integração entre dois sistemas fornecidos (Agendamento e RH, descritos na Subseção 4.4.1);

\section{Variáveis dependentes}

A seguir, na Tabela 4.1, são apresentadas as variáveis dependentes definidas para este estudo.

Tabela 4.1: Variáveis dependentes.

\begin{tabular}{|c|c|}
\hline EAI-Dados & EAI-WS \\
\hline $\mathrm{T}_{\mathrm{D}-\mathrm{EAI}-\mathrm{Dados}}$ & $\mathrm{T}_{\mathrm{D}-\mathrm{EAI}-\mathrm{WS}}$ \\
\hline LOC $_{\text {EAI-dados }}$ & LOC $_{\text {EAI-WS }}$ \\
\hline
\end{tabular}




\section{Variáveis de contexto}

As variáveis de contexto para este experimento são:

- Conhecimento de Web Service;

- Conhecimento de Banco de dados, especificamente, Mysql e ferramenta HeidiSQL;

- Conhecimento da linguagem PHP;

- Conhecimento da linguagem Java;

- Conhecimento do Servidor de aplicação Glassfish; e

- Conhecimento de JPA.

\section{Seleção dos sujeitos}

A seleção dos sujeitos do experimento foi feita por conveniência entre alunos de computação voluntários e profissionais de informática. Os sujeitos foram convidados a participar do estudo e tiveram liberdade de aceitar ou não e também, de desistir no meio do experimento.

\section{Projeto do Experimento}

$\mathrm{Na}$ Tabela 4.2 é apresentada a relação entre os sujeitos e as abordagens EAI utilizadas em cada parte do experimento. Participaram nove pessoas e não houve alternância entre os dois tipos de integração. Optou-se por trabalhar com uma amostragem de casualização sistematizada, que é um processo de amostragem probabilístico não aleatório. Em um processo sistemático, as unidades amostrais são selecionadas a partir de um esquema rígido e pré-estabelecido de sistematização, com o propósito de cobrir a população em toda sua extensão, a fim de obter um modelo sistemático simples e uniforme (BOLFARINE; BUSSAB, 2005). Vale salientar que decidiu-se sempre começar a trabalhar com EAI-Dados e depois, efetuar a outra integração EAI-WS porque havia um número pequeno de participantes e dividi-los em grupos faria com que as amostras não fossem suficientes para tratar estatisticamente. Adicionalmente, como a maioria dos participantes não conhecia a tecnologia de WS, para não desmotivá-los preferiu-se começar com a parte em que eles tinham mais conhecimento. 
Tabela 4.2: Projeto do experimento

\begin{tabular}{|c|c|c|}
\hline Sujeitos & Parte 1: Agenda-Dados & Parte 2: Agenda-WS \\
\hline P1 & EAI-Dados & EAI-WS \\
\hline P2 & EAI-Dados & EAI-WS \\
\hline P3 & EAI-Dados & EAI-WS \\
\hline P4 & EAI- Dados & EAI- WS \\
\hline P5 & EAI- Dados & EAI- WS \\
\hline P6 & EAI- Dados & EAI- WS \\
\hline P7 & EAI- Dados & EAI- WS \\
\hline P8 & EAI- Dados & EAI- WS \\
\hline P9 & EAI- Dados \\
\hline
\end{tabular}

\section{Instrumentação}

O material fornecido aos sujeitos para a realização do experimento foi composto de: diretrizes para a realização do estudo; tutorial sobre a montagem do ambiente e criação de Web Services, programas (código fonte Java e PHP) dos sistemas a serem integrados, esquema das bases de dados das aplicações a serem integradas. Foi também disponibilizado um questionário para identificar o perfil do participante (variáveis de contexto), um questionário para relato das impressões dos participantes sobre os mecanismos de integração e um formulário para coleta de resultados numéricos do estudo.

\section{Ameaças à validade dos resultados do experimento}

Um fator que pode comprometer a validade interna deste estudo experimental é a experiência do participante, por exemplo, a experiência dos participantes com a utilização de Web Services, banco de dados, PHP, JPA e programação em geral pode influenciar o resultado do estudo. Este fator será mitigado pela participação de sujeitos com e sem experiência nessas tecnologias.

É importante ressaltar que o envolvimento da organizadora do estudo poderia influenciar no resultado. Para não influenciar diretamente os resultados do estudo, a interessada fez apenas o papel de treinadora, esse é um procedimento, sob o ponto de vista, que garante a independência e imparcialidade da pesquisa realizada. 


\subsection{Execução do estudo experimental e validação dos dados}

Realizadas as fases de definição e planejamento, a próxima fase foi a de execução do estudo experimental. Nesta seção, são descritos os processos de preparação do estudo experimental, os participantes, a execução e, por fim a validação dos dados.

\subsubsection{Preparação do estudo experimental}

Antes que o experimento fosse executado, foram realizadas algumas tarefas pela autora, como a implementação dos sistemas, os materiais que seriam utilizados no estudo experimental, a preparação do ambiente e por fim, o piloto do experimento (este último feito por voluntários).

\section{Implementação dos Sistemas}

Primeiramente foram desenvolvidos os dois sistemas de agenda que foram utilizados no experimento, sendo que o primeiro abordava a integração por dados (EAI-Dados) e o segundo sistema abordava a integração por Web Services (EAI-WS).

\section{Materiais para o estudo experimental}

Os sistemas a serem integrados, descritos a seguir, foram: um Sistema de Agenda e um Sistema de RH. A fim de facilitar o entendimento por parte dos participantes do experimento, foram elaboradas as diretrizes do estudo: (1) descrição do Sistema Agenda, que contava com as descrições da EAI-Dados e EAI-WS e uma descrição mais elaborada do que precisava ser feito no experimento a fim de efetuar a integração com a tabela funcionários do sistema RH; e (2) manual para a montagem do ambiente, no caso dos participantes que fizeram o experimento à distância e não foi possível enviar a máquina virtual por ser um arquivo muito grande.

Além disso, foram escritos manuais para o treinamento e, por fim, o questionário que os participantes responderam ao final da execução do experimento. 


\section{Descrição do Sistema Agenda}

O Sistema Agenda foi desenvolvido na Linguagem PHP 5 e foi utilizado o banco de dados MySQL 5. Ele tem por objetivo agendar horários de reuniões dos contatos (pessoas que participarão da reunião). A tela possui os seguintes campos: Nome, Email, Telefone, Data da reunião e Hora da reunião. A base de dados chama-se Agenda e possui duas tabelas: Contato (com os campos: id_cont, nome, email, nome_guerra e telefone) e Agenda (com os campos: contatos_id_cont, dat_reuniao e hor_reuniao). A seguir a Figura 4.1 indica o design do banco de dados do sistema atual.

\begin{tabular}{|c|c|}
\hline agenda & contatos \\
\hline o cod_ag: INTEGER & id_cont: INTEGER \\
\hline$\checkmark$ contatos_id_cont: INTEGER (FK) & $\checkmark$ nome: VARCHAR(100) \\
\hline$\diamond$ dat_reuniao: DATE & $\checkmark$ email: VARCHAR(50) \\
\hline$\diamond$ hor_reuniao: TIME & $\vartheta$ endereco: INTEGER \\
\hline $\begin{array}{l}\text { 7) agenda_FKIndexI } \\
\Delta \text { contatos_id_cont }\end{array}$ & $\begin{array}{l}\nabla \text { nome_guerra: VARCHAR(20) } \\
\diamond \text { telefone: VARCHAR(20) }\end{array}$ \\
\hline
\end{tabular}

Figura 4.2: Relacionamento da tabela agenda com a tabela Contatos.

\section{Integração com o sistema do RH}

Para melhorar a integração entre os sistemas, pretende-se não mais trabalhar com a tabela Contatos, pois as informações são redundantes com o sistema de Recursos Humanos (RH) da empresa. Assim, deseja-se efetuar uma integração com o Sistema RH, cuja base de dados é RH e a tabela a ser utilizada é a de Funcionários (Tbfuncion) em que os campos são: matrícula ( $\left.c o d \_f u n c\right)$, nome do funcionário (nome_func), nome de guerra ou apelido (nome_guerra), endereço (des_endereco), telefone (des_telefone), email (des_email), cidade (des_cidade) e ativo ou não (des_ativo_func) na empresa.

É importante observar que, ao efetuar a lógica de integração, deve-se levar em conta que os tipos de dados idContato na tabela contato da base de dados Agenda é do tipo integer e na tabela Tbfuncion da base de dados RH, o atributo cod_func é do tipo string. 


\section{Preparação do ambiente}

O próximo passo foi efetuar a preparação do ambiente. A fim de facilitar a execução do experimento, foi criada uma máquina virtual para cada participante, em que o ambiente já estava com todos os programas instalados, por exemplo, Java, Netbeans para PHP e Java, Apache, Glassfish, Mysql, entre outros.

Vale salientar que, com a criação da máquina virtual, o trabalho foi facilitado, por causa da portabilidade do experimento. Caso um aluno tivesse a preferência de executar o experimento em seu computador, bastava apenas instalar a máquina virtual em seu notebook ou desktop. Também, foi mais fácil separar um experimento do outro, uma vez que cada participante podia alterar o seu código fonte e o seu banco de dados, pois estava tudo funcionando localmente.

\section{Piloto do Experimento}

Com o intuito de testar a instrumentação do experimento, foi efetuado um piloto do estudo experimental com dois alunos de pós-graduação do ICMC-USP e um profissional de informática da Embrapa Pecuária Sudeste de São Carlos. Por meio desse piloto foi possível detectar algumas falhas no experimento e assim, corrigi-las. Entretanto, os participantes não puderam concluir o experimento, ficando a parte 2 sem uma pré-validação.

\subsubsection{Participantes}

A autora (condutora do experimento) fez contato com alunos de pós-graduação e profissionais para convidá-los a participar voluntariamente do estudo. Inicialmente, no treinamento, participaram onze pessoas. No entanto, um participante não chegou a executar o experimento, tendo participado somente do treinamento, e um outro participante realizou somente a parte 1 do experimento, portanto esses dois participantes foram descartados.

Os participantes finais do experimento foram sete alunos de pós-graduação do ICMC-USP e dois profissionais de informática da Embrapa Pecuária Sudeste de São Carlos. 


\subsubsection{Execução do estudo experimental}

A realização do experimento foi feita em duas etapas (EAI-Dados e EAI-WS), sendo composta de um período de treinamento (aproximadamente uma hora) e um período de estudo em si.

A duração foi de aproximadamente dois dias, sendo que o participante teve liberdade de realizar as atividades no tempo que julgasse necessário.

\section{Treinamento}

Foi preparado um treinamento para ser ministrado a cada participante do período adequado de execução do estudo. Tanto o treinamento para a abordagem por dados quanto o treinamento para a abordagem WS tiveram duração de uma hora.

As diretrizes do estudo foram impressas e foram entregues a cada participante, assim como os formulários para identificar o perfil de cada um deles e o questionário. Para fins de exemplificar EAI-Dados e EAI-WS durante o treinamento, foi utilizado um sistema de CEP, também desenvolvido em PHP.

\section{Tarefas do Experimento}

A seguir, são descritas de forma sucinta, as tarefas de manutenção que foram efetuadas no Sistema Agenda (sistema utilizado no experimento) para efetuar a integração com a tabela funcionários do sistema RH. No apêndice B encontra-se a cópia do documento completo que descreve as tarefas que foram executadas pelos participantes do estudo experimental.

As tarefas visavam realizar a integração (tanto por acesso nativo aos dados como por Web Service), manter a inclusão das informações de agendamento na tabela Agenda do Sistema Agenda, sendo que os dados dos contatos não ficarão mais no programa Agenda, eles estarão gravados no Sistema RH. Uma outra tarefa a ser realizada é a alteração no cadastro de contatos, pois, agora será utilizada a tabela de funcionários (Tbfuncion) da base Rh e não mais a tabela contatos da base Agenda. 
A seguir, são definidas as tarefas que foram realizadas em cada tipo de integração, sendo que o experimento foi dividido em Integração por Dados e Integração por Web Services.

\section{Integração por dados (EAI-Dados)}

O passo inicial é o entendimento da integração a ser realizada e a definiç̧ão do projeto da solução. Executados os passos anteriores, pode-se começar a manutenção de integração no sistema de Agenda. O nome do projeto a ser usado é o AgendaDadosFunc.

A seguir, são dadas algumas sugestões para ajudar a implementar as alterações que deverão ser feitas nos formulários do projeto AgendaDados-Func, para efetuar a integração por dados.

- Formulários para inserir os funcionários:

O formInsertFunc.php, insertFunc.php: como agora será utilizada a tabela Tbfuncion, da base RH, ao efetuar a alteração deve-se verificar se todos os campos foram incluídos, uma vez que esta tabela possui mais campos que a tabela Contatos, da base de dados Agenda.

- Formulários para inserir a agenda:

○ formInsertag.php: Neste formulário deve-se levar em conta que não será utilizada mais a tabela contatos e sim, a tabela de funcionários (TbFuncion) da base de dados RH;

○ formInsertag2 .php: Com a nova integração, deve-se efetuar alterações na lógica. Preste atenção no tipo de select, porque ele executa uma busca individual; e

○ insertag.php: Veja como será feita gravação da chave estrangeira (idcon), pois ele pertence à tabela contatos e a mesma não será mais utilizada. 


\section{Integração por Web Service (WS)}

O passo inicial é o entendimento da integração a ser realizada e a definição do projeto da solução utilizando serviços, o que implica em analisar quais serviços precisarão ser criados.

É importante ressaltar que deverá ser implementado um projeto novo para a criação do(s) serviço(s) relacionado(s) à tabela de funcionários (TbFuncion) da base de dados Rh. Neste caso, o participante deverá criar tanto o(s) serviço(s) como um cliente para este(s) serviço(s).

Após definidos e criados os serviços, o próximo passo é fazer as modificações na aplicação cliente que irá consumir o serviço, que nesse caso é o projeto AgendaWSFunc.

A seguir, seguem as descrições dos formulários que sofrerão alterações e trabalharão com serviços.

- Formulários para inserir os funcionários:

- formInsertFunc.php: Como será utilizada a tabela tbfuncion, da base $\mathrm{RH}$, ao efetuar a alteração deve-se verificar se todos os campos foram incluídos, uma vez que esta tabela possui mais campos que a tabela contatos, da base Agenda;

○ insertFunc.php: A alteração que deverá ser feita neste formulário é no serviço, pois, deve-se usar o serviço de inserção que trabalha com a tabela tbfuncion, criado anteriormente no Java;

- Formulários para inserir a agenda:

○ formInsertagFunc .php: Formulário que contém a lógica de alimentar a combobox com o nome do contato da tabela contatos utilizando Web Services (é invocado o serviço de consulta criado utilizando a tabela TbFuncion); 
○ formInsertagFunc2.php: Com a nova integração, deve-se efetuar alterações na lógica. Preste atenção no tipo de select, porque ele executa uma busca individual; e

O insertag.php: Veja como será feita gravação da chave estrangeira (idcon), pois ele pertence à tabela contatos e a mesma não será mais utilizada.

\subsubsection{Validação dos dados}

Neste passo, foi verificado se os participantes conseguiram anotar corretamente as métricas nos formulários preenchidos. Conforme mencionado na Seção 4.4.2, após a verificação dos formulários, foi detectado que um dos dez participantes não chegou a finalizar todo o experimento. Por esse motivo, decidiu-se que esse participante seria desconsiderado para a próxima fase que é a fase de análise dos resultados. Portanto, o número total de participantes deste experimento foram nove indivíduos.

\subsection{Análise dos resultados e avaliação das hipóteses do estudo experimental}

Durante a análise dos dados foi utilizada a estatística descritiva, no qual foram calculadas médias, desvio padrão, quartil, coeficientes de assimetria e curtose, correlações entre as abordagens utilizadas, teste de normalidade, e por fim, teste das hipóteses. Além disso, foram analisadas as dificuldades encontradas pelos participantes em lidar com a tecnologia.

\subsubsection{Análise dos resultados}

Neste estudo experimental na análise dos resultados foi utilizada a análise exploratória, trabalhando assim com a estatística descritiva, estatística clássica e estatística gráfica (Box-plots), testes de médias, testes de normalidade e por fim, o teste de hipóteses que são descritos a seguir. 


\section{Resultado da análise exploratória}

Foi realizada uma análise descritiva dos resultados do estudo experimental, considerando o tempo de desenvolvimento e o número de linhas de códigos escritas (LOC), por meio do formulário preenchido pelos participantes. Os dados desse formulário foram utilizados para avaliar e comparar a relação entre as métricas, identificar as dificuldades encontradas na integração segundo as duas abordagens e, também, identificar as impressões pessoais de cada participante sobre as abordagens.

A seguir, na Tabela 4.3 são apresentados o tempo total gasto e a quantidade de linhas de códigos escritas para efetuar a integração por meio de EAI-Dados e EAI-WS.

Tabela 4.3: Tempo gasto (minutos) e as linhas de códigos escritas pelos participantes para a integração por EAI-Dados e EAI-WS.

\begin{tabular}{lccccc}
\hline \multirow{2}{*}{ PARTICIPANTES } & \multicolumn{2}{c}{ TEMPO } & & \multicolumn{2}{c}{ LOC } \\
\cline { 2 - 3 } \cline { 5 - 6 } & DADOS & WS & & DADOS & WS \\
\hline P1 & 67 & 120 & & 16 & 47 \\
P2 & 92 & 86 & & 16 & 42 \\
P3 & 82 & 83 & & 15 & 46 \\
P4 & 60 & 120 & & 16 & 44 \\
P5 & 70 & 117 & & 14 & 47 \\
P6 & 73 & 66 & & 14 & 52 \\
P7 & 240 & 150 & & 14 & 68 \\
P8 & 240 & 150 & & 14 & 60 \\
P9 & 96 & 86 & & 17 & 82 \\
\hline
\end{tabular}

\section{Medidas de tendência central}

Na tabela 4.4 são apresentadas as medidas de tendência central do estudo experimental.

Tabela 4.4: Medidas de tendência central

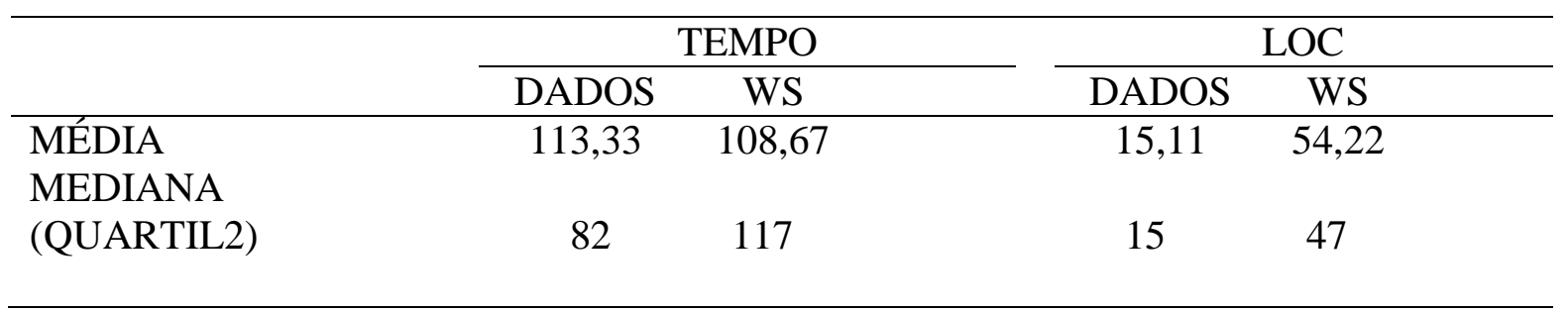

\section{Medidas de dispersão}

Na Tabela 4.5 são apresentadas as medidas de dispersão. 
Tabela 4.5: Medidas de dispersão

\begin{tabular}{|c|c|c|c|c|}
\hline & \multicolumn{2}{|r|}{ TEMPO } & \multicolumn{2}{|r|}{$\mathrm{LOC}$} \\
\hline & DADOS & WS & DADOS & WS \\
\hline MÍNIMO & 60 & 66 & 14 & 42 \\
\hline MÁXIMO & 240 & 150 & 17 & 82 \\
\hline AMPLITUDE & 180 & 84 & 3 & 40 \\
\hline QUARTIL 1 & 70 & 86 & 14 & 46 \\
\hline QUARTIL 2 & 82 & 117 & 15 & 47 \\
\hline \multicolumn{5}{|l|}{ (MEDIANA) } \\
\hline QUARTIL 3 & 96 & 120 & 16 & 60 \\
\hline DESVIO PADRÃO & 72,73 & 30,10 & 1,17 & 13,35 \\
\hline VARIÂNCIA & 5290,25 & 906,25 & 1,36 & 178,19 \\
\hline COEFICIENTE DE & 64,18 & 27,70 & 7,72 & 24,62 \\
\hline VARIAÇÃO & & & & \\
\hline
\end{tabular}

\section{Box-plots}

A Figura 4.3 mostra os box-plots criados para descrever graficamente os resultados referentes ao tempo gasto em minutos para desenvolver a solução de integração por dados e por WS, os quais são similares aos obtidos pelas estatísticas descritivas (tendência central e dispersão). Pode-se inferir nesta figura, que em EAI-Dados, o intervalo do tempo de desenvolvimento está entre 50 a 100 minutos. Com exceção do tempo de 240 minutos que pode ser considerado um outlier. Embora o valor 240 retrate um outlier, o mesmo não foi excluído do experimento porque é possível que um indivíduo demore este tempo para executar esta parte do experimento, talvez por causa das ameaças à validade dos resultados do experimento que são descritas neste capítulo. Já a parte de EAI-WS, pode-se considerar que o tempo de desenvolvimento está entre 50 e 150 minutos de desenvolvimento. Portanto, o tempo entre todos os participantes está mais homogêneo.

Na Figura 4.4 mostra-se os box-plots criados para descrever graficamente os resultados referentes às linhas de código escritas para desenvolver a solução de integração por dados e por WS. Pode-se inferir nesta figura, que a quantidade de linhas de códigos escritas (LOC) na parte de EAI-Dados (EAI_dLoc), está homogênea, estando o intervalo da LOC entre 14 e 17. Já na parte de EAI-WS (EAI_WSLoc), a maior parte das LOCs está homogênea, com exceção da LOC 80, que pode ser considerada um outlier. Assim, como aconteceu com a Figura 4.3, esse outlier não foi desconsiderado da análise, uma vez que, é possível que um indivíduo possa montar uma 
lógica de programação menor ou maior em relação à lógica dos outros, mas que chegue a alcançar os mesmos objetivos.

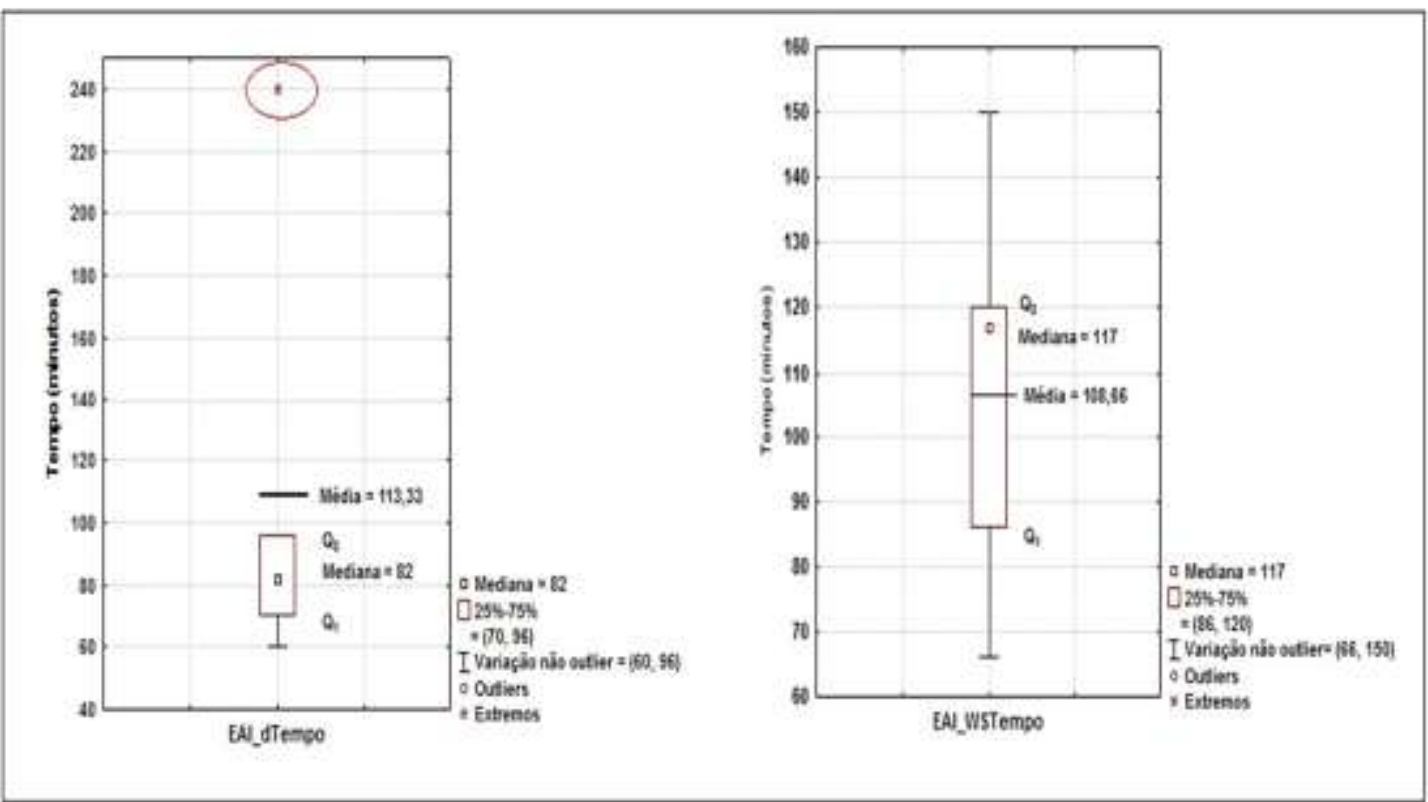

Figura 4.3: Box-plots do Tempo gasto para desenvolver a solução de integração por dados e por WS.

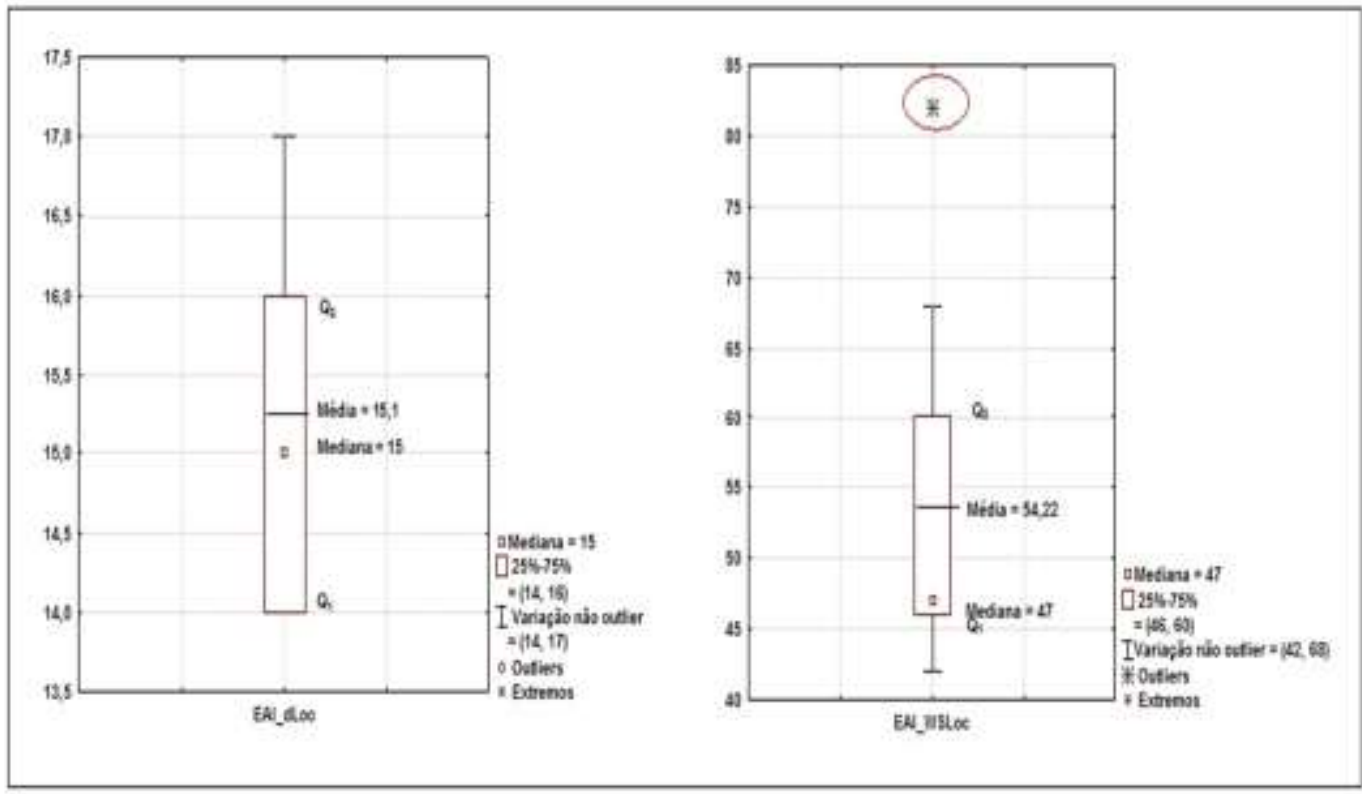

Figura 4.4: Box-Plots do número de linhas de código para desenvolver a solução de integração por dados e por WS. 


\section{Testes de Médias}

Os testes de médias (teste T), para este experimento, foram feitos com os dados da diferença entre o tempo de desenvolvimento das duas abordagens dados e WS, em que:

- $\quad \mathrm{dTempo}=$ Tempo Dados - Tempo WS.

Além disso, também foi feita a diferença entre as linhas de códigos escrita nas duas abordagens dados e WS, em que:

- $\quad \mathrm{dLOc}=$ LOC Dados - LOC WS.

O resultado dessa diferença é mostrado na Tabela 4.6.

Tabela 4.6: Testes de médias

\begin{tabular}{lccccccc}
\hline PARTICIPANTES & \multicolumn{2}{c}{ TEMPO } & & \multicolumn{2}{c}{ LOC } & dTEMPO & dLOC \\
\cline { 2 - 3 } \cline { 8 - 8 } & DADOS & WS & & DADOS & WS & & \\
\hline P1 & 67 & 120 & & 16 & 47 & -53 & -31 \\
P2 & 92 & 86 & & 16 & 42 & 6 & -26 \\
P3 & 82 & 83 & & 15 & 46 & -1 & -31 \\
P4 & 60 & 120 & & 16 & 44 & -60 & -28 \\
P5 & 70 & 117 & & 14 & 47 & -47 & -33 \\
P6 & 73 & 66 & & 14 & 52 & 7 & -38 \\
P7 & 240 & 150 & & 14 & 68 & 90 & -54 \\
P8 & 240 & 150 & & 14 & 60 & 90 & -46 \\
P9 & 96 & 86 & & 17 & 82 & 10 & -65 \\
\hline
\end{tabular}

A seguir é ilustrado o Box-plot das diferenças do Tempo EAI-Dados e Tempo EAIWS (Dif_Tempo) e da Loc EAI-Dados e EAI-WS (Dif_LOC) na Figura 4.5. É importante ressaltar que não há valores discrepantes nesse Box-plot das diferenças.

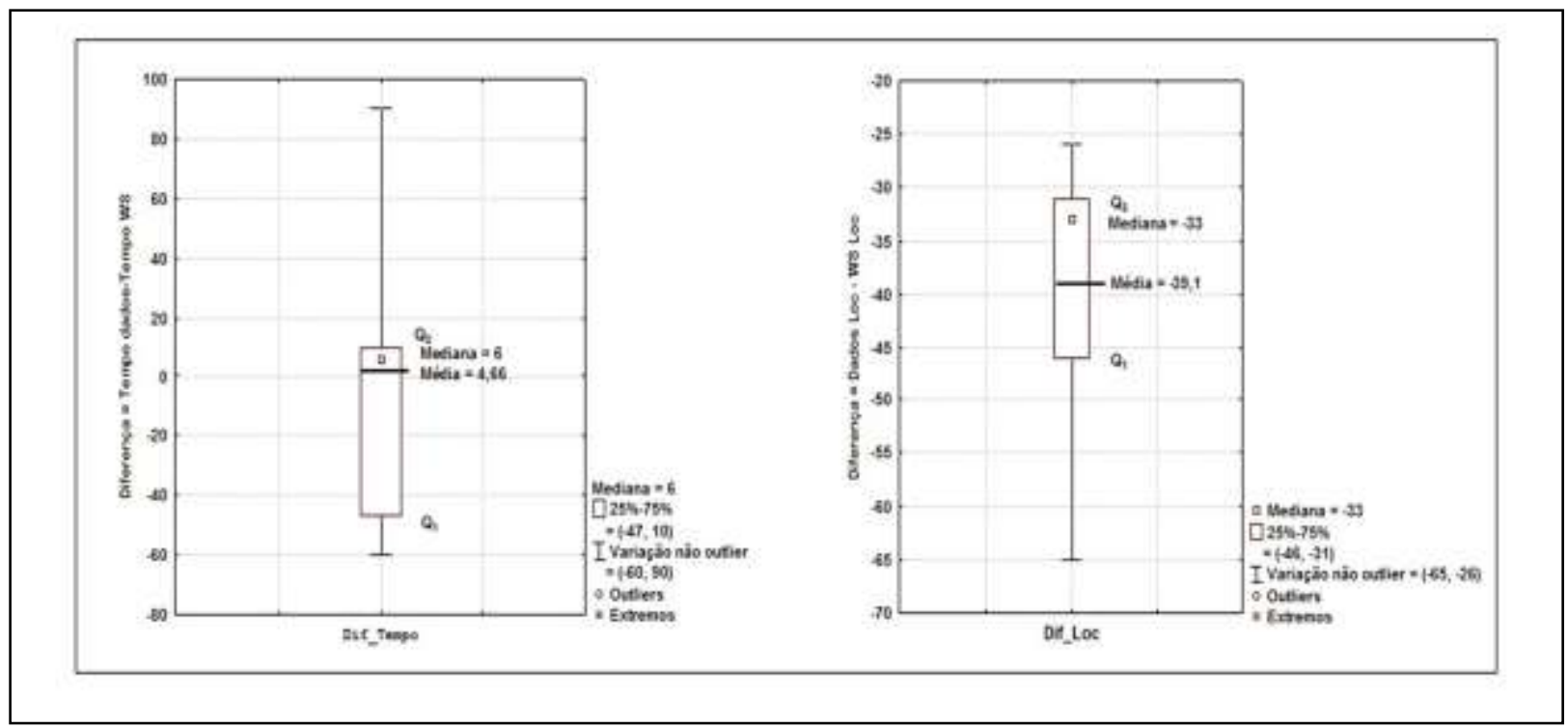

Figura 4.5: Box-plots das variáveis dTempo (Dif_Tempo) e dLoc (Dif_Loc). 


\section{Testes de normalidade}

Antes de realizar os testes de hipóteses, foram aplicados os seguintes testes para verificar a normalidade das amostras (dTempo e dLOC).

\section{Resultados dos testes de normalidade}

Na Tabela 4.7 são apresentados os testes de normalidade do estudo experimental, citados acima, considerando o tempo gasto e a linhas de código escritas para desenvolver a solução de integração tanto por dados como por WS.

Obteve-se como resultado, que as amostras (dTempo e dLOC) se ajustam à distribuição normal, como se pode observar na Tabela 4.7, a seguir.

De acordo com o coeficiente de curtose (kurtosis), os valores obtidos estão próximos de zero, podendo ser considerado normal, embora os valores sejam negativos, consideram-se como valores absolutos.

Conforme o teste de assimetria (skewness), a distribuição também é normal, uma vez que os valores tanto do tempo como da LOC, estatisticamente, estão próximos do valor zero.

Por fim, no teste de Shapiro-Wilk, considerando $\mathrm{p}=0,05$, pode-se inferir que $\mathrm{p}$-valor $>$ p. Então neste caso, a hipótese $\mathrm{H}_{0}$ deste teste de normalidade não é rejeitada e, podese afirmar que, com um nível de significância de 5\%, a amostra provém de uma população com distribuição normal, concordando assim, com as respostas obtidas pelos coeficientes de assimetria e curtose.

Tabela 4.7: Testes de normalidade

\begin{tabular}{lcc}
\hline & TEMPO & LOC \\
\hline CURTOSE & $-0,6237874$ & $-1,1088749$ \\
ASSIMETRIA & 0,59808613 & 0,25300437 \\
SHAPIRO-WILK & W=0,867835 & W=0,873326 \\
& p-valor $=\mathbf{0 , 1 1 6 5}$ & p-valor $=\mathbf{0 , 1 3 3 4}$ \\
\hline
\end{tabular}

Há casos em que as distribuições não seguem a normalidade devido aos valores discrepantes (outliers) necessitando assim, de uma transformação nos dados para estabilizar a variância e normalizar os dados. 


\section{Teste de Hipóteses}

De acordo com as recomendações de Wholin et al. (2000) e também, por causa do resultado dos testes de normalidade, foi utilizado o teste $\mathrm{T}$ pareado para testar as hipóteses.

\section{Teste T Pareado}

A primeira hipótese definida é a hipótese do tempo gasto para desenvolver a solução de integração por dados ( $\left.\mathrm{T}_{\mathrm{D}-\mathrm{EAI} \text {-Dados }}\right)$ e o tempo gasto para desenvolver a solução de integração por WS ( $\left.\mathrm{T}_{\mathrm{D}-\mathrm{EAI}-\mathrm{WS}}\right)$. A seguir são mostradas as hipóteses nulas e alternativas desta primeira hipótese:

- HN1: $\mathrm{T}_{\mathrm{D}-\mathrm{EAI} \text {-Dados }}>=\mathrm{T}_{\mathrm{D}-\mathrm{EAI}-W S} ; \mathrm{e}$

- HA1: $\mathrm{T}_{\mathrm{D}-\mathrm{EAI} \text {-Dados }}<\mathrm{T}_{\mathrm{D}-\mathrm{EAI}-W S}$.

A segunda hipótese definida é a hipótese das linhas de códigos escritas na integração por dados (LOC $\left.\mathrm{EAI}_{\mathrm{EA}-d a d o s}\right)$ e as linhas de códigos escritas na integração por

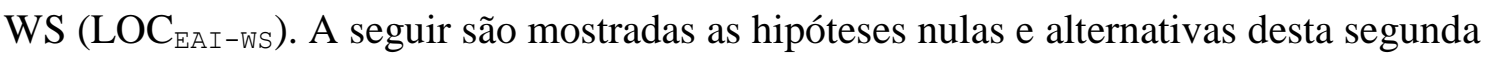
hipótese:

- HN2: $\mathrm{LOC}_{\mathrm{EAI}-\text { dados }}>=\mathrm{LOC}_{\mathrm{EAI}-W \mathrm{~W}} ; \mathrm{e}$

- HA2: $\mathrm{LOC}_{\mathrm{EAI}-\text { dados }}<\mathrm{LOC}_{\mathrm{EAI}-W S}$.

A Tabela 4.8 mostra os valores do p-valor das amostras de tempo e LOC (Vide o Apêndice D da Tabela 1 - Valores de $\mathbf{t}$ nos níveis de $10 \%$ a $0,1 \%$ de probabilidade).

Tabela 4.8: Teste-T pareado

\begin{tabular}{lcc}
\hline & TEMPO & LOC \\
\hline Teste $\mathrm{T}$ & $\mathrm{t}=0,25$ & $\mathrm{t}=-8,85$ \\
& $\mathbf{p}$-valor $=\mathbf{0 , 5 9 6 1}$ & $\mathbf{p}$-valor $<\mathbf{0 , 0 0 0 1}$ \\
Valor crítico de & & \\
$t_{(0,05 ; 8)}=2,31$ & & \\
\hline
\end{tabular}

\section{Conclusão do teste de hipóteses}

Por meio do teste T pareado, foi possível afirmar que:

- O tempo gasto para desenvolver a solução de integração por dados não diferiu estatisticamente $(\mathrm{p}=0,05)$ do tempo gasto para desenvolver a solução de integração por WS. Neste caso, não se rejeitou a hipótese nula (HN1); e 
- O número de linhas de código escritas para desenvolver a solução por dados foi estatisticamente menor $(\mathrm{p}=0,05)$ que o número de linhas de código escritas para desenvolver a solução por WS. Neste caso, rejeitou-se a hipótese nula (HN2), e foi aceita a hipótese alternativa (HA2).

Portanto, os testes de hipóteses confirmam os resultados intuitivos mostrados pelos box-plots da subseção 4.5.1, de que o tempo de desenvolvimento tanto por dados como por WS estão mais ou menos equiparados. Adicionalmente, nas linhas de código escritas, usando EAI-dados são escritas menos linhas de código do que usando EAIWS.

\section{Correlação}

Na Figura 4.6 é ilustrado o gráfico de dispersão para verificar a correlação entre o tempo e as linhas de código escritas. No entanto, pode-se inferir que, os dados estão muito dispersos uns dos outros.

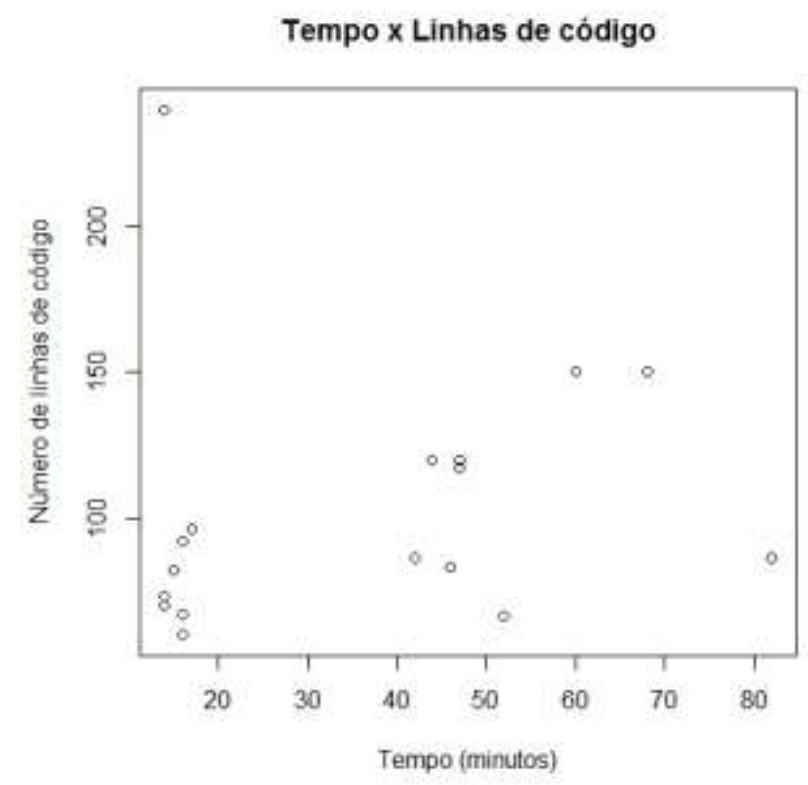

Figura 4.6: Gráfico de dispersão do Tempo com LOC.

A seguir é ilustrada a Tabela 4.9 que foi utilizada na correlação. Na parte de WS, BD, PHP, Java, Glassfish e JPA, o número 0 significa não conhece e o número 1 significa tem conhecimento. Já na parte de experiência, os valores fazem referência aos anos de experiência em programação que os participantes possuem. Por último, na parte 
de escolaridade, os valores significam: 1- graduação; 2- especialização; 3- mestrado; e 4- doutorado.

Tabela 4.9: Dados utilizados na correlação

\begin{tabular}{ccccccccccc}
\hline Participantes & $\begin{array}{c}\text { dTem- } \\
\text { po }\end{array}$ & dLOC & WS & BD & PHP & Java & Glassfish & JPA & Experiência & $\begin{array}{c}\text { Escola- } \\
\text { ridade }\end{array}$ \\
\hline P1 & -53 & -31 & 1 & 1 & 1 & 1 & 1 & 1 & 9 & 2 \\
P2 & 6 & -26 & 1 & 1 & 0 & 1 & 0 & 1 & 6 & 3 \\
P3 & -1 & -31 & 1 & 1 & 1 & 1 & 1 & 1 & 7 & 3 \\
P4 & -60 & -28 & 0 & 1 & 0 & 1 & 0 & 0 & 4 & 2 \\
P5 & -47 & -33 & 1 & 1 & 1 & 1 & 1 & 0 & 9 & 2 \\
P6 & 7 & -38 & 1 & 1 & 1 & 1 & 0 & 0 & 9 & 3 \\
P7 & 90 & -54 & 1 & 1 & 0 & 1 & 1 & 1 & 23 & 4 \\
P8 & 90 & -46 & 0 & 1 & 0 & 1 & 1 & 1 & 7 & 1 \\
P9 & 10 & -65 & 1 & 1 & 1 & 1 & 1 & 0 & 6 & 3 \\
\hline
\end{tabular}

Na Figura 4.7 é ilustrado o gráfico de dispersão para verificar a correlação entre o dTempo e o dLOC. No entanto, pode-se inferir que, os dados estão muito dispersos uns dos outros.

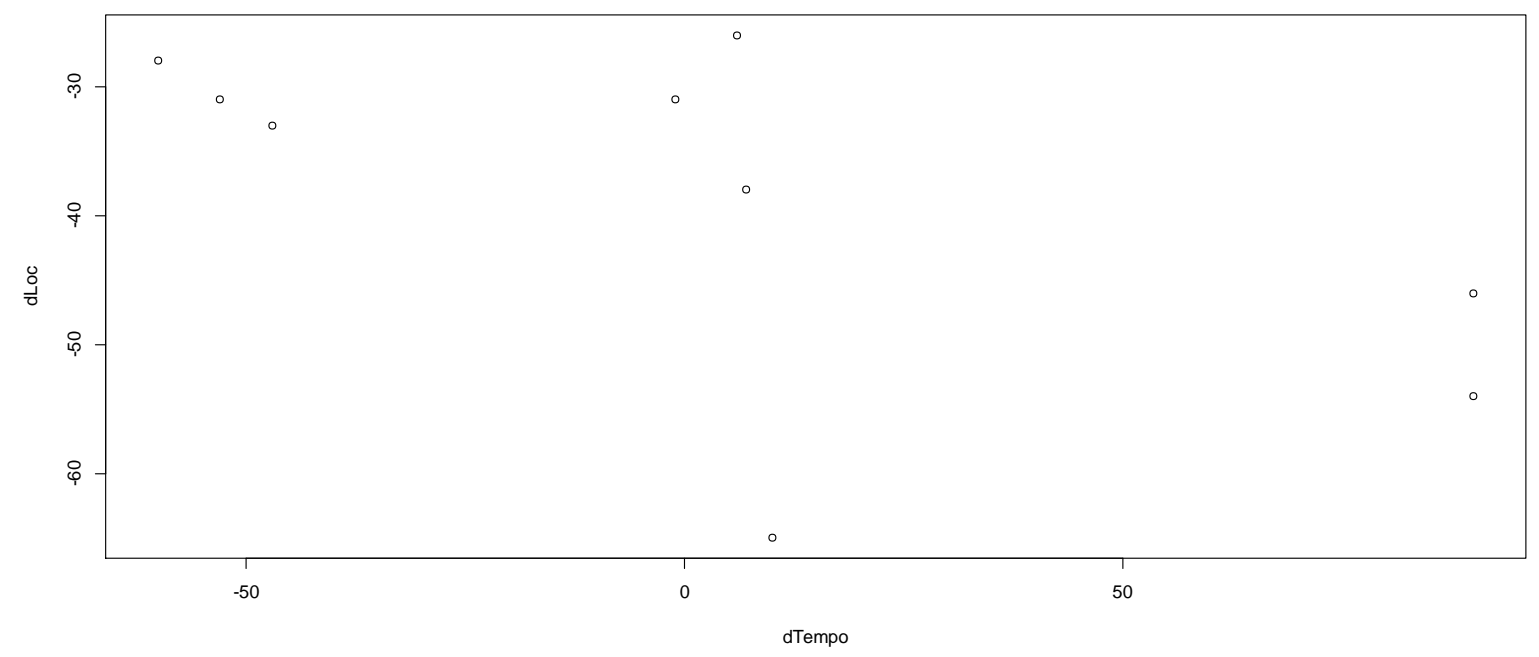

Figura 4.7: Gráfico de dispersão do dTempo com dLOC.

Na Tabela 4.10, é apresentada a correlação entre as variáveis de contexto com as abordagens EAI-Dados e EAI-WS. Foi utilizado o Coeficiente de correlação de Pearson para verificar se as variáveis de contexto influenciaram nos resultados. Observando esta tabela, pode-se inferir que não houve uma correlação entre as variáveis de contexto com as abordagens EAI-Dados e EAI-WS, uma vez que o coeficiente de correlação dos itens da tabela (Participante, WS, PHP, Glassfish, JPA, Experiência) é muito baixo. 
Tabela 4.10: Correlação com as variáveis de contexto

\begin{tabular}{lcccccccc}
\hline & WS & BD & PHP & Java & Glassfish & JPA & Experiência & Escolaridade \\
\hline \multirow{2}{*}{ dTempo } & $-0,105$ & - & $-0,457$ & - & 0,273 & 0,462 & 0,540 & 0,225 \\
dLOC & $-0,090$ & - & $-0,043$ & - & $-0,477$ & 0,135 & $-0,387$ & $-0,282$ \\
\hline
\end{tabular}

\subsubsection{Análise das dificuldades encontradas pelos participantes e suas impressões pessoais}

Além da análise dos dados quantitativos, foi aplicado também um questionário mais subjetivo, a fim de que os participantes do experimento pudessem descrever suas principais dificuldades e impressões pessoais que eles tiveram quando realizaram o estudo experimental. Com essas informações foi possível também definir novas ameaças à validade deste experimento.

\section{Ameaças à validade do experimento}

A seguir são descritas as variáveis que podem ter sido uma ameaça à validade do experimento, fazendo com que a execução das tarefas se tornasse mais onerosa que o previsto:

- Falta de conhecimento e prática em PHP;

- Falta de conhecimento em Web Services;

- Tarefa de reiniciar o Glassfish várias vezes; e

- Entendimento da lógica usada e o que precisava ser alterado, uma vez que o sistema foi feito por outra pessoa e não havia muito tempo disponível para efetuar a manutenção e resolver o problema.

Outros fatores que podem ser considerados ameaças à validade externa desse experimento: (1) escolha da linguagem PHP ao invés da linguagem Java, visto que quatro participantes não sabiam PHP e todos sabiam Java. No entanto, não se pode garantir que todos os participantes tivessem conhecimento do JSF, que teria que ser usado juntamente com Java; (2) não foi coletado em separado o tempo gasto com aprendizado de PHP, o que pode ter influenciado negativamente o experimento. Por esse motivo, como o experimento EAI-Dados foi executado primeiro, o participante pode ter embutido esse tempo na contagem do tempo de implementação. Essa situação não aconteceu no segundo experimento (EAI-WS) porquê o participante já possuía os conhecimentos básicos de PHP para trabalhar no experimento. Assim, se este tempo 
fosse subtraído do tempo total gasto na parte 1 do experimento, talvez a hipótese HA1 fosse provada. Esse fato foi constatado também por alguns participantes que mencionaram no questionário que a parte de EAI-WS foi menos complexa de executar, pois já estavam mais ambientados com o sistema e a linguagem PHP; (3) em relação à população de sujeitos, o grupo era pequeno, uma vez que eram voluntários e um dos requisitos básicos para os sujeitos era de possuir certa experiência com programação e banco de dados. Além disso, o grupo era mais ou menos homogêneo, pois com exceção dos dois profissionais de informática da Embrapa, o restante dos participantes eram estudantes de pós graduação do ICMC-USP; (4) considerou-se que a ordem em que as integrações são feitas não afetaria o resultado, pois o conhecimento obtido a respeito do sistema após fazer EAI-WS ou EAI-Dados não seria utilizado diretamente na outra parte do experimento. Embora já se soubesse que o entendimento dos esquemas de dados dos sistemas Agenda e RH faziam parte de ambas as integrações, acreditava-se que esse tempo seria irrisório e não precisasse ser medido, visto que os sistemas são triviais e bastante similares ao sistema CEP utilizado no treinamento. No entanto, observou-se posteriormente que os alunos tiveram certa dificuldade nesse aspecto, portanto o tempo gasto deveria ter sido subtraído para não afetar os resultados; e (5) o experimento não foi conduzido em um ambiente real, pois foi realizado em meio acadêmico.

Desta forma, as conclusões obtidas pelos testes de hipóteses realizados neste experimento não podem ser generalizados para todos os casos. Para que isso aconteça, seria necessário realizar uma avaliação mais abrangente, com grupos maiores de participantes e em um ambiente de produção real.

\section{Análise das dificuldades encontradas pelos participantes}

De acordo com os questionários preenchidos, puderam ser observadas algumas dificuldades técnicas dos participantes durante a condução dos experimentos, relatadas a seguir.

\section{Dificuldades técnicas na abordagem EAI-Dados}

Na Figura 4.8, pode-se inferir que a maioria dos participantes não tiveram dificuldades técnicas com a abordagem EAI-Dados. Um dos participantes alegou ter dificuldades, 
tendo relatado que a sua maior dificuldade foi com a linguagem PHP, por não possuir muito conhecimento prévio.

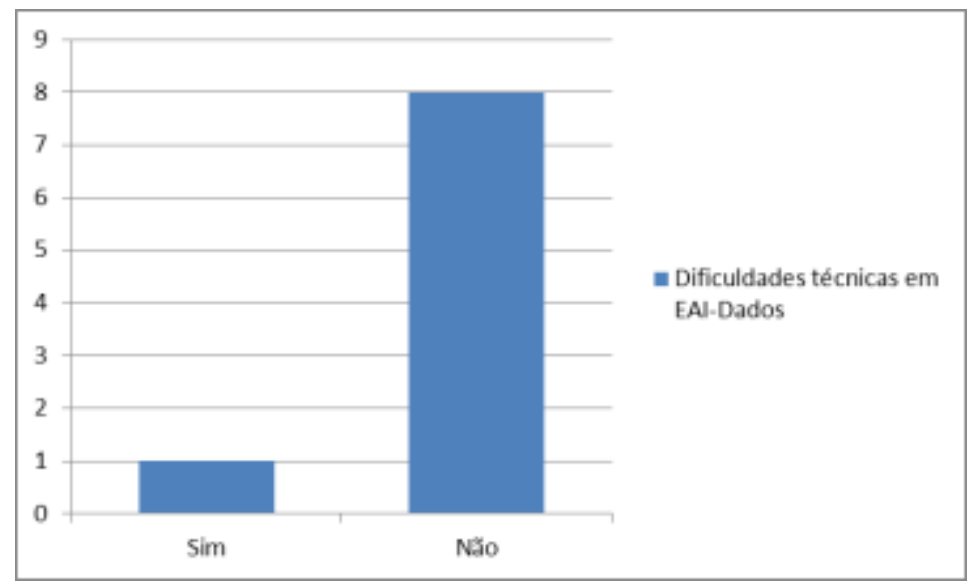

Figura 4.8: Dificuldades técnicas da abordagem EAI-Dados.

\section{Dificuldades técnicas na abordagem EAI-WS}

$\mathrm{Na}$ Figura 4.9, pode-se concluir que houve mais participantes que tiveram dificuldades técnicas na abordagem EAI-WS se comparamos à abordagem EAI-Dados. As pessoas que tiveram dificuldades relataram que uma das maiores dificuldades foi o não conhecimento da implementação de Web Services e também, quando eles estavam implementando, o Glassfish falhava e por esse motivo, tinha que reiniciá-lo várias vezes e, com isso eles perderam tempo para implementar o código de WS.

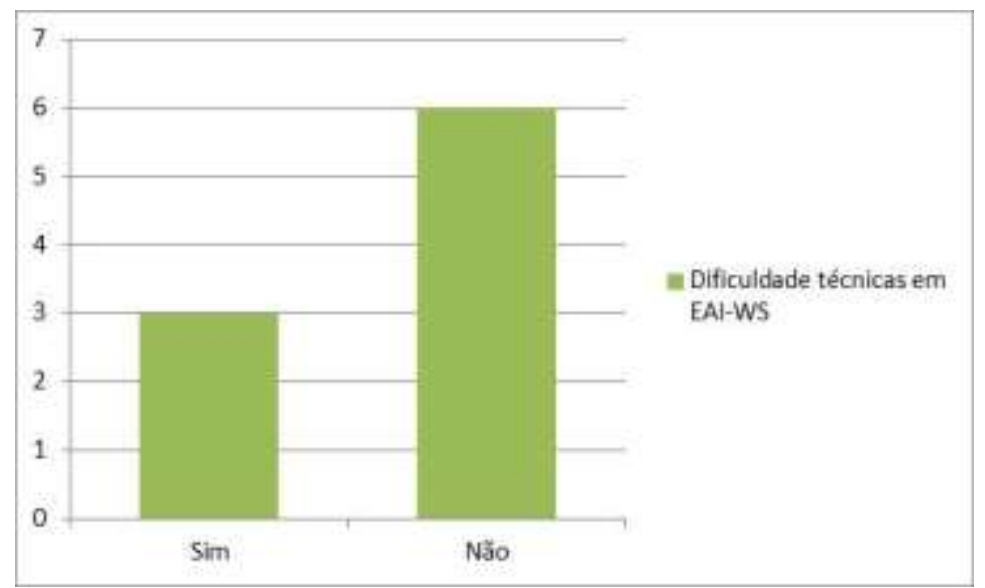

Figura 4.9: Dificuldades técnicas da abordagem EAI-WS. 


\section{Dificuldades conceituais na abordagem EAI-Dados e EAI-WS}

Não houve dificuldades conceituais em nenhuma das duas abordagens (EAI-Dados e EAI-WS) por parte dos participantes.

\section{Análise das impressões pessoais dos participantes}

A última pergunta do questionário foi a mais subjetiva de todas. Foi perguntado quais das abordagens foram mais fáceis de trabalhar: EAI-Dados ou EAI-WS.

Os participantes que disseram que EAI-Dados foi mais fácil de trabalhar alegaram que essa abordagem era menos trabalhosa, por ter menos passos a seguir e também, porque eles já possuíam mais experiência em trabalhar com essa abordagem. Já os indivíduos que disseram que EAI-WS foi melhor de se trabalhar, relataram que essa abordagem é mais fácil por causa do reúso. Por fim, os participantes que chegaram à conclusão que as duas abordagens são iguais em relação à facilidade de se trabalhar foi a maioria, como se pode ver na Figura 4.10.

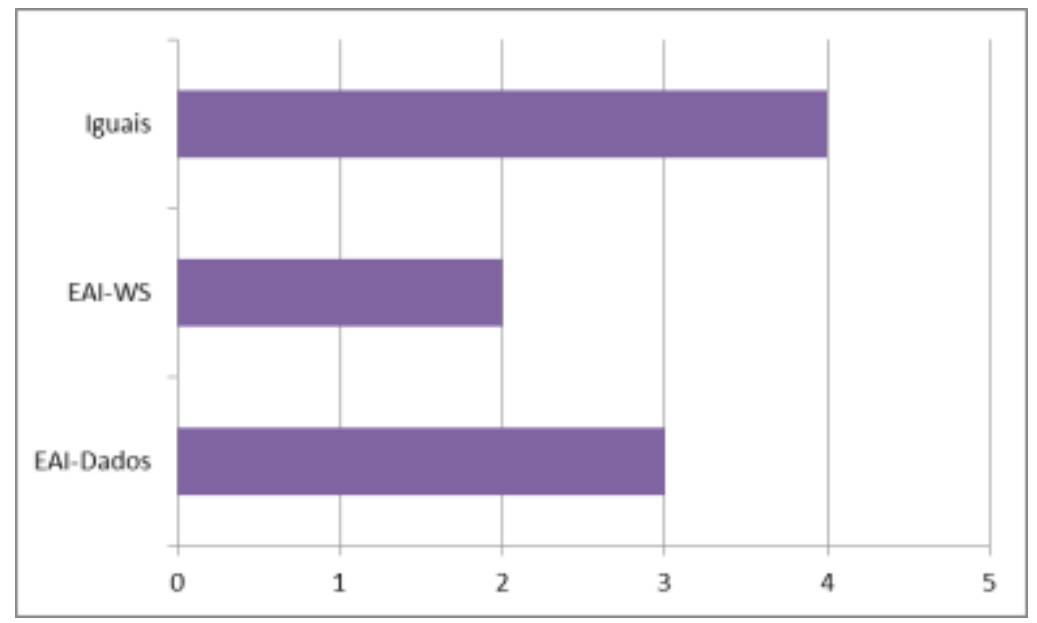

Figura 4.10: Quantitativo da impressão dos participantes em relação às abordagens.

\subsection{Discussão}

Os resultados obtidos neste estudo experimental revelam que na amostragem de tempo de desenvolvimento, tanto a abordagem EAI-Dados como a abordagem EAI-WS, estatisticamente, não diferiram uma da outra, indo contra a hipótese alternativa HA1.

Já na amostragem de linhas de códigos escritas, foi provado estatisticamente que a LOC da abordagem EAI-Dados é menor que a LOC da abordagem EAI-WS, estando de acordo com a hipótese alternativa HA2. 
No entanto, conforme comentado na Seção 4.5.2, algumas ameaças à validade surgiram após a finalização do experimento, isto é, não haviam sido consideradas durante o planejamento. Essas ameaças poderão ser tratadas em um próximo experimento, permitindo obter novas conclusões sobre o tempo de desenvolvimento despendido nas duas abordagens. Alguns dos cuidados a serem tomados em uma futura replicação do experimento são: a inclusão de coleta de tempo gasto no aprendizado da linguagem de programação e em depuração de erros decorrentes de falta de experiência no ambiente de desenvolvimento; e a realização das partes 1 e 2 alternadamente, para reduzir a ameaça do aprendizado obtido pelo aluno em uma das partes facilitar a parte seguinte.

Houve indícios de que a abordagem EAI-WS é mais trabalhosa, uma vez que a quantidade de linhas de código é bem maior do que na abordagem EAI-Dados. Por outro lado, apesar da abordagem EAI-WS ser mais trabalhosa, como foi dito por alguns participantes do experimento, esta abordagem possui um bom grau de reúso, assim, outros sistemas poderão fazer uso do serviço criado, podendo agilizar o desenvolvimento de software.

Por esses motivos, o experimento foi útil para coletar indícios das vantagens de WS para realizar EAI, além de ter sido uma ótima oportunidade para aprender mais sobre a realização de experimentos controlados, uma vez que não foi encontrado na literatura nenhum experimento parecido com este estudo experimental. Além disso, foi utilizado como base, apesar de serem experimentos diferentes do apresentado neste trabalho, os trabalhos de ELER, (2012) e OLIVEIRA, (2012), que também realizaram experimentos envolvendo Web Services.

O primeiro autor trabalhou com um experimento controlado para investigar e avaliar o uso de informações estruturais fornecidas por serviços testáveis para a realização das atividades de monitoração. $\mathrm{O}$ objetivo geral desse experimento foi verificar se existem vantagens em utilizar, além dos resultados funcionais, informações de teste estrutural fornecidas por serviços testáveis. Essa verificação foi realizada por meio de uma comparação entre os resultados obtidos por monitoradores que utilizaram apenas os resultados funcionais da execução dos casos de teste com os resultados obtidos por monitoradores que utilizaram os resultados funcionais e estruturais da execução dos casos de teste. $\mathrm{O}$ foco quantitativo do experimento foi medir quantas mudanças cada abordagem conseguiu identificar e quais operações foram alteradas. $\mathrm{O}$ foco qualitativo 
foi medir a confiança dos monitoradores das duas abordagens sobre os resultados da monitoração.

Já o segundo autor trabalhou com a avaliação da manutenibilidade dos Web Services: RESTful e SOAP-WSDL. Os critérios foram: tempo gasto na manutenção e a modificabilidade dos serviços web. A avaliação foi realizada para responder à seguintes questões:

- Qual o tipo de Web Services é mais manutenível do lado do cliente?

- Qual o tipo de Web Services é mais manutenível do lado do servidor?

- Quais dos Web Services avaliados: RESTful e SOAP-WSDL proporcionam o menor custo com gastos de manutenção e evolução para as empresas de softwares que desenvolvem Web Services?

\subsection{Considerações Finais}

Neste capítulo foram apresentadas as análises dos dados obtidos por meio de um formulário preenchido pelos participantes deste estudo experimental. Além disso, foram analisados dois tipos de hipóteses, resultando assim, em respostas quantitativas para a questão feita no objetivo do experimento: "Em termos de tempo de desenvolvimento e código produzido, é mais fácil realizar EAI-WS ou EAI-Dados?"

No entanto, a escolha da melhor abordagem para integração também vai depender do tipo de aplicação e as regras de negócios que deverão ser seguidas, o que motivou a escrita dos padrões a serem apresentados no capítulo seguinte. 


\section{Padrões para EAI}

\subsection{Considerações Iniciais}

Conforme mencionado nos capítulos anteriores, a integração de aplicações empresariais apresenta diversos problemas, para os quais a solução depende do contexto em que a integração ocorre. Várias restrições podem ocorrer, causando problemas a serem solucionados, que devem ser levados em consideração ao optar por um projeto usando integração por dados ou via WS. Assim, a documentação desses problemas e soluções no formato de padrões de software é uma boa maneira de disponibilizar a outros desenvolvedores o conhecimento adquirido em EAI, facilitando seu reúso. Este capítulo descreve como foram identificados e documentados cinco padrões de EAI (Seção 5.2). Dois desses padrões são apresentados na Seção 5.3. Finalmente, discute como pretendese validar e evoluir este conjunto de padrões (Seção 5.4).

\subsection{Mineração dos Padrões}

Durante a fase de estudo sobre integração de sistemas empresariais, em especial na fase de implementação de Web Services, houve a intenção de efetuar um estudo para descobrir qual a melhor forma de se integrar sistemas, ou seja, por meio dos Web Services ou pelo acesso nativo à base de dados.

Primeiramente, em sua monografia da qualificação, a autora havia proposto identificar diretrizes de integração utilizando o acesso direto ao banco de dados e também, utilizando Web Services. No entanto, após discussões durante o exame de qualificação, foi sugerido que se investigasse a possibilidade de propor padrões de integração de EAI, identificando na prática quais problemas e soluções têm sido mais comumente empregados e documentando-os no formato de padrões. 
Assim, com base em exemplos reais de integração de sistemas da Embrapa Soja de Londrina e do ICMC-USP de São Carlos, iniciou-se a identificação dos problemas e soluções, originando um conjunto de sete padrões, que posteriormente foram refinados resultando em cinco padrões, conforme será explicado adiante. Para cada um desses padrões foi realizada a implementação de um exemplo e a escrita do texto com problema, contexto, forças, solução e consequências.

Por exemplo, no padrão 1, tratava-se do acesso direto via $\mathrm{BD}$, que se pode ver na Figura 5.1, em que, o sistema de recepção de visitas (banco de dados mysql 4 e linguagem de programação Delphi 6) e o sistema de controle orçamentário da Embrapa Soja (banco de dados interbase 6 e linguagem de programação Delphi 5), acessava diretamente a base de dados do sistema legado do RH, que foi desenvolvida utilizando interbase 6.5. Como os dois sistemas citados anteriormente foram desenvolvidos utilizando a linguagem Delphi, a qual possuía drivers para acessar tanto o banco mysql como o banco interbase, foi possível efetuar a integração com tranquilidade.

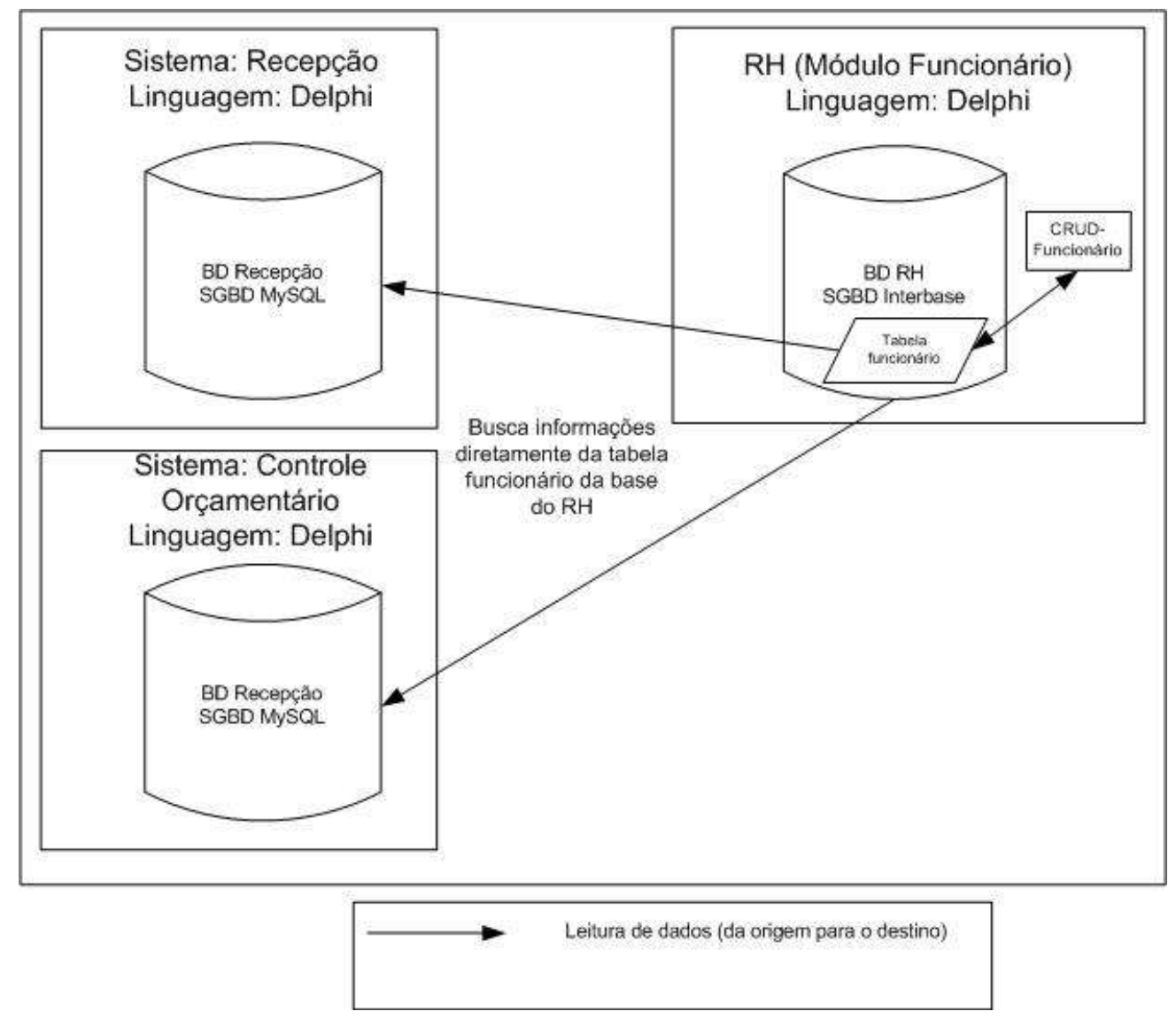

Figura 5.1: Exemplo da utilização do Padrão 1 na Embrapa Soja. 
Já no Padrão 2, foi implementado um Web Service que acessava os dados do sistema do RH no modo somente leitura. Neste caso, foi simulada a implementação de dois sistemas da Embrapa Soja, Sistemas de recepção de visitas e sistema de projetos científicos que acessam um Web service com as informações do RH, conforme ilustrado na Figura 5.2.

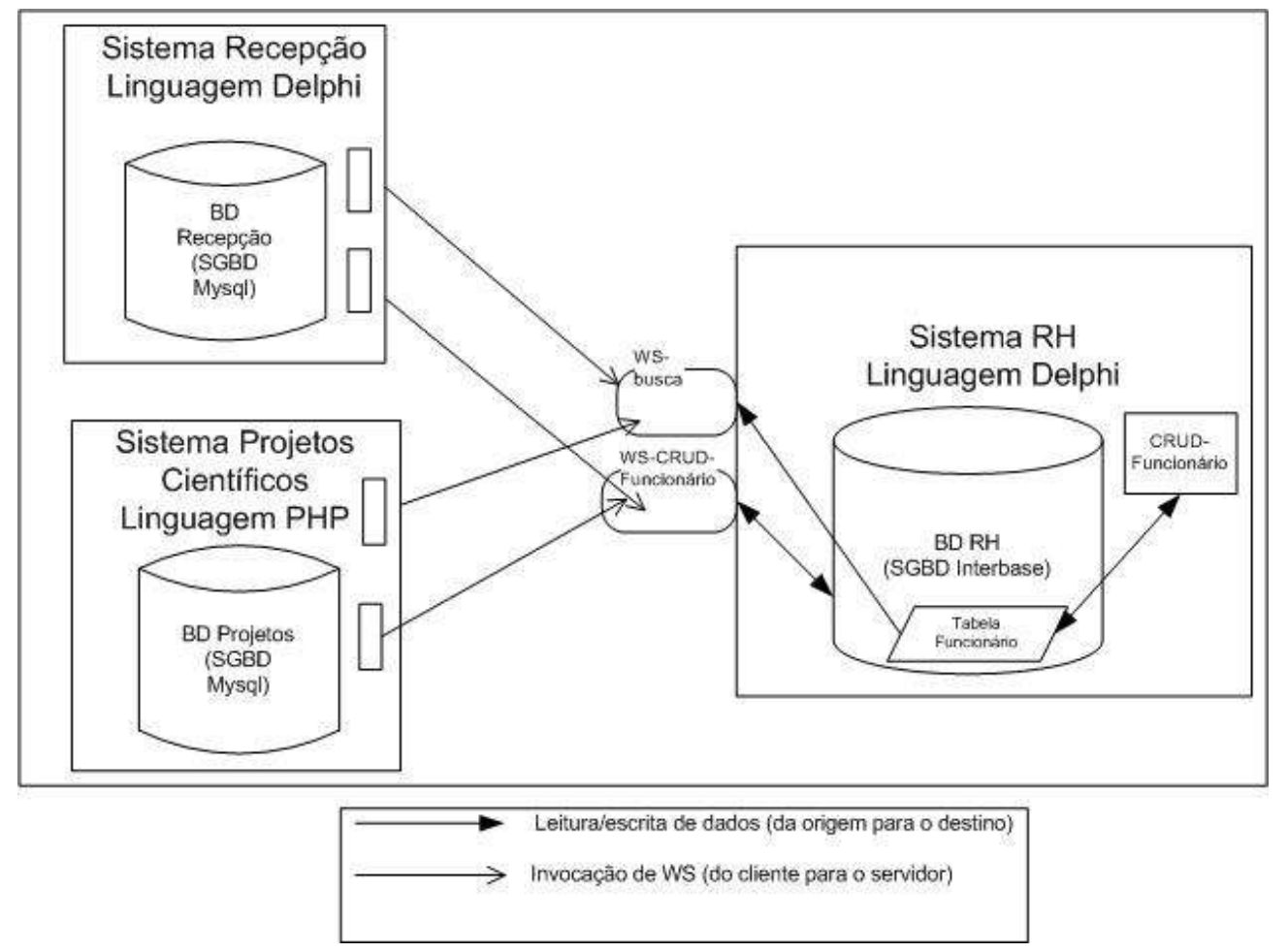

Figura 5.2 Exemplo da utilização do Padrão 2 na Embrapa Soja.

$\mathrm{Na}$ Listagem 5.1 apresenta-se os trechos de código referentes à persistência (persistence.xml) por meio do JPA, em que a tabela Funcionário da base de dados RH (em interbase 6.5) foi transformada em uma classe java (Funcionario.java, Listagem 5.2) que servirá como fonte de apoio para os Web Services WS-busca e WS-CRUD acessarem as informações da tabela Funcionário.

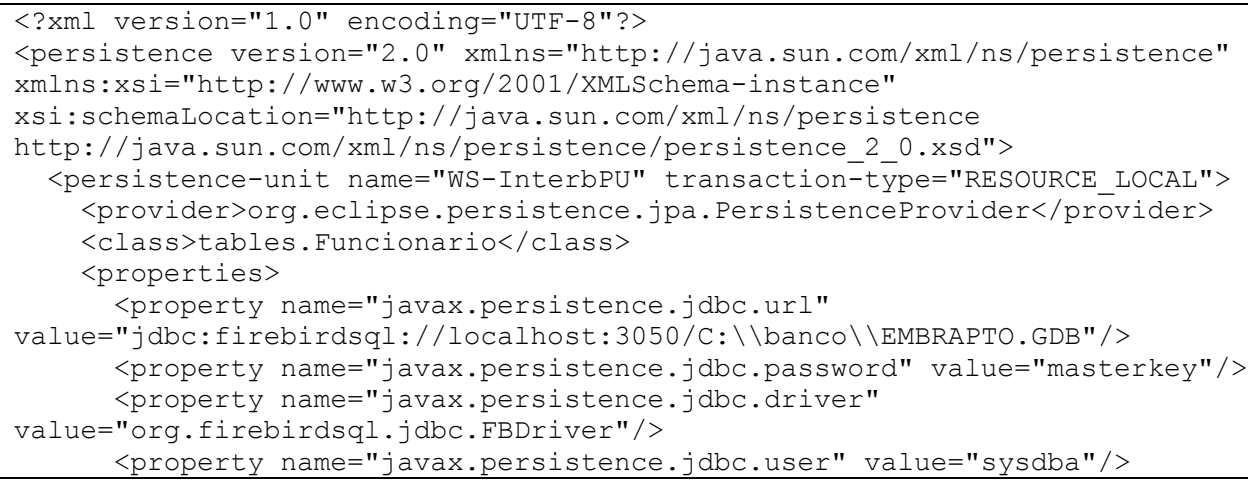




\begin{tabular}{lc}
16 & $</$ properties $>$ \\
17 & $</$ persistence-unit $>$ \\
18 & $</$ persistence $>$ \\
\hline
\end{tabular}

Listagem 5.1: Arquivo Persistence.xml que efetua a persistência por meio do JPA da tabela Funcionário da base de dados $\mathrm{RH}$.

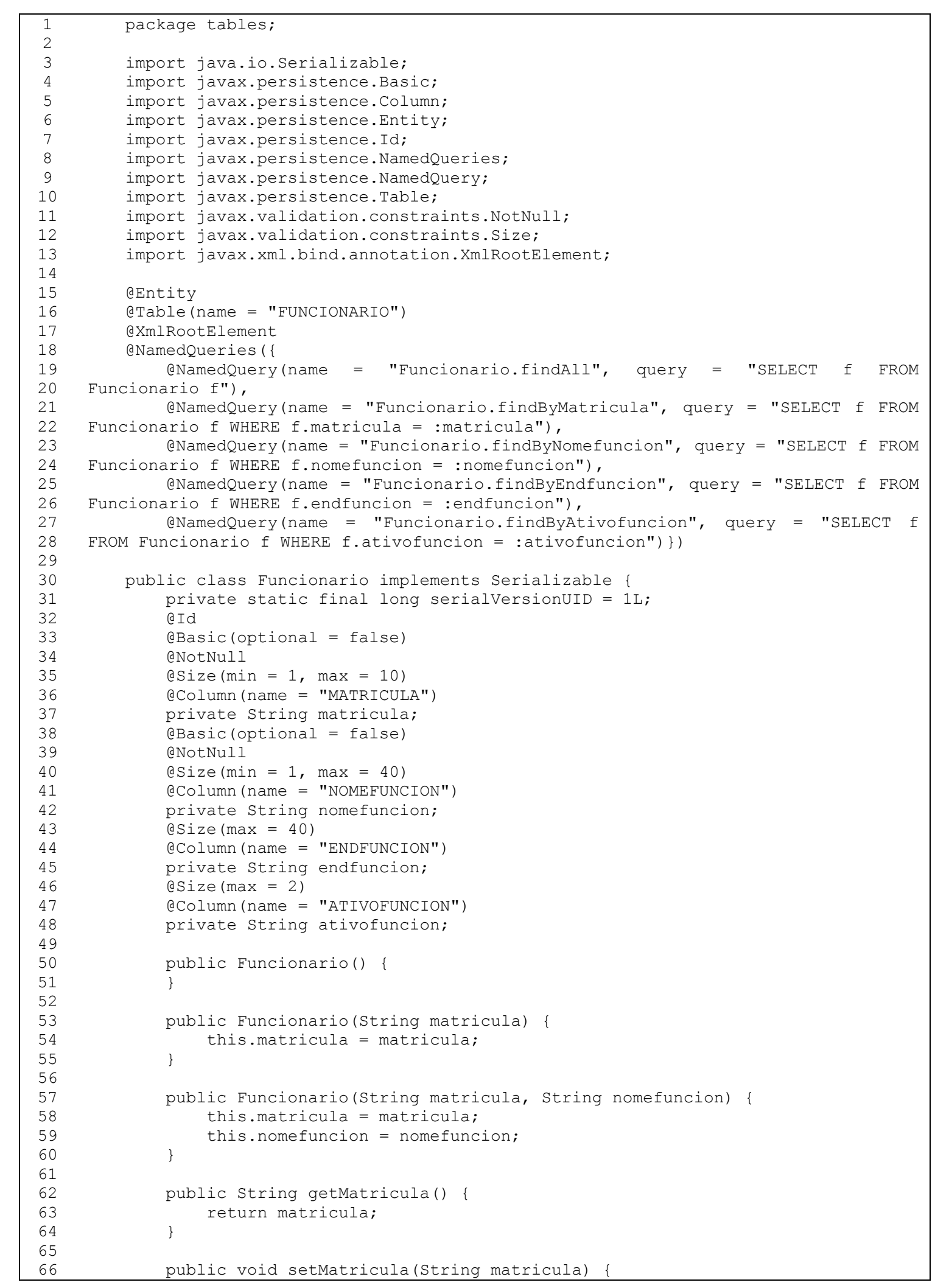




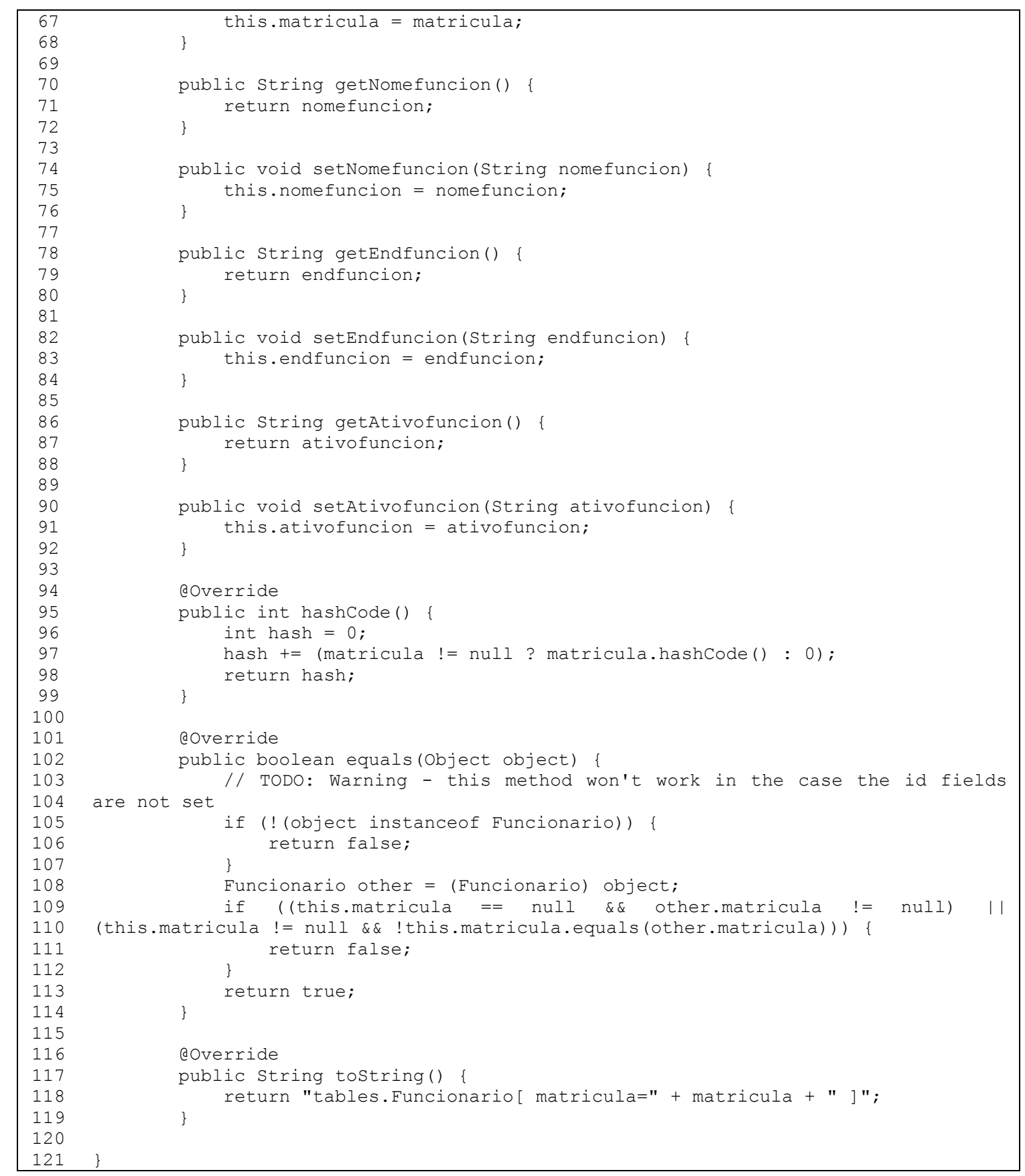

Listagem 5.2: Classe Funcionario.java que foi gerada por meio da persistência da tabela Funcionário da base de dados $\mathrm{RH}$.

Na Listagem 5.3 apresenta-se a implementação do Web Service WS-busca. Foram desenvolvidos dois tipos de consultas: a primeira (linhas 19 a 28) em que são mostrados todos os funcionários e a segunda (linhas 31 a 43) em que são feitas consultas individuais de funcionários.

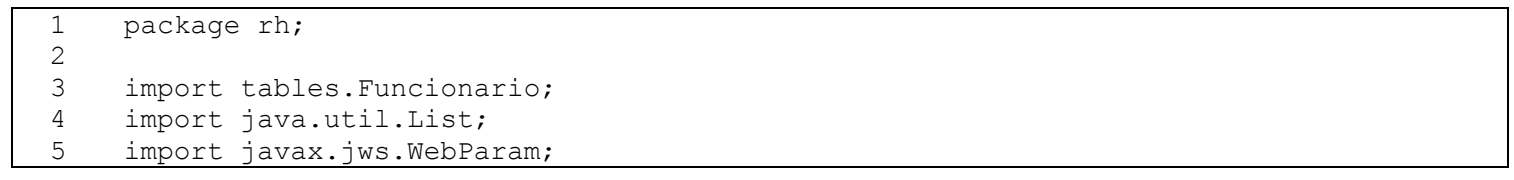




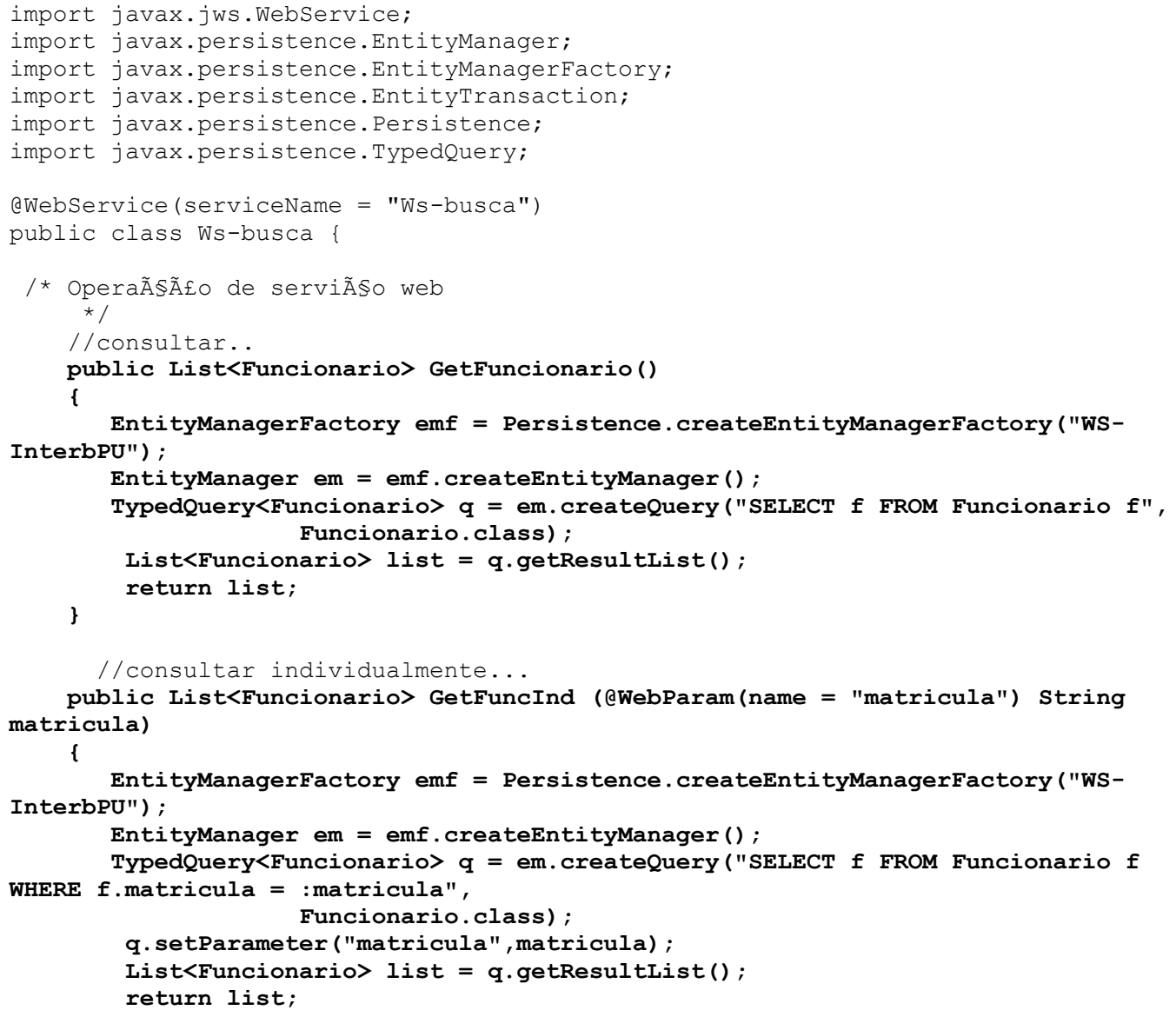

Listagem 5.3: Lógica do Web Service WS-busca que efetua consultas da tabela Funcionário da base de dados $\mathrm{RH}$.

Na Listagem 5.4 apresenta-se o código-fonte referente ao consumo do Web Service WS-busca por meio da linguagem de programação PHP em que é efetuada a integração do Sistema Projetos Científicos com a tabela Funcionários da base RH (linhas 23 a 45).

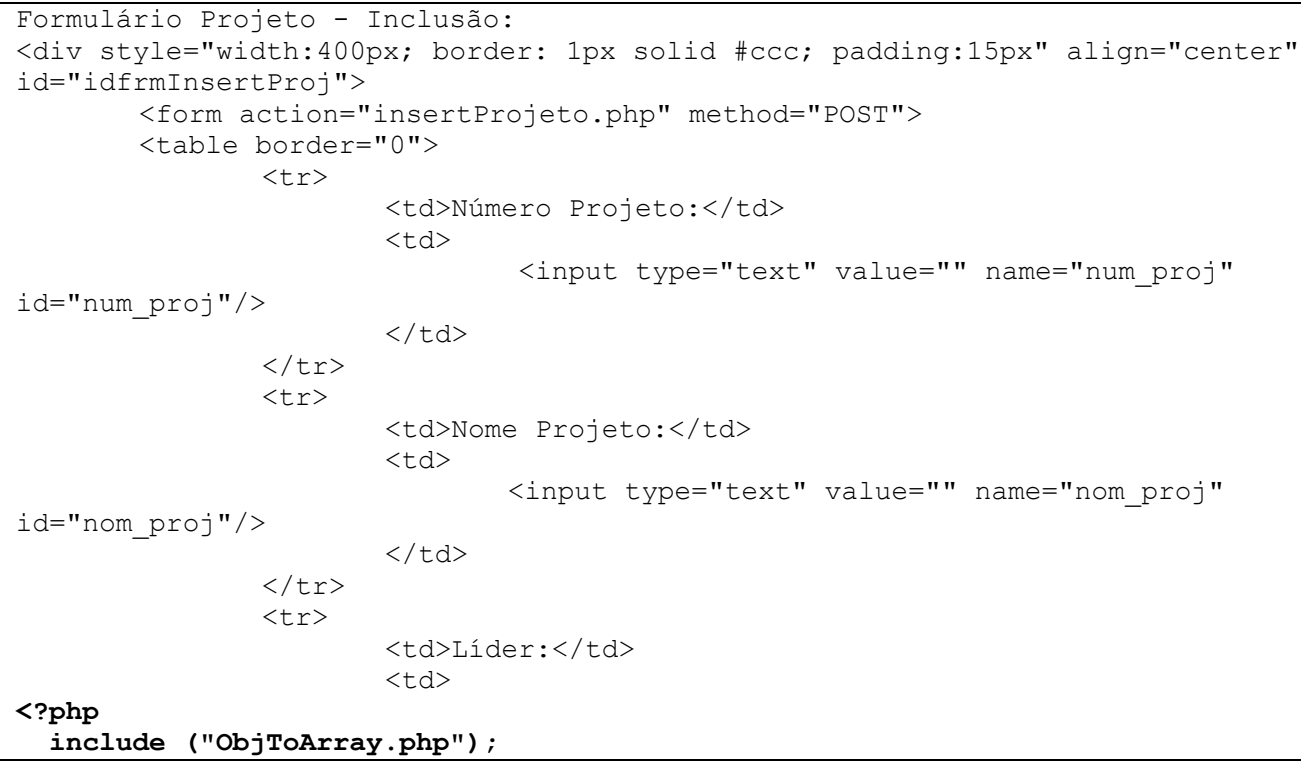




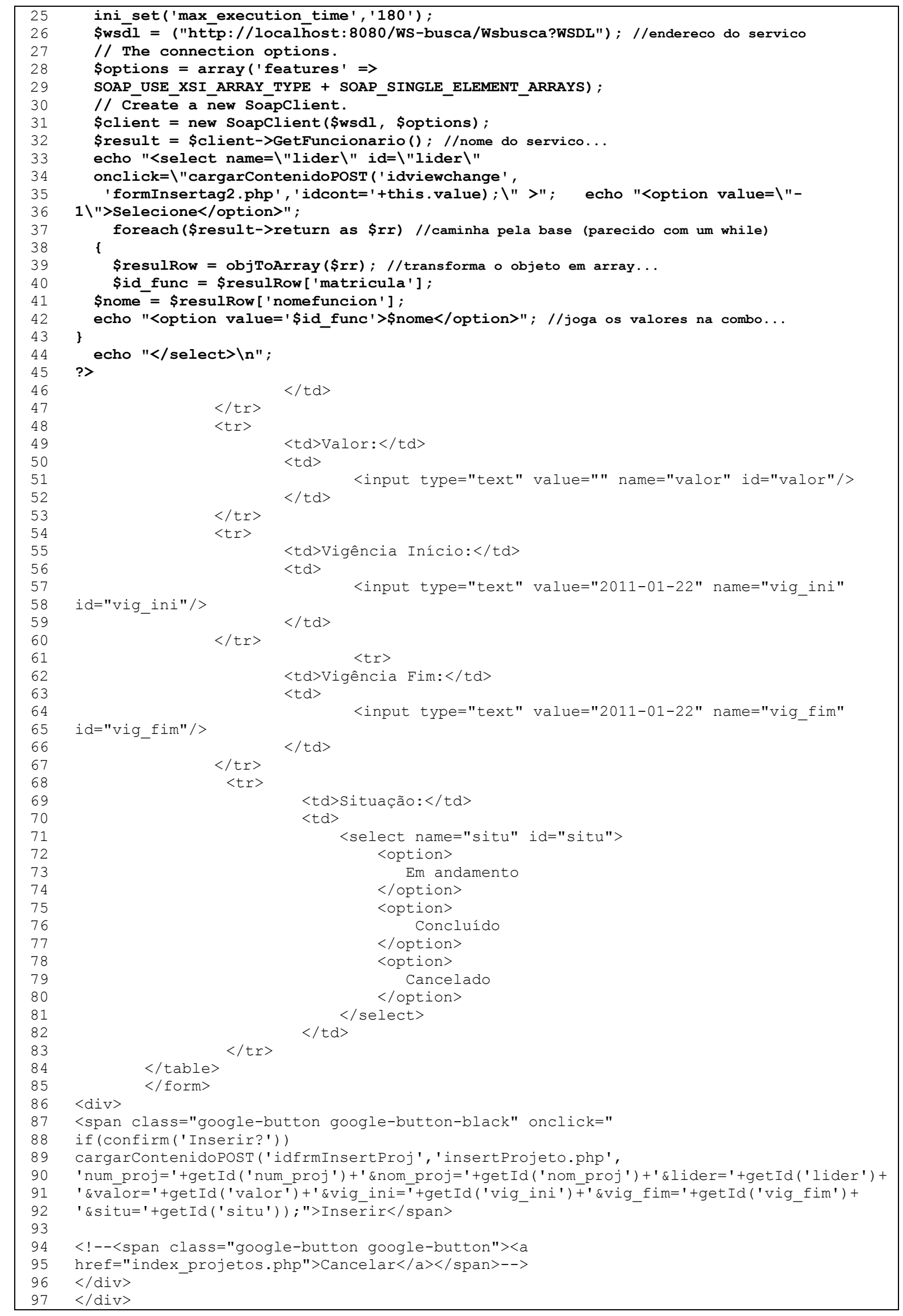

Listagem 5.4: Consumo do Web Service WS-CRUD por meio da Linguagem PHP. 
Analogamente, a implementação foi feita para todos os sete padrões, e em seguida foi escrito um artigo para submissão ao evento SugarLoafPLoP 2012 (KANESHIMA; BRAGA, 2012). O artigo passou por diversas iterações com o shepherd, em que o conjunto de sete padrões foi refinado, originando cinco padrões finais para apresentação durante a conferência. Durante a conferência, o artigo passou por uma sessão de oficina de escrita do autor (writers' workshop), em que mais uma vez houve sugestões de melhoria para que os padrões possam ser publicados em sua versão final nos proceedings (anais) do evento. Durante a fase do Writer's Workshop do SugarLoafPLoP'2012 foram identificados alguns pontos que precisavam ficar mais claros no artigo e as contribuições dos participantes deste evento foram muito importantes para melhorar a escrita e o entendimento dos padrões.

Na próxima seção descrevem-se o objetivo e a motivação de propor os padrões para EAI, apresenta-se uma visão geral do conjunto de padrões e descrevem-se dois dos padrões em detalhes. Os demais padrões encontram-se no Apêndice C.

\subsection{Padrões para EAI}

\subsubsection{Objetivos e Motivação para os padrões}

Não se pode afirmar que efetuar a integração de sistemas é simples e também, não é possível afirmar que há uma resposta para resolver todos os problemas de integração de sistemas empresariais.

No entanto, é comum obter informações de desenvolvedores que já tiveram a experiência em resolver problemas similares, de forma que essa solução possa ser usada várias vezes para resolver problemas semelhantes. Assim, padrões para EAI são considerados como sugestões e/ou conselhos que descrevem soluções para problemas que acontecem com frequência ao integrar aplicações empresariais. É importante ressaltar que, se usados corretamente, esses padrões de integração podem ajudar a preencher a grande lacuna que há entre a visão de alto nível de integração da implementação do sistema (HOHPE; WOOLF, 2003).

A motivação para apresentar um conjunto de padrões para EAI é facilitar a tomada de decisões do engenheiro de software responsável pela integração de sistemas, visto que embora existam vários padrões para integração relacionados aos padrões propostos, eles estão escritos em diferentes formatos, ou seja, muitos deles têm o seu foco na 
arquitetura e na padronização de códigos de implementação. Portanto, não focam nos diversos contextos de regras de negócios que podem estar presentes no momento da integração. Por exemplo, por decisões de negócios pode ser desejável que apenas um sistema seja responsável pelas operações de CRUD. Esse é o caso da Embrapa, por exemplo, em que apenas o setor de Recursos Humanos da empresa tem a responsabilidade de cadastrar pessoas. Outros sistemas que precisam de dados devem ter acesso somente de leitura, e ainda assim, somente a certos campos restritos. Assim, o uso de padrões como os da Seção 2.7 torna-se difícil por ter que interpretar cada contexto e confrontar com as diversas soluções alternativas, podendo haver dificuldade em encontrar o padrão correto. Espera-se, com o conjunto apresentado nesta dissertação, facilitar o uso dos padrões de EAI, com maior segurança de que as regras de negócios estão sendo levadas em consideração.

\subsubsection{Visão geral dos padrões}

Para todos os padrões apresentados, o contexto de aplicação do padrão leva em conta os seguintes fatores:

- Dificuldade de compartilhamento: se as aplicações a serem integradas pertencem à mesma empresa ou empresas parceiras, pode haver facilidade em compartilhar bases de dados, fornecendo direito de acesso às aplicações e não precisando recorrer a serviços. Com isso pode-se ganhar em desempenho, pois exige-se menor processamento das informações decorrente do uso de serviços. Por outro lado, se não há essa facilidade, WS podem ser melhores;

- O desempenho é crítico, com grande volume de acessos aos dados? Dependendo do tipo de aplicação a ser integrada, pode haver muito volume de acessos de um sistema para outro, inviabilizando WS e havendo preferência por acesso por dados. No entanto, isso deve ser analisado em conjunto com os demais fatores para permitir uma decisão mais acertada;

- A sincronização é essencial no sistema? Dependendo do tipo de aplicação a ser integrada, os dados devem estar sempre sincronizados, não havendo tolerância alguma a dados inconsistentes. Em outras aplicações, pode ser tolerável alguma falta de sincronização, dentro de certos períodos de tempo pré-definidos; e 
- O acesso na maioria das vezes é do tipo somente leitura? Muitas vezes a integração pode ser projetada de forma que um dos sistemas concentre as informações e os demais sistemas apenas acessem as informações, sem necessidade de alterar. Esse fator influencia bastante a solução, já que mecanismos mais complexos são necessários para permitir alteração de informações.

A Tabela 5.5 apresenta como cada padrão leva em conta cada um dos fatores discutidos anteriormente. Nota-se que essas são as combinações mais comuns, portanto pode haver outros contextos em que esses padrões não são adequados, levando à necessidade de outros padrões a serem documentados futuramente.

Tabela 5.5: Contexto dos padrões

\begin{tabular}{|l|c|c|c|c|c|}
\hline \multirow{2}{*}{ Fator } & \multicolumn{5}{|c|}{ Padrão } \\
\cline { 2 - 6 } & $\begin{array}{c}1- \\
\text { Acesso } \\
\text { direto via } \\
\text { BD }\end{array}$ & $\begin{array}{c}2- \\
\text { Acesso } \\
\text { direto via } \\
\text { WS }\end{array}$ & $\begin{array}{c}3- \\
\text { Duplicaçãa } \\
\text { o interme- } \\
\text { diária com } \\
\text { acesso via } \\
\text { BD }\end{array}$ & $\begin{array}{c}4- \\
\text { Duplicação } \\
\text { interme- } \\
\text { diária com } \\
\text { acesso via } \\
\text { WS }\end{array}$ & $\begin{array}{c}5- \\
\text { Duplica- } \\
\text { ção via } \\
\text { monitor } \\
\text { e WS }\end{array}$ \\
\hline $\begin{array}{l}\text { Há dificuldade de } \\
\text { compartilhamento? }\end{array}$ & Não & Sim & Não & Sim & Sim \\
\hline $\begin{array}{l}\text { Desempenho é crítico, com } \\
\text { grande volume de acesso aos } \\
\text { dados? }\end{array}$ & Não & Não & Sim & Sim & Não \\
\hline Sincronização é essencial? & Sim & Sim & Não & Não & Sim \\
\hline $\begin{array}{l}\text { Acesso é principalmente do } \\
\text { tipo somente leitura? }\end{array}$ & Não & Não & Sim & Não & Não \\
\hline
\end{tabular}

O problema a ser resolvido é comum a todos os padrões apresentados, por isso ele é descrito a seguir e não é repetido em cada padrão.

- Problema: Como integrar informações presentes em sistemas distintos, desenvolvidos possivelmente em diferentes plataformas, de forma a evitar inconsistência de informações e mantendo o desempenho compatível com o contexto de integração? 


\subsubsection{Exemplos dos padrões propostos}

Para fins de ilustração, a seguir são fornecidas as descrições detalhadas de dois dos padrões propostos neste trabalho. Os demais padrões podem ser encontrados no Apêndice C.

\section{Padrão 3 - Duplicação intermediária com acesso via BD}

- Nome: Duplicação intermediária com acesso via BD.

- Contexto: Está sendo desenvolvida uma aplicação empresarial (Sistema 1) em que parte das informações necessárias já existem em outra aplicação (Sistema legado), possivelmente em plataforma diferente da nova aplicação. A aplicação cliente (Sistema 1) não tem necessidade de armazenar essas informações, mas somente utilizá-la para cumprir seus objetivos de negócios, realizando apenas consulta ou alteração nessas informações. As aplicações pertencem a mesma empresa ou a empresas parceiras em que há facilidade de compartilhamento de recursos. O desempenho é crítico, pois há um alto volume de informações a ser integrada, mas não é tão importante que as informações estejam sempre consistentes entre as aplicações, havendo tolerância para sincronização periodicamente.

- Forças: diante do contexto apresentado, pode-se pensar em importar as informações sempre que necessário, mantendo duplicação desses dados, para melhorar o desempenho, porém isso requer recursos adicionais e pode levar a problemas de inconsistência de dados; como o Sistema 1 apenas consulta as informações do Sistema legado, a maior preocupação é em atender os requisitos de desempenho, já que nesse contexto específico consistência é tolerável; como os sistemas podem estar em plataformas diferentes, manter uma base duplicada com as informações já convertidas do banco do legado para o sistema 1 e também trabalhar com filtros de campos ou seja, copiar para um sistema auxiliar somente as informações necessárias para o sistema 1, pode agilizar a consulta.

- Solução: a Figura 5.3 ilustra a solução proposta pelo padrão, que sugere ter uma duplicação dos dados comum aos dois sistemas já convertidos para a mesma plataforma dos Sistemas 1 e 2, a fim de melhorar o desempenho. É 
efetuada uma cópia periódica da tabela $\mathrm{X}$ do Sistema legado (SGBD a) para a tabela Y do Sistema Auxiliar (SGBD b). Além disso, o acesso ao Sistema Auxiliar é feito via consulta autorizada ao BD, recuperando as informações sempre que for preciso (sob demanda). Vale salientar que o Sistema legado é totalmente responsável por realizar operações de inserção, alteração e remoção do BD, por meio do módulo CRUD-X. Os Sistemas 1 e 2 utilizam os dados consultados para cumprir seus objetivos de negócios. A justificativa para esse sistema auxiliar baseia-se em dois fatores: a) o Sistema legado em geral tem um BD diferente e que precisa de conversão para ser usado nos sistemas 1, 2 e outros sistemas, causando problemas de desempenho ou b) o número de acessos é muito grande, portanto um $\mathrm{BD}$ fisicamente mais próximo da aplicação cliente e já no formato necessário pode melhorar bastante o desempenho além da existência do filtro de informações em que são trazidos apenas dados que serão utilizados pelos Sistemas 1 e 2;

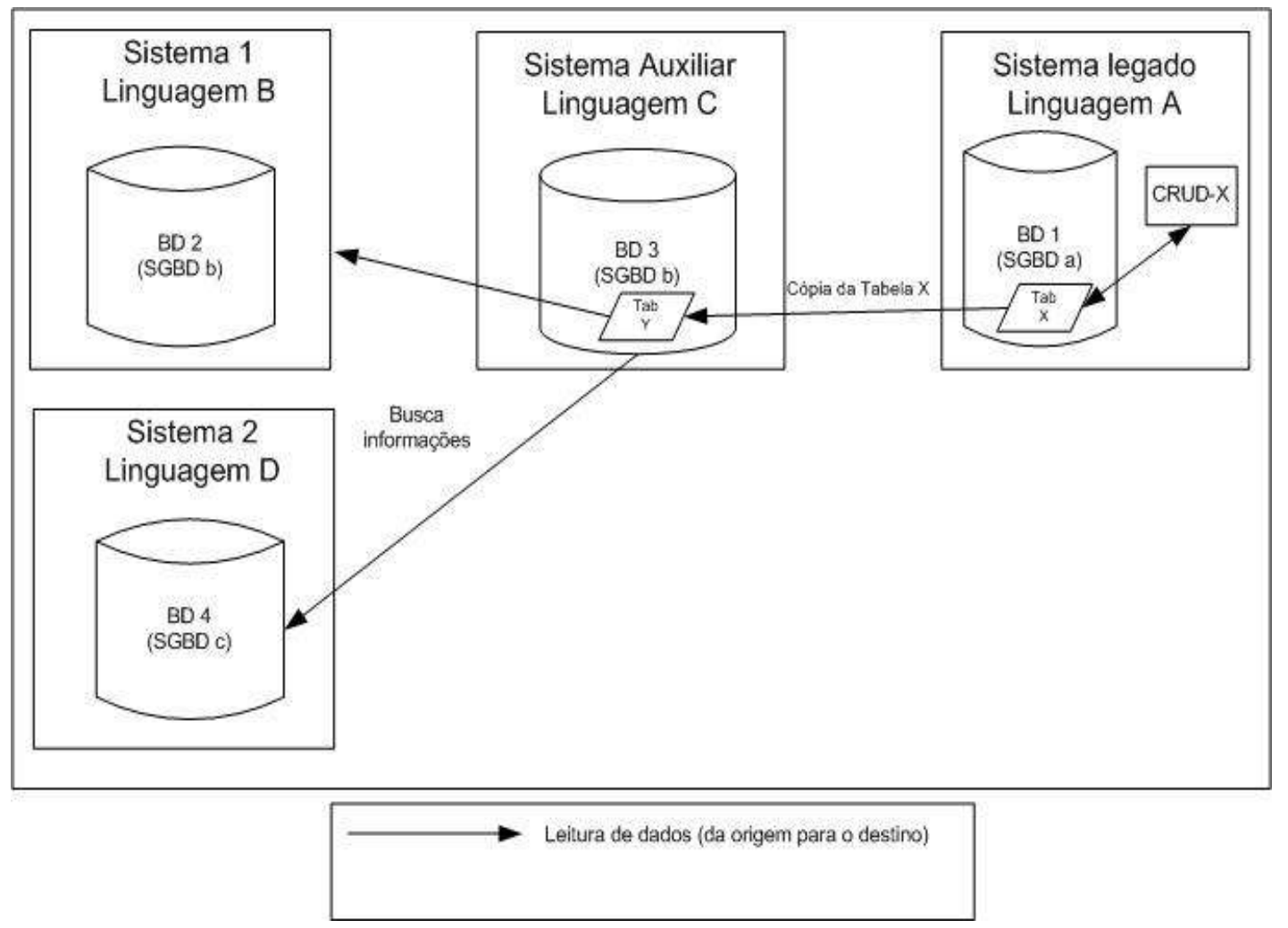

Figura 5.3: Solução proposta pelo Padrão 3.

- Consequências: (1) desempenho: razoável. Considerando o acesso ao Sistema Auxiliar, o desempenho é bom, porém, o Sistema Auxiliar precisará fazer a cópia periodicamente e, dependendo da frequência com que isso 
tenha que ser feito e a quantidade de registros a copiar, ele pode ter períodos de baixo desempenho; (2) cópia pode ser utilizada caso haja alguma falha no Sistema Legado, ou como backup; (3) inconsistência dos dados: há duplicação de dados e nem sempre os dados estão atualizados, pois a cópia é periódica; (4) segurança: caso a Tabela X contenha dados sigilosos, será necessário tomar alguma precaução ao fazer a cópia (além da autenticação, que permite acesso total ao $\mathrm{BD}$, deveria ser possível algum esquema que permitisse copiar apenas algumas colunas e/ou registros); e (5) uso restrito: nem sempre bastará copiar uma tabela para resolver o problema de EAI. Em geral várias tabelas relacionadas serão necessárias para fazer a integração e isso envolverá lógica uma mais complexa.

\section{Padrão 4 - Duplicação intermediária com acesso via WS}

- Nome: Duplicação intermediária com acesso via WS.

- Contexto: estão sendo desenvolvidas aplicações empresariais (Sistemas 1 e 2) em que parte das informações necessárias já existem em outra aplicação (Sistema legado), possivelmente em plataforma diferente. Alguns dados locais dessas aplicações não são de interesse da aplicação que concentra a manutenção dos dados, por isso deseja-se mantê-los apenas localmente em cada sistema. As aplicações pertencem a diferentes empresas com certa dificuldade de compartilhamento de recursos. O desempenho é crítico, pois há um alto volume de informações a ser integrada, mas não é tão importante que as informações estejam sempre consistentes entre as aplicações, havendo tolerância para sincronização periodicamente.

- Forças: o acesso ao outro sistema poderia ser feito por meio de cópia periódica das informações que interessam aos sistemas, sincronizando-as periodicamente. Porém, isso pode levar a problemas de inconsistência de dados; o acesso direto à tabela do outro sistema garante que os dados estão sempre atualizados, embora possa causar problemas de desempenho e exija permissões especiais para realizar o acesso; como os dados locais podem não interessar à outra aplicação, eles poderiam ser mantidos apenas localmente, implicando na necessidade de módulos CRUD para isso. Entretanto, os dados poderiam ser mantidos pelo outro lado, que ficaria responsável por 
informações que não lhe interessam, dessa forma, simplificaria e centralizaria a manutenção em um só local; como os sistemas 1 e 2 querem não apenas consultar as informações do Sistema Legado, mas também atualizá-las, seria interessante ter um mecanismo para fazer tais atualizações localmente e sincroniza-las periodicamente.

- Solução: a Figura 5.4 ilustra a solução proposta pelo padrão, que sugere criar Sistema Auxiliar para manter os dados locais, realizando a conversão para a tecnologia local para aumentar desempenho. $\mathrm{O}$ acesso às informações é feito por meio de um Web Service oferecido pelo Sistema Auxiliar, que efetua a cópia das informações do Sistema legado que são essenciais para os sistemas 1 e 2 por meio do Web Service WS-incluídos. Vale salientar ainda que as operações de inserção, alteração e remoção do BD é feita em dois sistemas: se os dados forem locais (de interesse apenas dos Sistemas 1 e 2), são feitas no Sistema Auxiliar, por meio do Web Service WS-CRUD-T. Caso sejam dados de interesse de todos os sistemas, sua manutenção é feita por meio do módulo CRUD-X no Sistema Legado. Nota-se que, opcionalmente, pode-se oferecer um WS para efetuar a manutenção dos dados (WS-CRUD-X). Em sistemas em que não há necessidade de alterar os dados remotamente, oferece-se somente o WS-Busca. A decisão de manter os dados em um sistema auxiliar foi tomada por causa de uma regra de negócios que pode estar presente no contexto de aplicação do padrão, segundo a qual é necessário incluir informações peculiares de interesse apenas para um dos sistemas, mas que não devem estar disponíveis nos sistemas originais. Além disso, pode ser que a aplicação legada tenha um BD com esquema diferente e que precise de conversão para ser usado no Sistema 1 ou 2. 


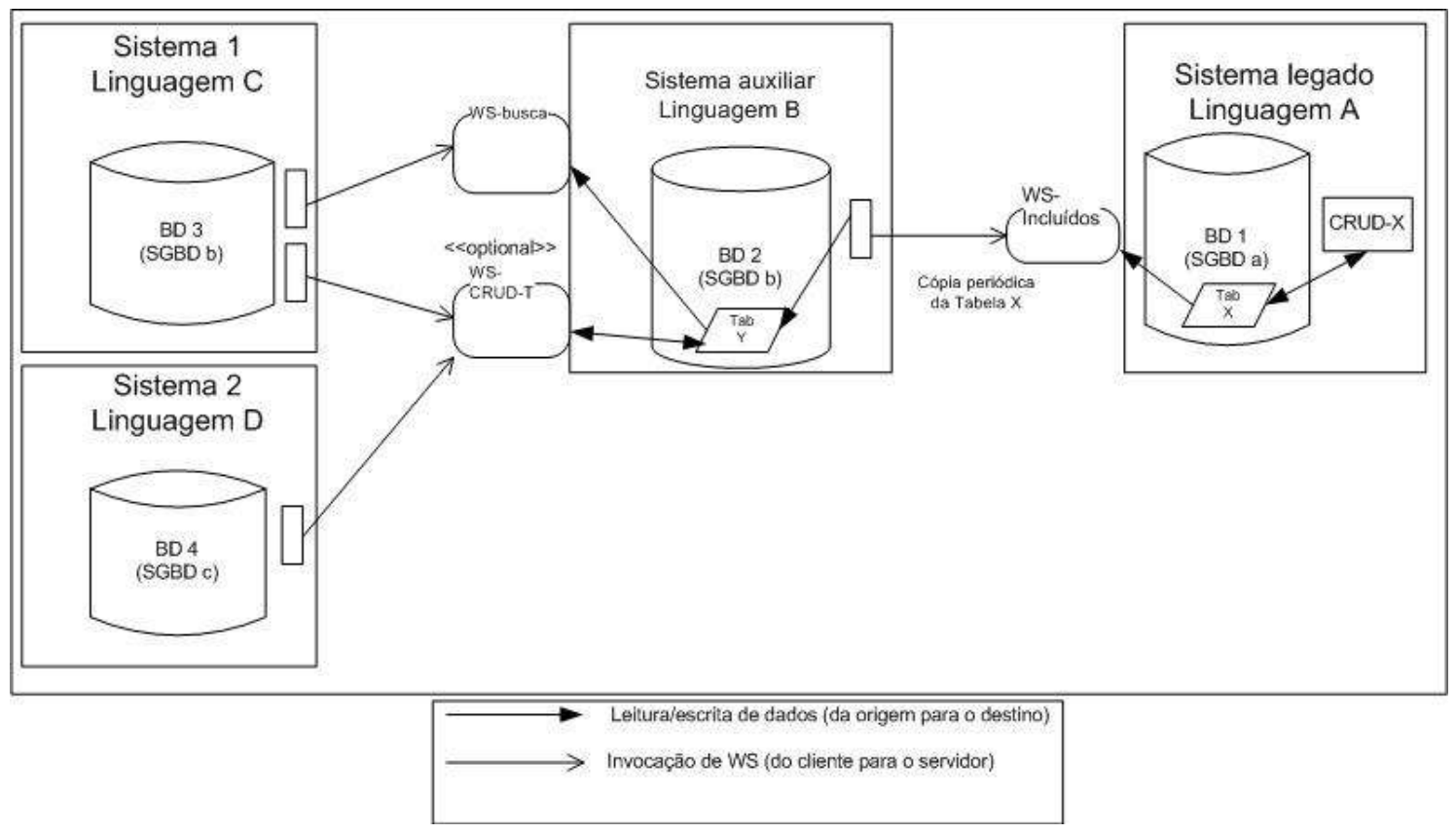

Figura 5.4: Solução proposta pelo Padrão 4.

- Consequências: (1) segurança: o acesso é feito por meio do serviço, portanto só são retornados os dados realmente disponibilizados pelo serviço; (2) reúso: outros sistemas podem acessar o WS-busca e WS-CRUD-T; (3) manutenibilidade: o WS-CRUD-T concentra toda a lógica de inclusão/alteração/exclusão de registros locais; (4) flexibilidade: pode-se manter registros localmente que não são de interesse da outra aplicação (isso também pode caracterizar uma desvantagem de inconsistência); inconsistência dos dados: duas formas de inconsistência: dados mantidos localmente não são visíveis para a outra aplicação e sincronização dos dados duplicados depende de atualização periódica invocada pelo Sistema Auxiliar; e (6) desempenho: caso o volume de dados a copiar seja grande (por exemplo, a tabela toda, ou várias tabelas, ou ainda muitos registros que representem um grande volume de informações) ou caso o Sistema Legado sofra alterações com muita frequência, o uso de WS pode comprometer o desempenho.

- Usos Conhecidos: (1) na Empresa Brasileira de Pesquisa Agropecuária (EMBRAPA Soja) será implementada essa solução, para facilitar a inclusão e/ou manutenção das informações dos empregados terceirizados que não possuem cadastro no Sistema RH. Além disso, outros sistemas poderão 
efetuar a inclusão, alteração, exclusão por meio do WS-CRUD-T e buscar informações do WS-busca; e (2) no sistema SGPC, desenvolvido no ICMCUSP, dados de pessoas são importados periodicamente da intranet, ao mesmo tempo em que se permite registrar pessoas apenas localmente. $\mathrm{Na}$ versão atual do sistema isso é feito via $\mathrm{BD}$, mas prevê-se a substituição por serviços em uma próxima versão;

- Padrões relacionados: Nas Subseções 2.7.2 e 2.7.3 foram abordados os temas de RPCs (Chamadas de procedimentos remotos) e transferência de arquivos (padrão File Transfer) do livro de Gregor Hohpe e Bobby Woolf (2003) que também são abordados respectivamente nos padrões 2 (Apêndice C) e 3 (Subseção 5.3.3). RPC é o modelo seguido pelos Web Services, abstraindo aspectos de independência de plataforma/linguagem de programação. Portanto, pode-se dizer que este padrão combina o padrão RPC e o padrão File Transfer para oferecer uma solução para o problema de EAI no contexto especificado.

\subsubsection{Validação e Evolução dos Padrões}

Os padrões apresentados na subseção 5.3.3 ilustram duas formas diferentes de EAI, a primeira com acesso direto ao BD e a segunda com WS. Nota-se que essas soluções são similares, mas atendem diferentes contextos de integração, de acordo com regras de negócios específicas da organização. Os demais padrões (Apêndice C) apresentam variações na forma de integrar as aplicações de acordo com os requisitos específicos de cada contexto.

É importante ressaltar que os padrões propostos estão sendo aplicados na Embrapa Soja, e, posteriormente, serão aplicados no sistema SGPC do ICMC-USP, podendo portanto, haver a inclusão de novos padrões com novos contextos, por exemplo, novas possibilidades de combinar os fatores da Tabela 5.5 e, também, conforme a evolução dos padrões já existentes. 


\subsection{Considerações Finais}

Neste capítulo foram apresentados padrões para EAI sob uma ótica diferente de muitos padrões existentes, uma vez que, a maior parte desses padrões abordam aspectos mais técnicos de implementação.

Os padrões propostos neste capítulo têm o seu foco nos diversos contextos de regras de negócios que podem estar presentes no momento da integração e que podem colaborar no trabalho dos engenheiros de software ao efetuar tomadas de decisões sobre qual tipo de integração deverá ser utilizada em determinadas situações, por exemplo, no padrão 3 (subseção 5.3.3) pode-se observar que sua adoção é interessante quando a base de dados se encontra disponível e de fácil acesso dentro de uma empresa. Neste caso, provavelmente não seria interessante gastar um tempo a mais para implementar Web Services. Já no caso do padrão 4 (subseção 5.3.3), se as informações dos funcionários precisarem ser disponibilizadas para outras empresas terceirizadas de desenvolvimento, por exemplo, manutenção ou desenvolvimento de uma intranet, não seria interessante que essas empresas tivessem acesso à base de dados da empresa, por esse motivo, seria interessante a utilização de Web Services. Além disso, esses padrões levaram em consideração outros fatores mencionados na Seção 5.3.2, tais como a tolerância à inconsistência temporária entre os dados dos sistemas e a necessidade de alto desempenho da aplicação.

Por fim, no próximo capítulo são descritas as conclusões e contribuições deste trabalho de mestrado. 


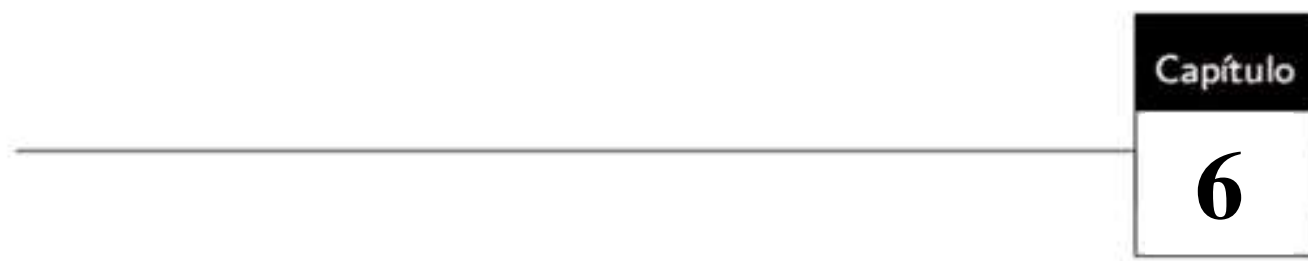

\section{Conclusão}

\subsection{Considerações Iniciais}

Nesta dissertação de mestrado foi apresentada a comparação (com base na norma ISOIEC 9126-1) entre as abordagens EAI-dados e EAI-WS, por meio de uma revisão bibliográfica, revisão sistemática e experiências profissionais da autora e orientadora deste trabalho.

A fim de complementar esta comparação, foi feito um estudo experimental, obtendo assim, alguns dados numéricos sobre o uso de EAI-dados e EAI-WS, em que foram apresentadas as análises dos dados obtidos e por fim, a análise das hipóteses, resultando assim, respostas quantitativas para a questão feita no objetivo do experimento: "Em termos de tempo de desenvolvimento e código produzido, é mais fácil realizar EAI-WS ou EAI-Dados?".

O experimento resultou em respostas quantitativas para a questão citada logo acima. No entanto, a escolha da melhor abordagem para integração também vai depender do tipo de aplicação e as regras de negócios que deverão ser seguidas. Por esse motivo, foram criados padrões para EAI em que são descritas as situações que acontecem com frequência na hora de se integrar sistemas corporativos.

\subsection{Contribuições}

Pode-se destacar como principais contribuições deste trabalho:

- Da comparação (com base na norma ISO-IEC 9126-1) entre as abordagens EAIDados e EAI-WS, pode-se verificar por meio da revisão bibliográfica, revisão sistemática e experiências da autora e orientadora deste trabalho, fatores que devem ser avaliados antes de efetuar algum tipo de integração dentro de uma 
empresa, uma vez que, embora os resultados indiquem que EAI-WS é melhor do que EAI-Dados na grande maioria dos fatores de comparação, para apoiar a decisão de um desenvolvedor ao realizar EAI é recomendado que todos os aspectos envolvidos no projeto de integração sejam cuidadosamente analisados. Portanto, a decisão deve ser feita com base no contexto particular em que a integração está ocorrendo, considerando assim, todas as variações possíveis das características analisadas;

- Da parte do experimento, os resultados obtidos neste estudo revelam que na amostragem de tempo de desenvolvimento, tanto a abordagem EAI-Dados como a abordagem EAI-WS, estatisticamente, não diferiram uma da outra, indo contra a hipótese alternativa HA1. Já na amostragem de linhas de códigos escritas, foi provado estatisticamente que a LOC da abordagem EAI-Dados é menor que a LOC da abordagem EAI-WS, estando de acordo com a hipótese alternativa HA2. Houve indícios de que a abordagem EAI-WS é mais trabalhosa, uma vez que a quantidade de linhas de código é bem maior do que na abordagem EAIDados. Por outro lado, apesar da abordagem EAI-WS ser mais trabalhosa, como foi dito por alguns participantes do experimento, esta abordagem possui um bom grau de reúso, assim, outros sistemas poderão fazer uso do serviço criado, podendo agilizar o desenvolvimento de software. Por esses motivos, o experimento foi útil para coletar indícios das vantagens de WS para realizar EAI, além de ter sido um bom aprendizado sobre a realização de experimentos controlados. No entanto, a escolha da melhor abordagem para integração também vai depender do tipo de aplicação e as regras de negócios que deverão ser seguidas, o que motivou a escrita dos padrões para EAI; e

- Por fim, da parte de Padrões para EAI, a contribuição foi a criação dos cinco padrões para resolver determinadas situações de integração em um ambiente corporativo. Assim, a documentação desses problemas e soluções no formato de padrões de software é uma boa maneira de disponibilizar a outros desenvolvedores o conhecimento adquirido em EAI, facilitando seu reúso. 


\subsection{Dificuldades e limitações}

$\mathrm{Na}$ parte do experimento, as dificuldades encontradas foram em relação à quantidade de participantes, uma vez que foi difícil encontrar participantes que possuíssem disposição para efeturar o experimento e que tivessem uma certa experiência em Web Services, JPA, Glassfish e PHP, que eram desejáveis nesse experimento. Além disso, conforme comentado na Subseção 4.4.2, algumas ameaças à validade surgiram após a finalização do experimento, isto é, não haviam sido consideradas durante o planejamento, fazendo com que a execução das tarefas se tornasse mais onerosa que o previsto. São elas: (1) falta de conhecimento e prática em PHP; (2) falta de conhecimento em Web Services; (3) tarefa de reiniciar o Glassfish várias vezes; e (4) entendimento da lógica usada e o que precisava ser alterado, uma vez que o sistema foi feito por outra pessoa e que não havia muito tempo disponível para efetuar a manutenção e resolver o problema.

Uma das dificuldades encontradas na implementação dos padrões foi de trabalhar com banco de dados de um sistema legado. Tratava-se de um banco muito lento e trabalhar com ele juntamente com o JPA foi um pouco difícil, tendo sido gastos alguns dias para encontrar a solução de integração.

\subsection{Trabalhos futuros}

Como trabalhos futuros decorrentes desta dissertação, em relação ao experimento destacam-se:

- As ameaças descritas na subseção 4.5.2 poderão ser tratadas em um próximo experimento, permitindo obter novas conclusões sobre o tempo de desenvolvimento despendido nas duas abordagens.

- Outros objetivos poderiam ser alvo de experimentos, como por exemplo investigar em que situações de integração é mais fácil utilizar EAI-Dados ou EAI-WS. Para isso, poderiam ser feitos experimentos dos seguintes tipos: (1) realizar a integração de um sistema legado com uma aplicação de outra empresa; (2) migrar um sistema dentro de uma mesma empresa; (3) integrar o sistema legado com um novo sistema na mesma empresa, mas continuar usando o legado para algumas funcionalidades; (4) projetar dois novos sistemas que interagem, 
cada um de uma empresa diferente; e (5) projetar dois novos sistemas que interagem, na mesma empresa.

- Alguns dos cuidados a serem tomados em uma futura replicação do experimento são: a inclusão da coleta de tempo gasto no aprendizado da linguagem de programação e em depuração de erros decorrentes de falta de experiência no ambiente de desenvolvimento; e a realização das partes 1 e 2 alternadamente, para reduzir a ameaça do aprendizado obtido pelo aluno em uma das partes vir a facilitar a parte seguinte.

Para finalizar, na parte de padrões, como trabalhos futuros pode-se citar:

- Efetuar a instanciação dos padrões aqui propostos de acordo com as situações de alguns sistemas do ICMC-USP que precisam ser integrados a outros sistemas. Isso poderá originar novos padrões e aprimoramento dos padrões propostos.

- A versão em inglês dos padrões está sendo escrita para a versão final dos anais do SugarloafPLoP a serem publicados no Portal da ACM. Com isso, os padrões ficarão mais facilmente acessíveis e poderão receber sugestões de melhorias futuras. 
APPLETON, B. Patterns and Software: Essential Concepts and Terminology, disponível na WWW na URL: http://www.bradapp.com/docs/patterns-intro.pdf. Acesso em: 17 setembro. 2012.; 1997.

BHOSLE, U. EAI competitive comparison. Disponível em: http://www.b3websolutions.com/index.php?option=com_content\&task=view\&id $=69 \&$ Itemid $=89$. Acesso em: 17 setembro. 2012.; 2002 .

BOLFARINE, H.; BUSSAB, W. O. (2005). Elementos de Amostragem. Ed. Blücher, São Paulo.

BUSCHMANN, F. et at. A System of Patterns, Wiley, 1996. Gamma, E.; Helm, R.; Johnson, R.; Vlissides, J. Design Patterns - Elements of Reusable Object-Oriented Software. Reading-MA, Addison-Wesley, 1995.

CHANNABASAVAIAH, K.; HOLLEY, K.; IBM GLOBAL SERVICES; TUGGLE, E. M.; IBM SOFTWARE GROUP. Migrating to a service-oriented architecture. IBM DeveloperWorks. New York: [s.n.]. Disponível em: <ftp://129.35.224.15/software/info/openenvironment/G224-7298-00_Final.pdf>. Acesso em: 27 maio. 2012. , 2004

DAVIES, J. Enterprise Application Integration (EAI). Disponível em: <https://blogs.oracle.com/jeffdavies/entry/architects_dictionary>. Acesso em: 15 maio. 2012.

DEHNE, D.; DIMARE, J. Service-oriented architecture Unlocking hidden value in insurance systems. Disponível em: <ftp://public.dhe.ibm.com/common/ssi/ecm/en/gbe03196usen/GBE03196USEN.PDF $>$. Acesso em: 10 maio. 2012.

DENG, W.; YANG, X.; ZHAO, H.; LEI, D.; LI, H. Study on EAI Based on Web Services and SOA. 2008 International Symposium on Electronic Commerce and Security. Anais... [S.1.]: IEEE. Disponível em: <http://ieeexplore.ieee.org/lpdocs/epic03/wrapper.htm?arnumber=4606033>. Acesso em: 27 maio 2012, 2008.

ELER, M. M., Uso da técnica de teste estrutural para o teste e monitoração de serviços / Marcelo Medeiros Eler; orientador Paulo Cesar Masiero. ICMC-USP- São Carlos, 2012. 132 p.

ENDREI, M.; ANG, J.; ARSANJANI, A. et al. Patterns: Service-Oriented Architecture and Web Services. Disponível em: <http://www.redbooks.ibm.com/abstracts/sg246303.html?Open>. Acesso em: 10 maio. 2012.

ERL, T. Service-Oriented Architecture (SOA): Concepts, Technology, and Design. Upper Saddle River, NJ USA: Prentice Hall, 2005. p. 792. 
FERNANDEZ, F. H. Discussion of a conceptual model for Enterprise Application Integration. [S.1.]: University of Campinas, 2004.

GUDIVADA, V. N.; NANDIGAM, J. Enterprise application integration using extensible Web services. IEEE International Conference on Web Services (ICWS'05). Anais... [S.1.]: Ieee. Disponível em: <http://ieeexplore.ieee.org/lpdocs/epic03/wrapper.htm?arnumber=1530781>. , 2005

Gamma, E.; Helm, R.; Johnson, R.; Vlissides, J. Design Patterns - Elements of Reusable Object-Oriented Software. Reading-MA, Addison-Wesley, 1995.

HÄMÄLÄINEN, N. Larkki-project TECHNOLOGIES AT THE ENTERPRISE 1 Introduction, 2002.

HOHPE, G.; WOOLF, B. Enterprise Integration Patterns. v. 1, p. 574, 2003.

ISO/IEC 9126-1: 2000. Software engineering- Software product quality- Part 1: Quality Model.

JIANG, B. Developing Information Service Platform for Clusters of Small-Medium Enterprises in Heterogenous Environment. 2008 ISECS International Colloquium on Computing, Communication, Control and Management. Anais... [S.1.]: Ieee. Disponível em: <http://ieeexplore.ieee.org/lpdocs/epic03/wrapper.htm?arnumber=4609835>. Acesso em: 28 maio. 2012. , 2008.

KANESHIMA, E; BRAGA, R. T. V. Padrões para Integração de Aplicações Empresariais (EAI) In: 9th Latin American Conference on Pattern Languages of Programming, Natal - RN - Brazil. SugarloafPLoP 2012 Proceedings. , 2012. p.50-66.

KRAFZIG, D.; BANKE, K.; SLAMA, D. Enterprise SOA: Service-Oriented Architecture Best Pratices. 1st. ed. Indianapolis: Prentice Hall, 2004. p. 384.

LÄMMER, A. A Procedure Model for a sOA-based Integration of Enterprise systems. International Journal of Enterprise Information Systems, v. 4, n. April-June, p. 1-12, 2008.

LIEGL, P. The strategic impact of service oriented architectures. 14th Annual IEEE International Conference and Workshops on the Engineering if Computer-Based System (ECBS'07). Anais... Vienna: [s.n.]. , 2007.

LINTHICUM, D. S. Enterprise Application Integration. 1. ed. [S.1.]: Wesley, Publisher Addison, 1999. p. 400.

LINTHICUM, D. S. Next Generation Application Integration. 1. ed. Boston: Addison Wesley, 2003. p. 488.

MAHMOOD, Z. Enterprise Application Integration based on Service Oriented Architecture. INTERNATIONAL JOURNAL OF COMPUTERS, v. 1, n. 3, p. 5, 2007. 
MAHMOUD, Q. H. Service-Oriented Architecture ( SOA ) and Web Services: The Road to Enterprise Application Integration ( EAI ). Disponível em: <http://www.oracle.com/technetwork/articles/javase/soa-142870.html>.

MERSON, P.; BIANCO, P.; KOTERMANSKI, R. Evaluating a Service-Oriented Architecture. $\quad$ [S.l: $\quad$ s.n.]. Disponível em: <http://www.sei.cmu.edu/library/abstracts/reports/07tr015.cfm>., 2007.

NIELSEN, S. P., HARTLEY, J., LARMOUR, A., SUDARSANAM, S., WALMSLEY, A., \& YAMAMOTO, H. (2001). Front cover Applying the Patterns for e-business to Domino and WebSphere Scenarios (p. 310). Disponível em: ibm.com/redbooks.

OLIVEIRA, R. R. Avaliação de manutenibilidade entre as abordagens de web services RESTful e SOAP-WSDL ; orientadora Renata Pontin de Mattos Fortes. ICMC-USPSão Carlos, 2012.91 p.

ORT, E. Service-Oriented Architecture and Web Services: concepts, Technologies, and Tools. Disponível em: <http://java.sun.com/developer/technicalArticles/WebServices/soa2/soa2.pdf>.

PAPAZOGLOU, M. P. Service -Oriented Computing: Concepts, Characteristics and Directions. Fourth International Conference on Web Informaticon Systems Enginnering (WISE'03). Anais... [S.1: s.n.]. , 2003.

PAUTASSO, C.; ZIMMERMANN, O.; LEYMANN, F. Restful web services vs. "big"” web services: making the right architectural decision. Proceedings of the 17th international conference on World Wide Web. Anais... New York, NY, USA: ACM. Disponível em: <http://doi.acm.org/10.1145/1367497.1367606>. , 2008

RHOTON, J. Cloud Computing Explained: Implementation Handbook for Enterprises. 2. ed. [S.1.]: Recursive Press, 2010. p. 472.

SHAPIRO, S. S.; WILK, M. B. An analysis of variance test for normality ( complete samp1es ) t. v. 52, n. 3, p. 591-611, 2007.

SILBERSCHATZ, A.; KORTH, H.; SUDARSHAN, S. Sistema de banco de dados. 3. ed. São Paulo: Person Makron Books, 1999.

SPIEGEL, M. R. Estatística. 2ª ed., São Paulo: McGraw-Hill, 1985.

SOSNOSKI, D. Serviços da Web Java: Básico de WS-Security no Axis2. Disponível em: <http://www.ibm.com/developerworks/br/library/j-jws4/index.html>. Acesso em: 22 maio. 2012.

TRAVASSOS, G. H. Introdução à engenharia de software experimental. 2002.

W3C. Web Services Description Language (WSDL) 1.1, 2001. Disponível em: <http://www.w3.org/TR/wsdl>.

W3C, EXTENSIBLE Markup Language (XML). W3C Ubiquitous Web domain, 2003. Disponível em: <http://www.w3.org/XML/>. Acesso em: 28 ago. 2012. 
W3C. Web Services Architecture, 2004. Disponível em: <http://www.w3.org/TR/2004/NOTE-ws-arch-20040211/>. Acesso em: 28 ago. 2012.

W3C. SOAP Version 1.2: messaging framework. 2. ed. W3C Recommendation, 2007. Disponível em: <http://www.w3.org/TR/2007/REC-soap12-part1-20070427/>. Acesso em: Acesso em: 28 ago. 2012.

WHOLIN, C. et al. Experimentation in software engineering - an introduction. Massachusetts: Kluwer Academic, 2000. p. 204 


\section{Revisão sistemática sobre EAI e Web Services na integração de sistemas corporativos}

Uma revisão sistemática consiste em um meio de identificação, avaliação e interpretação de todos os trabalhos de pesquisa relevantes e disponíveis sobre uma questão de pesquisa, tópico ou fenômeno de interesse (Kitchenham, 2004). Apesar de demandar maior esforço do que uma revisão tradicional, uma revisão sistemática tem como premissa evitar viés por parte dos revisores, apresentando também outras vantagens como a possibilidade de ser auditada e replicada. Dentre os processos existentes, neste trabalho utiliza-se o sugerido por Biolchini (2005).

O principal objetivo desta revisão sistemática, denominada "Revisão sistemática sobre EAI e Web Services na Integração de Sistemas Corporativos", foi de obter uma visão global da utilização de Web Services na Integração de Sistemas Corporativos sob a ótica de EAI, com um panorama das principais vantagens e desvantagens por meio da identificação de trabalhos que abordaram este tema.

O planejamento da revisão sistemática foi realizado de acordo com o modelo de protocolo apresentado por Biolchini (2005).

\section{Planejamento da Revisão Sistemática}

\section{Objetivos da Pesquisa}

- Objetivo 1: Identificar a utilização dos Web Services no contexto de Integração de Sistemas Corporativos;

- Objetivo 2: Identificar as principais dificuldades que têm sido relatadas na utilização de Web Services na Integração de Sistemas Corporativos; e

- Objetivo 3: Identificar as principais vantagens que têm sido relatadas na utilização de Web Services na Integração de Sistemas Corporativos.

\section{Formulação das Questões de Pesquisa: Escopo e Especificidades}

- Questão Primária (QP): Como os Web Services têm sido utilizados no contexto de Integração de Sistemas Corporativos?

- Questão Secundária 1 (QS1): Quais as principais dificuldades que têm sido relatadas na utilização de Web Services na Integração de Sistemas Corporativos?

- Questão Secundária 2 (QS2): Quais as principais vantagens que têm sido relatadas na utilização de Web Services na Integração de Sistemas Corporativos? 
- Questão Secundária 3 (QS3): EAI e Web Services são parceiros ou rivais na integração de sistemas corporativos?

\section{Estratégia de Busca para Seleção de Estudos Primários}

- Fontes: IEEE Explore, ACM, Springer Link, Scopus, ISI Web of Knowledge, Scirus e bases não abertas que são informações disponibilizadas por grandes empresas (Por exemplo: IBM);

- Língua dos trabalhos: Inglesa por essa ser a língua internacionalmente aceita para a redação de trabalhos científicos;

- Palavras-chave: System integration, Web Services, SOA; e

- Sinônimos: Application integration, Integration of enterprise systems, Webservices, Web-Services, Service Oriented Architecture, Service Architecture, Service-Oriented e Service Based.

\section{Critérios e Procedimentos para Seleção dos Estudos}

\section{Critérios de Inclusão}

Os seguintes critérios de inclusão de trabalhos foram definidos para atender a cada uma das questões de pesquisa:

- Critério de Inclusão 1 (CI1): relata a utilização de Web Services como forma de apoio à Integração de Sistemas Corporativos;

- Critério de Inclusão 2 (CI2): relata as dificuldades que têm sido encontradas na utilização de Web Services na Integração de Sistemas Corporativos;

- Critério de Inclusão 3 (CI3): relata as principais vantagens que têm sido encontradas na utilização de Web Services na Integração de Sistemas Corporativos; e

- Critério de Inclusão 4 (CI4): relata as principais vantagens da utilização do EAI e Web Services.

\section{Critérios de Exclusão}

Os seguintes critérios de exclusão de trabalhos foram definidos para atender a cada uma das questões de pesquisa:

- Critério de Exclusão 1 (CE1): O estudo apresenta um relato de integração de sistemas corporativos contudo, não utiliza Web Services;

- Critério de Exclusão 2 (CE2): O estudo apresenta um relato de integração de sistemas contudo, não se refere a integração de sistemas corporativos;

- Critério de Exclusão 3 (CE3): Estudos primários que não estejam completos, ou seja, o texto inteiro não está disponível na base de busca;

- Critério de Exclusão 4 (CE4): Estudos primários duplicados em mais de uma base de busca;e

- Critério de Exclusão 5 (CE5): Estudos primários escritos em línguas diferentes do inglês. 


\section{Execução da Revisão Sistemática}

\section{Construção da string de busca}

Para a construção das strings de busca, foram utilizados os sinônimos das palavraschave identificados na subseção 2.3.1.3. Construiu-se uma string completa utilizando os operadores lógicos "e" (AND) e "ou" (OR), como a apresentada a seguir na Tabela 2.3:

Tabela A1: String de busca completa.

((System integration OR Application integration OR

Integration of enterprise systems $\mathrm{OR}$ Integration of enterprise applications) AND (Web Service OR Webservices OR WebServices) AND (SOA OR Service Oriented Architecture OR Service-Oriented OR Service Architecture OR Service Based))

\section{Seleção Preliminar de Trabalhos}

Obteve-se um total de 260 trabalhos que foram selecionados por meio das strings nas máquinas de busca. Nessa fase de seleção preliminar foram lidos os abstracts de todos esses trabalhos. Utilizou-se a ferramenta open source JabRef ${ }^{6}$ - Gerenciador de Referências Bibliográficas para auxiliar a leitura. Após a leitura do abstract de cada trabalho foram utilizados os critérios de Inclusão e Exclusão definidos na fase de planejamento com o intuito de executar a seleção preliminar dos estudos primários. As informações dessa seleção foram armazenadas em uma planilha do Excel. Observa-se que foi feita uma planilha para cada máquina de busca, inclusive uma planilha para os trabalhos incluídos, excluídos e repetidos. As colunas dessas planilhas são: nome do trabalho, autores, informação complementar, fonte e por fim, a justificativa (qual o critério de inclusão/exclusão).

\section{Resultados obtidos após a seleção preliminar}

Houve a inclusão de 29 trabalhos, mas havia 10 trabalhos repetidos. Desta forma, houve um total de 19 trabalhos que foram lidos na íntegra, que são listados na Tabela 2.4. Após a leitura na íntegra desses 19 trabalhos, houve a exclusão de 7 trabalhos, que são listados na Tabela 2.5, juntamente com uma observação sobre a razão de terem sido excluídos. Portanto, houve a inclusão de 12 trabalhos que são apresentados na Tabela 2.6 juntamente com os critérios de inclusão. Na Tabela 2.7 são descritos os estudos que relataram a utilização de Web Services como forma de apoio à Integração de Sistemas Corporativos. Na Tabela 2.8 são descritos os estudos que relatam as dificuldades que têm sido encontradas na utilização de Web Services na Integração de Sistemas Corporativos. Na Tabela 2.9 são apresentados os estudos que relatam as vantagens que têm sido encontradas na utilização de Web Services na Integração de Sistemas Corporativos. Na Tabela 2.10 são descritos os estudos que relatam as principais vantagens da utilização da EAI e Web Services.

\footnotetext{
6 JabRef - Gerenciador de Referências Bibliográficas. Site: http://jabref.sourceforge.net/
} 
Tabela A2: Demonstrativo dos 19 trabalhos que foram lidos na íntegra.

\begin{tabular}{|c|c|c|}
\hline $\begin{array}{c}\mathbf{N}^{\mathbf{0}} \\
\text { Estudo } \\
\end{array}$ & Título do trabalho & Autores \\
\hline E1 & A procedure model for a SoA-based integration of enterprise systems & $\begin{array}{l}\text { Lämmer et. al, } \\
2008\end{array}$ \\
\hline E2 & $\begin{array}{l}\text { A scenario-based verification technique to assess the compatibility of collaborative } \\
\text { business processes }\end{array}$ & $\begin{array}{l}\text { Backer et. al, } \\
2009\end{array}$ \\
\hline E3 & A semantic service oriented architecture for Enterprise Application Integration & Zhang et. al, 2009 \\
\hline E4 & An Integrated Development Environment for Web Service Composition & Chafle et. al, 2007 \\
\hline E5 & $\begin{array}{l}\text { Architectures for enterprise integration and interoperability: Past, present and } \\
\text { future }\end{array}$ & Chen et. al, 2008 \\
\hline E6 & $\begin{array}{l}\text { Developing Information Service Platform for Clusters of Small-Medium } \\
\text { Enterprises in Heterogenous Environment }\end{array}$ & Jiang, 2008 \\
\hline E7 & $\begin{array}{l}\text { Enabling Enterprise Resources Reusability and Interoperability through Web } \\
\text { Services }\end{array}$ & $\begin{array}{l}\text { Wang \& Zhang, } \\
2006\end{array}$ \\
\hline E8 & Enterprise Application Integration Using Extensible Web Services & $\begin{array}{l}\text { Gudivada et. al, } \\
2005\end{array}$ \\
\hline E9 & $\begin{array}{l}\text { Event-driven service coordination for business process integration in ubiquitous } \\
\text { enterprises }\end{array}$ & Kong et al, 2009 \\
\hline E10 & Implementation of semantic services in enterprise application integration & $\begin{array}{l}\text { Martinek et al, } \\
2008\end{array}$ \\
\hline E11 & Inter-enterprise System and Application Integration: A Reality Check & $\begin{array}{l}\text { Cardoso et al, } \\
2008\end{array}$ \\
\hline E12 & Interoperable enterprise systems: Principles, concepts, and methods & Vernadat, 2007 \\
\hline E13 & $\begin{array}{l}\text { Modeling on SOA-based Virtual Enterprise Multi-source Heterogeneous Service } \\
\text { Integration }\end{array}$ & Chen et al, 2009 \\
\hline E14 & $\begin{array}{l}\text { Research of Enterprise Application Integration Base on Service Oriented } \\
\text { Architecture }\end{array}$ & $\begin{array}{l}\text { Wei \& Dengyi, } \\
2009\end{array}$ \\
\hline E15 & $\begin{array}{l}\text { Restful Web Services vs. "big"' Web Services: making the right architectural } \\
\text { decision }\end{array}$ & $\begin{array}{l}\text { Pautasso et al, } \\
2008\end{array}$ \\
\hline E16 & Study on EAI Based on Web Services and SOA & Deng et. al, 2008 \\
\hline E17 & Web Services and IT Management & Kumar, 2005 \\
\hline E18 & $\begin{array}{l}\text { Web services and process management: a union of convenience or a new area of } \\
\text { research? }\end{array}$ & $\begin{array}{l}\text { Zhao \& Cheng, } \\
2005\end{array}$ \\
\hline E19 & Web services: current solutions and open problems & $\begin{array}{l}\text { Ismaili \& } \\
\text { Sisediev, } 2008\end{array}$ \\
\hline
\end{tabular}

Tabela A3: Quantitativo do critério de exclusão.

\begin{tabular}{|c|c|c|}
\hline $\begin{array}{c}\mathbf{N}^{\mathbf{o}} \\
\text { Estudo }\end{array}$ & Critério de Exclusão & Observação \\
\hline E2 & CE2 & $\begin{array}{l}\text { Este artigo refere-se às outras formas de composição de serviços diferentes } \\
\text { de BPEL, por exemplo: Redes de Petri. Portanto, trata-se de um assunto } \\
\text { que provavelmente não será abordado no trabalho de mestrado proposto. }\end{array}$ \\
\hline E4 & CE2 & $\begin{array}{l}\text { Este artigo propõe uma IDE para a composição de serviços. Portanto, trata- } \\
\text { se de um assunto que provavelmente não será abordado no trabalho de } \\
\text { mestrado proposto }\end{array}$ \\
\hline E5 & CE1 & $\begin{array}{l}\text { Este estudo relata vários tipos de arquiteturas para integrações } \\
\text { empresariais, inclusive EAI com SOA, mas não aborda o assunto com Web } \\
\text { Services. }\end{array}$ \\
\hline E7 & CE2 & $\begin{array}{l}\text { Este artigo relata a integração de aplicativos (de rede), mas não a integração } \\
\text { de sistemas corporativos (apesar do Framework HLA proposto, ser viável } \\
\text { para a integração de serviços nas empresas). E, se for comparar (com os } \\
\text { artigos já lidos), existem outros frameworks que trabalham com SOA e a } \\
\text { tecnologia de Web Services sob a ótica de EAI que seriam mais } \\
\text { interessantes para este trabalho de mestrado. }\end{array}$ \\
\hline & CE2 & Este estudo relata uma integração de empresas ubíquas, sendo que o foco \\
\hline
\end{tabular}




\begin{tabular}{|c|c|l|}
\hline E9 & & deste trabalho é no ambiente corporativo. \\
\hline E13 & CE2 & $\begin{array}{l}\text { Este estudo relata uma integração de empresas virtuais, sendo que o foco } \\
\text { deste trabalho é no ambiente corporativo. }\end{array}$ \\
\hline E17 & CE2 & $\begin{array}{l}\text { Este artigo refere-se à Web Services mas não relata a sua integração em } \\
\text { sistemas corporativos. }\end{array}$ \\
\hline
\end{tabular}

Tabela A3: Quantitativo dos critérios de inclusão e questões da pesquisa.

\begin{tabular}{|l|l|}
\hline $\begin{array}{c}\mathbf{N}^{\mathbf{}} \\
\text { Estudo }\end{array}$ & \multicolumn{1}{c|}{ Critério de Inclusão } \\
\hline$E 1$ & $C I 1$, CI2 e CI3 \\
\hline$E 3$ & $C I 2$, CI3 e CI4 \\
\hline$E 6$ & CI1 e CI3 \\
\hline$E 8$ & CI1 e CI4 \\
\hline$E 10$ & CI1 \\
\hline$E 11$ & CI2 e CI3 \\
\hline$E 12$ & CI1 e CI4 \\
\hline$E 14$ & CI1, CI2,CI3 E CI4 \\
\hline$E 15$ & CI1 CI3 \\
\hline$E 16$ & CI1, CI3 e CI4 \\
\hline$E 18$ & CI1 e CI3 \\
\hline$E 19$ & $C I 2, C I 3$ e CI4 \\
\hline
\end{tabular}

Tabela A4: Critérios de inclusão 1.

\begin{tabular}{|c|l|}
\hline $\begin{array}{c}\mathbf{N}^{\mathbf{0}} \\
\text { Estudo }\end{array}$ & \multicolumn{1}{c|}{ Critérios de Inclusão 1 } \\
\hline E1 & $\begin{array}{l}\text { É apresentado um modelo de processo de integração de sistemas empresariais baseado em SOA } \\
\text { com a tecnologia de Web Services. }\end{array}$ \\
\hline E6 & $\begin{array}{l}\text { Apresenta uma discussão de algumas técnicas fundamentais para a integração de aplicativos em } \\
\text { ambientes heterogêneos (inclusive dos sistemas legados) por meio da utilização de Web Services. }\end{array}$ \\
\hline E8 & $\begin{array}{l}\text { Descreve uma abordagem para Enterprise Application Integration (EAI), utilizando os Web } \\
\text { Services extensível. }\end{array}$ \\
\hline E10 & $\begin{array}{l}\text { Apresenta-se uma abordagem para a implementação de Web Services semânticos na integração de } \\
\text { aplicações empresariais (EAI). }\end{array}$ \\
\hline E12 & $\begin{array}{l}\text { O artigo discute as arquiteturas e métodos para construir sistemas corporativos interoperáveis, e os } \\
\text { seus autores propõe a orientação a serviços, para apoiar as operaçôes, tanto à nível de negócios } \\
\text { (eventos de negócios, serviços de negócios, processos de negócios) como à nível de aplicação } \\
\text { (workflow, TI e Web Services e programas de aplicação). }\end{array}$ \\
\hline E14 & $\begin{array}{l}\text { As abordagens SOA e EAI podem trabalhar em conjunto com um Web Service para efetuar a } \\
\text { integração com outras aplicações em um ambiente corporativo. }\end{array}$ \\
\hline E15 & $\begin{array}{l}\text { Muitos estilos diferentes podem ser usados para integrar aplicações empresariais. Portanto, pode-se } \\
\text { usar a tecnologia de Web Services (SOAP, WSDL, WS-Addressing, WS-ReliableMessaging, WS- } \\
\text { Security, etc) ou trabalhar com o RESTful que utiliza a Interface de Programação de Aplicações } \\
\text { (API) do serviços da Web 2.0 e, possui a simplicidade de publicação e consumo de um serviço. }\end{array}$ \\
\hline E16 & $\begin{array}{l}\text { Utiliza-se a tecnologia de Web Service e SOA no Framework EAI proposto neste artigo, para } \\
\text { efetuar a integração de sistemas corporativos. }\end{array}$ \\
\hline E18 & $\begin{array}{l}\text { Neste artigo, é abordada a questão de que os Web Services e o gerenciamento de processo em um } \\
\text { ambiente corporativo podem ser considerados uma nova área de pesquisa. }\end{array}$ \\
\hline
\end{tabular}


Tabela A5: Critérios de inclusão 2.

\begin{tabular}{|c|l|}
\hline $\begin{array}{c}\mathbf{N}^{\mathbf{0}} \\
\text { Estudo }\end{array}$ & \multicolumn{1}{c|}{ Critérios de Inclusão 2 } \\
\hline E1 & $\begin{array}{l}\text { Fazendo-se uso de SOA e da tecnologia de Web Services na integração de sistemas e aplicativos já } \\
\text { existentes, a principal desvantagem é a necessidade de revisão do código fonte a fim de encontrar } \\
\text { possíveis dependências. Isto também é verdade para os sistemas corporativos. }\end{array}$ \\
\hline E3 & $\begin{array}{l}\text { Apesar dos padrões de serviço como WSDL, SOAP, UDDI e a Business Process Execution } \\
\text { Language (BPEL), trouxeram um novo potencial para SOA, eles apenas fornecem uma solução } \\
\text { parcial para a interoperabilidade, principalmente para as empresas que possuem ambientes } \\
\text { tecnológicos unificados. Um exemplo disso é que a WSDL baseia-se na sintaxe, para a recuperação } \\
\text { de serviços e em palavras-chave que provavelmente podem acarretar resultados inadequados. Dessa } \\
\text { forma, a descoberta de serviço utilizando a tecnologia de Web Services tradicional pode se tornar } \\
\text { demorado e propenso a erros. }\end{array}$ \\
\hline E11 & $\begin{array}{l}\text { A abundância de sobreposição de normas para a composição de Web Services é muito grande e isso } \\
\text { pode desencadear a criação de uma nova "torre de Babel”. }\end{array}$ \\
\hline E14 & $\begin{array}{l}\text { Embora os Web Services tradicionais simplifiquem a SOA, as tecnologias são exclusivamente sintáticas. } \\
\text { E19 }\end{array}$ \\
\hline E19 & $\begin{array}{l}\text { Foi proposta a avaliação do desempenho de um conjuntos de ferramentas de Web Services e chegou-se a } \\
\text { enclusão que o seu uso na integração não é justificada por suas capacidades de desempenho mas sim, }\end{array}$ \\
\hline
\end{tabular}

Tabela A6: Critérios de inclusão 3.

\begin{tabular}{|c|l|}
\hline $\begin{array}{c}\mathbf{N}^{\mathbf{0}} \\
\text { Estudo }\end{array}$ & \multicolumn{1}{c|}{ Critérios de Inclusão 3 } \\
\hline E1 & $\begin{array}{l}\text { Os Web Services melhoram a adaptabilidade dos sistemas para os processos de negócio e } \\
\text { aumentam a sua eficiência. }\end{array}$ \\
\hline E3 & $\begin{array}{l}\text { Foi proposto uma arquitetura orientada a serviço para EAI e foram aplicados os princípios do Web } \\
\text { Service Modeling Ontology (WSMO) para este novo tipo de arquitetura a fim de melhorar a } \\
\text { descoberta de serviços, permitindo aos usuários pesquisar por conceitos ontológicos e não por } \\
\text { palavras-chave. }\end{array}$ \\
\hline E6 & $\begin{array}{l}\text { Utilizando os Web Services é possível aproveitar a linguagem atual, plataforma, e aplicações do } \\
\text { sistema, inclusive dos sistemas legados.. }\end{array}$ \\
\hline E11 & $\begin{array}{l}\text { Ao usar o SAWSDL, o padrão semântico para Web Services, é possível reduzir o uso do re- } \\
\text { mapeamento se for entendido os quatro aspectos ou níveis de interoperabilidade: (1) sistema, (2) } \\
\text { sintaxe, (3) estrutura e (4) semântica }\end{array}$ \\
\hline $\begin{array}{l}\text { Em uma integração de sistemas corporativos, utilizando Web Service em conjunto com ontologias, } \\
\text { pode-se criar uma base de conhecimento distribuído, tornando-se assim, muito mais fácil o } \\
\text { entendimento de um serviço. }\end{array}$ \\
\hline E15 & $\begin{array}{l}\text { O Web Service SOAP objetiva proporcionar interoperabilidade entre as tecnologias de middleware } \\
\text { heterogêneas e promover o fraco acoplamento dos serviços. }\end{array}$ \\
\hline E16 & $\begin{array}{l}\text { Os Web Services podem publicar, localizar e transferir as aplicações modularizadas na web. Além } \\
\text { disso, eles podem ser implantados por outras aplicações que podem encontrá-los e solicitá-los. As } \\
\text { funções oferecidas pelos Web Services podem ser simples, mas também podem ser mais complexas } \\
\text { quando estes possuem a lógica de negócios. }\end{array}$ \\
$\begin{array}{l}\text { Web Services fornecem um novo padrão para as empresas pois eles têm a capacidade de criar um } \\
\text { ambiente onde os sistemas podem comunicar-se uns com os outros. }\end{array}$ \\
$\begin{array}{l}\text { Web Services são auto-suficientes, e são capazes de realizar suas atividades e também podem } \\
\text { trabalhar em conjunto com outros Web Services, a fim de realizar um processo de negócio em um } \\
\text { ambiente corporativo. }\end{array}$ \\
\hline
\end{tabular}

Tabela A7: Critérios de inclusão 4.

\begin{tabular}{|c|l|}
\hline $\begin{array}{c}\mathbf{N}^{\mathbf{0}} \\
\text { Estudo }\end{array}$ & \multicolumn{1}{c|}{ Critérios de Inclusão 4} \\
\hline$E 3$ & $\begin{array}{l}\text { Foi proposta uma arquitetura orientada a serviço para EAI e foram aplicados os princípios do Web } \\
\text { Service Modeling Ontology (WSMO) para este novo tipo de arquitetura a fim de melhorar a } \\
\text { descoberta de serviços, permitindo aos usuários pesquisar por conceitos ontológicos e não por } \\
\text { palavras-chave. }\end{array}$ \\
\hline$E 8$ & EAI aparece como uma possível solução na integração de sistemas dentro de um ambiente \\
\hline
\end{tabular}




\begin{tabular}{|c|c|}
\hline & $\begin{array}{l}\text { corporativo, pois, ao invés de substituir os sistemas legados, utiliza as suas funcionalidades para a } \\
\text { realização de novos requisitos e para que isso aconteça, EAI pode trabalhar em conjunto com o } \\
\text { Web Service. }\end{array}$ \\
\hline E12 & $\begin{array}{l}\text { Como EAI possui algumas limitações, pode-se trabalhar com a solução de construir sistemas de } \\
\text { baixo acoplamento em que os pedidos de apoio aos processos de negócios, são feitos por meio de } \\
\text { serviços (Web Services). }\end{array}$ \\
\hline$E 14$ & $\begin{array}{l}\text { WSMO é uma ontologia formal para descrever vários aspectos relacionados com os Web Services } \\
\text { Semânticos em EAI, e o seu objetivo é definir uma tecnologia consistente para eles, fornecendo } \\
\text { meios para a descoberta semi-automática, composição e execução de Web Services. }\end{array}$ \\
\hline E16 & $\begin{array}{l}\text { Como a finalidade da EAI não é finalizar uma solução, utiliza-se a SOA e a tecnologia de } \mathrm{Web} \\
\text { Services para dar um retorno mais flexível a essa solucão }\end{array}$ \\
\hline E19 & $\begin{array}{l}\text { Web Services têm recebido grande interesse por causa do seu potencial em trabalhar com } \\
\text { integrações do tipo business-to-business ou integração de aplicações empresariais (EAI). Eles } \\
\text { permitem a interoperabilidade entre componentes de software, fornecendo mecanismos baseados } \\
\text { em padrões para a descrição, descoberta e troca de mensagens/integração. }\end{array}$ \\
\hline
\end{tabular}

\section{Resumo dos Artigos incluídos}

A seguir apresenta-se um resumo dos 12 artigos selecionados na revisão sistemática. Foi dada mais ênfase aos artigos que apresentam propostas que serviram para embasar o projeto de mestrado aqui apresentado (E6, E8 e E16). Os demais artigos foram sumarizados em apenas um parágrafo.

Tabela A8: Resumo dos artigos.

\begin{tabular}{|c|c|}
\hline $\begin{array}{c}\mathbf{N}^{\mathbf{o}} \\
\text { Estudo }\end{array}$ & Resumo \\
\hline E1 & $\begin{array}{l}\text { Um modelo de processo de quatro fases para uma integração orientada a serviços dos sistemas de } \\
\text { aplicação foi descrito neste artigo. Na primeira fase, é executada uma reengenharia dos sistemas } \\
\text { que deverão ser integrados. Nesta fase, são definidas as principais funcionalidades de um sistema } \\
\text { que serão transformadas em serviços. Na segunda fase, é feita a detecção das funções similares e é } \\
\text { verificado se elas podem ser agrupadas em uma única funcionalidade ou não. Na terceira fase, é } \\
\text { feita a transformação daquelas funcionalidades definidas na primeira fase em serviços. E, por } \\
\text { último, na quarta fase é feita a composição dos serviços. Uma das vantagens desse modelo de } \\
\text { processo é a descrição passo-a-passo da transformação das funcionalidades de um ou mais sistemas } \\
\text { em uma arquitetura orientada a serviços. }\end{array}$ \\
\hline$E 3$ & $\begin{array}{l}\text { Neste artigo foi proposta uma abordagem orientada a serviços semânticos para EAI em que foram } \\
\text { aplicados os princípios do WSMO. Primeiramente foi melhorada a descoberta de serviços por meio } \\
\text { da tecnologia de pesquisa em Web semântica que permite aos clientes dos serviços utilizarem a } \\
\text { pesquisa utilizando conceitos de ontologias ao invés de pesquisar por palavras-chave e com isso, a } \\
\text { pesquisa pode se tornar mais rápida. }\end{array}$ \\
\hline E6 & $\begin{array}{l}\text { Foi apresentada neste artigo, uma discussão de algumas técnicas fundamentais para a integração de } \\
\text { aplicativos em ambientes heterogêneos. A técnica mais relevante para este trabalho de mestrado foi } \\
\text { a técnica de decompor as funcionalidades de um sistema legado e depois, empacotá-las por meio de } \\
\text { um wrapper e disponibilizadas em Web Services. }\end{array}$ \\
\hline
\end{tabular}




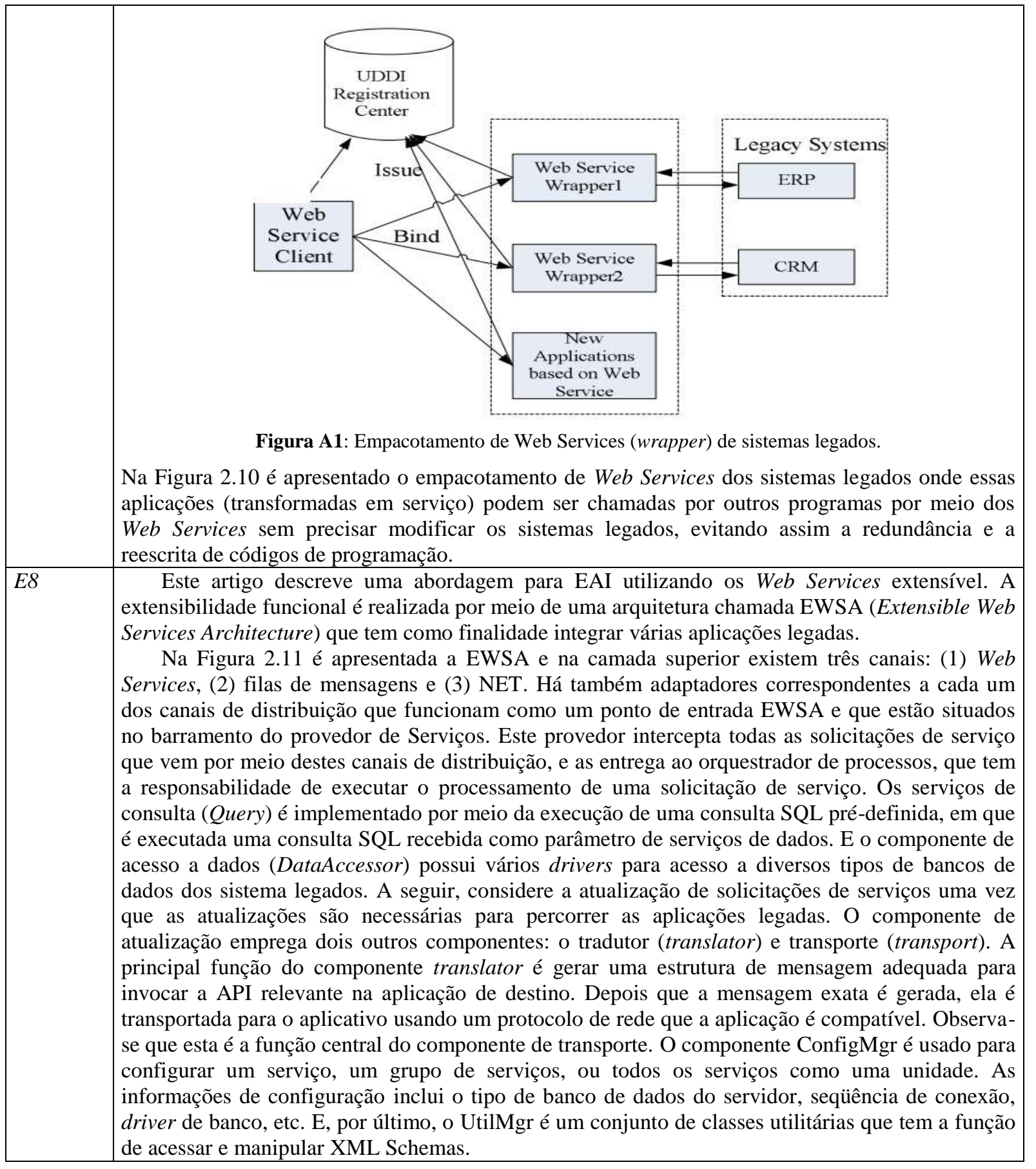




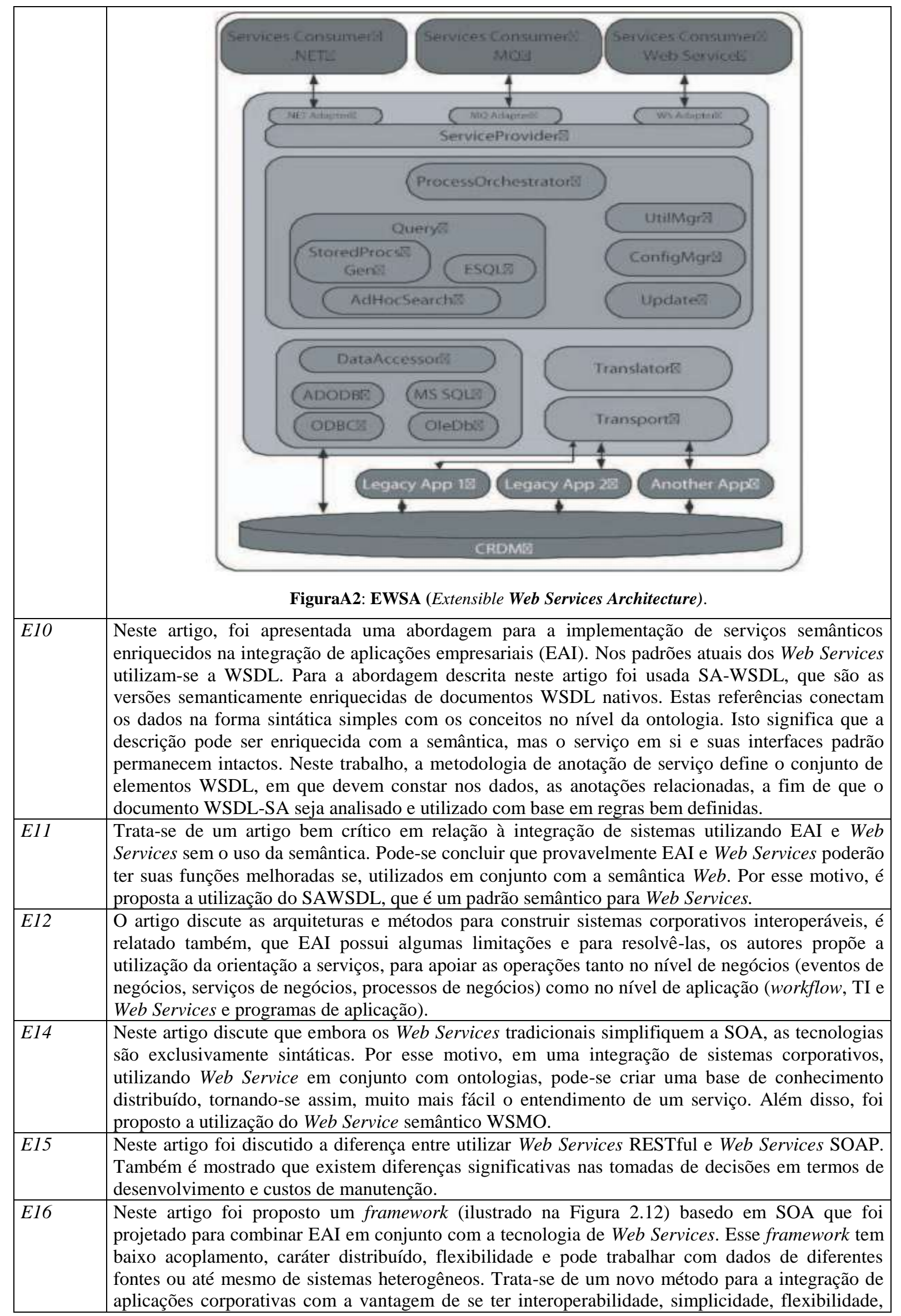




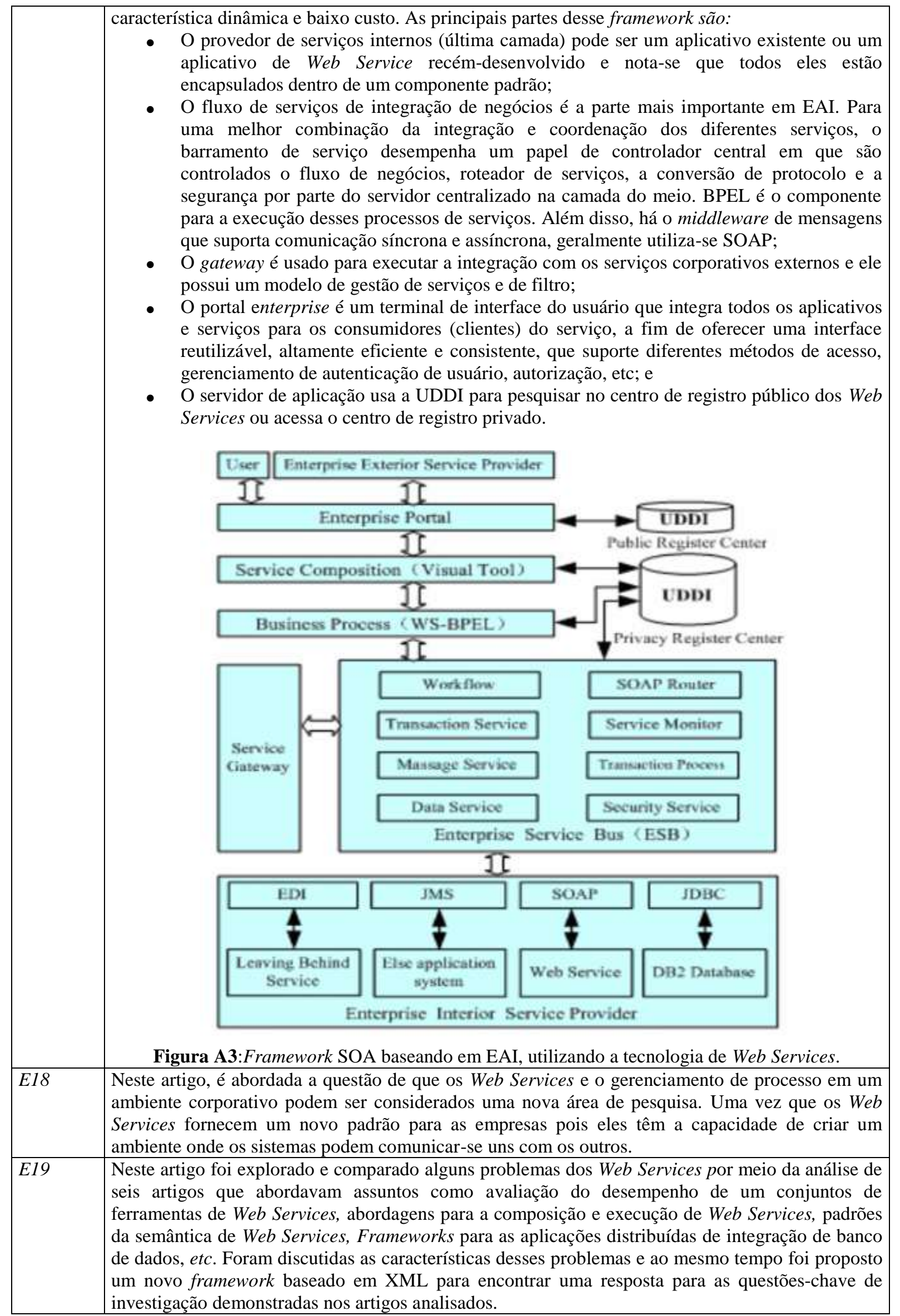




\section{Análise dos Resultados da Revisão Sistemática}

Esta revisão teve como objetivo identificar os trabalhos que envolveram a aplicação de técnicas e critérios e outras questões relacionadas à utilização de Web Services na Integração de Sistemas Corporativos sob a ótica de EAI. A seguir são apresentados os resultados obtidos com a execução da revisão sistemática, de acordo com os objetivos e questões de pesquisa propostos:

- Na seleção preliminar dos trabalhos conclui-se que as máquinas de buscas IEEE e ACM possuem uma porcentagem maior de trabalhos em relação às outras máquinas de busca;

- Pode-se concluir também que no ano de 2008 houve uma grande quantidade de estudos primários incluídos;

- Os critérios de inclusão mais utilizados foram o Critério 1 e o Critério 3, seguido do Critério 4 e por último o Critério 2; e

- O critério de exclusão mais utilizados foi o Critério 2.

\section{Considerações finais da revisão sistemática}

Observou-se, por meio deste trabalho, a importância de SOA e Web Services na integração de sistemas nos dias atuais e, com o passar dos anos, o número de pesquisas à respeito de Web Services na integração de sistemas corporativos vêm crescendo gradativamente e EAI e Web Services podem ser parceiros para resolver os problemas de integração de sistemas corporativos.

Conclui-se que a realização da revisão sistemática proporcionou um melhor direcionamento na execução de pesquisas sobre o tópico Web Services na Integração de Sistemas Corporativos sob a ótica de EAI e ela teve grande utilidade para este trabalho de mestrado, uma vez que por meio da sua execução muitos trabalhos foram encontrados e puderam embasar a comparação realizada no Capítulo 3.

\section{Referências da revisão sistemática}

BACKER, M. D.; SNOECK, M.; MONSIEUR, G.; LEMAHIEU, W. A scenario-based verification technique to assess the compatibility of collaborative business processes. Data $\boldsymbol{\&}$ Knowledge Engineering, v. 68, n. 6, p. 531-551, 2009.

BIOLCHINI, J.; MIAN, P. G.; NATALI, A. C. C.; TRAVASSOS, G. H. Systematic review in software engineering. . Rio de Janeiro: [s.n.]. , 2005

CARDOSO, J.; AALST, W. V. D.; BUSSLER, C.; SHETH, A. Inter-enterprise System and Application Integration: A Reality Check. Enterprise Information Systems 9th International Conference, ICEIS. Anais... [S.1: s.n.]. , 2008

CHAFLE, G.; DAS, G. An Integrated Development Environment for Web Service Composition. IEEE International Conference on Web Services (ICWS'07), 2007.

CHEN, DAVID; DOUMEINGTS, G.; VERNADAT, F. Architectures for enterprise integration and interoperability: Past, present and future. Computers in Industry, v. 59, n. 7, p. 647-659, set 2008 .

CHEN, DEJUN; DU, Z.; HU, R.; ZHOU, Z.; JI, C. Modeling on SOA-based Virtual Enterprise Multi- source Heterogeneous Service Integration. 7th IEEE International Conference on Industrial Informatics (INDIN 2009), 2009.

DENG, W.; YANG, X.; ZHAO, H.; LEI, D.; LI, H. Study on EAI Based on Web Services and SOA. 2008 International Symposium on Electronic Commerce and Security. Anais... [S.1.]: IEEE. Disponível em: 
<http://ieeexplore.ieee.org/lpdocs/epic03/wrapper.htm?arnumber=4606033>. Acesso em: 27 maio. 2012. , 2008

GUDIVADA, V. N.; NANDIGAM, J. Enterprise application integration using extensible Web services. IEEE International Conference on Web Services (ICWS'05). Anais... [S.1.]: Ieee. Disponível em: <http://ieeexplore.ieee.org/lpdocs/epic03/wrapper.htm?arnumber=1530781>., 2005

ISMAILI, F. Web Services - Current Solutions and Open Problems. 8th WSEAS International Conference on applied informatics and communications (AIC'08). Anais... [S.1: s.n.]. , 2008

JIANG, B. Developing Information Service Platform for Clusters of Small-Medium Enterprises in Heterogenous Environment. 2008 ISECS International Colloquium on Computing, Communication, Control and Management. Anais... [S.l.]: Ieee. Disponível em: <http://ieeexplore.ieee.org/lpdocs/epic03/wrapper.htm?arnumber=4609835>. Acesso em: 28 maio. 2012. , 2008

KITCHENHAM, B. Procedures for performing systematic reviews. Joint Technical Report TR/SE-0401. . Keele/Staffs-UK and Eversleigh-Australia: [s.n.]. , 2004

KONG, J.; JUNG, J.-YOON; PARK, J. Event-driven service coordination for business process integration in ubiquitous enterprises. Computers \& Industrial Engineering, v. 57, n. 1, p. 1426, 2009.

KUMAR, P. Web Services and. . [S.1: s.n.]. , 2005

LU, W.; ZHANG, D. Research of Enterprise Application Integration Base on Service Oriented Architecture. 2009 International Conference on Computational Intelligence and Software Engineering. Anais... [S.1.]: Ieee. Disponível em:

<http://ieeexplore.ieee.org/lpdocs/epic03/wrapper.htm?arnumber=5362693>. , dez 2009

LÄMMER, A. A Procedure Model for a sOA-based Integration of Enterprise systems. International Journal of Enterprise Information Systems, v. 4, n. April-June, p. 1-12, 2008.

MARTINEK, P.; TOTHFALUSSY, B.; SZIKORA, B. Implementation of Semantic Services in Enterprise Application Integration. v. 7, n. 10, p. 1658-1668, 2008.

PAUTASSO, C.; LEYMANN, F. RESTful Web Services vs . "Big " Web Services : Making the Right Architectural Decision Categories and Subject Descriptors. . [S.l: s.n.]. , 2008

VERNADAT, F. B. Interoperable enterprise systems: Principles, concepts, and methods. Annual Reviews in Control, v. 31, n. 1, p. 137-145, jan 2007.

WANG, H.; ZHANG, H. Enabling Enterprise Resources Reusability and Interoperability through Web Services. IEEE International conference on e-business Engineering (ICEBE'06), 2006.

ZHANG, L.; ZHOU, S.; ZHU, M. A Semantic Service Oriented Architecture for Enterprise Application Integration. 2009 Second International Symposium on Electronic Commerce and Security. Anais... [S.1.]: Ieee. Disponível em:

<http://ieeexplore.ieee.org/lpdocs/epic03/wrapper.htm?arnumber=5209832>. Acesso em: 28 maio. 2012. , 2009

ZHAO, J. L.; CHENG, H. K. Web services and process management: a union of convenience or a new area of research? Decision Support Systems, v. 40, n. 1, p. 1-8, jul 2005. 


\section{Descrição das tarefas do Estudo Experimental}

\section{Descrição do Sistema Agenda (antes da integração com o RH)}

O Sistema Agenda foi desenvolvido na Linguagem PHP 5 e foi utilizado o banco de dados MySQL 5. Ele tem por objetivo agendar horários de reuniões dos contatos (pessoas que participarão da reunião). A tela possui os seguintes campos: Nome, Email, Telefone, Data da reunião e Hora da reunião. A base de dados chama-se Agenda e possui 2 tabelas: Contato (com os campos id_cont, nome, email, nome_guerra e telefone) e Agenda (com os campos contatos_id_cont, dat_reuniao e hor_reuniao). A seguir a Figura 1 mostra o design do banco de dados do sistema atual.

\begin{tabular}{|c|c|c|}
\hline agenda & \multirow[b]{3}{*}{ Rel_01 } & contatos \\
\hline i cod_ag: INTEGER & & V id_cont: INTEGER \\
\hline$\checkmark$ contatos_id_cont: INTEGER (FK) & & $\nabla$ nome: VARCHAR(100) \\
\hline$\checkmark$ dat_reuniao: DATE & $\nu$ & $\diamond$ email: VARCHAR(50) \\
\hline$\checkmark$ hor_reuniao: TIME & & $\diamond$ endereco: INTEGER \\
\hline $\begin{array}{l}\Delta \text { agenda_FKIndexI } \\
\checkmark \text { contatos_id_cont }\end{array}$ & & $\begin{array}{l}\vartheta \text { nome_guerra: VARCHAR(20) } \\
\vartheta \text { telefone: VARCHAR(20) }\end{array}$ \\
\hline
\end{tabular}

Figura B1: Relacionamento da tabela agenda com a tabela Contatos. Ambas da mesma base de dados Agenda. sucinta.

A seguir, seguem as descrições dos formulários do sistema Agenda de forma

- ConsultaMysql.php : possui informações sobre o host, usuário, senha e o banco de dados. Além disso, ela possui lógicas para conexões em PHP, executar consultas (que podem ser select, update, insert ou delete) entre outras lógicas. Trata-se de uma lógica pronta que foi baixada na internet e ela pode ser reutilizada em qualquer outro sistema que usem essas funções;

- Formulários para inserir os contatos:

○ formInsertContato.php: Formulário que contém o desenho da tela de cadastro de contatos; 
○ insertContato.php: Formulário que contém a lógica de inserção do contato utilizando o acesso nativo à tabela contatos;

\section{- Formulários para inserir a agenda:}

○ formInsertag.php : Formulário que contém a lógica de alimentar a combobox com o nome do contato da tabela contatos;

○ formInsertag2.php: Formulário que contém o desenho da tela de cadastro da Agenda. Observa-se que neste formulário, há uma consulta que traz a informação do contato escolhido no formInsertag.php, a fim de trazer os dados do Nome, Nome de guerra ou apelido, Telefone e Email desta tabela no formato read-only (somente leitura);

- insertag.php: Formulário que efetua a inserção dos dados do cadastro agenda na tabela agenda;

- formSearchag.php: Formulário que contém o desenho da tela de consulta;

- searchag.php: Fomulário que desenha a consulta e mostra os seus resultados;

- formvisuag.php: Formulário que mostra a informação da agenda, que foi escolhida na consulta, de forma mais detalhada; e

- index.php: Menu principal do sistema.

\section{Integração com o sistema do RH}

Para melhorar a integração entre os sistemas, pretende-se não mais trabalhar com a tabela Contatos, pois as informações são redundantes com o sistema de Recursos Humanos (RH) da empresa. Assim, deseja-se efetuar uma integração com o Sistema RH, cuja base de dados é RH e a tabela a ser utilizada é a de Funcionários (Tbfuncion) em que os campos são: matrícula ( $\left.c o d \_f u n c\right)$, nome do funcionário (nome_func), nome de guerra ou apelido (nome_guerra), endereço (des_endereco), telefone (des_telefone), email (des_email), cidade (des_cidade) e ativo ou não (des_ativo_func) na empresa. A Figura 1 a seguir mostra a base Rh com a tabela Tbfuncion.

É importante observar que, ao efetuar a lógica de integração, deve-se levar em conta que os tipos de dados idContato na tabela contato da base de dados Agenda é do tipo integer e na tabela Tbfuncion da base de dados Rh, o atributo cod_func é do tipo string. 


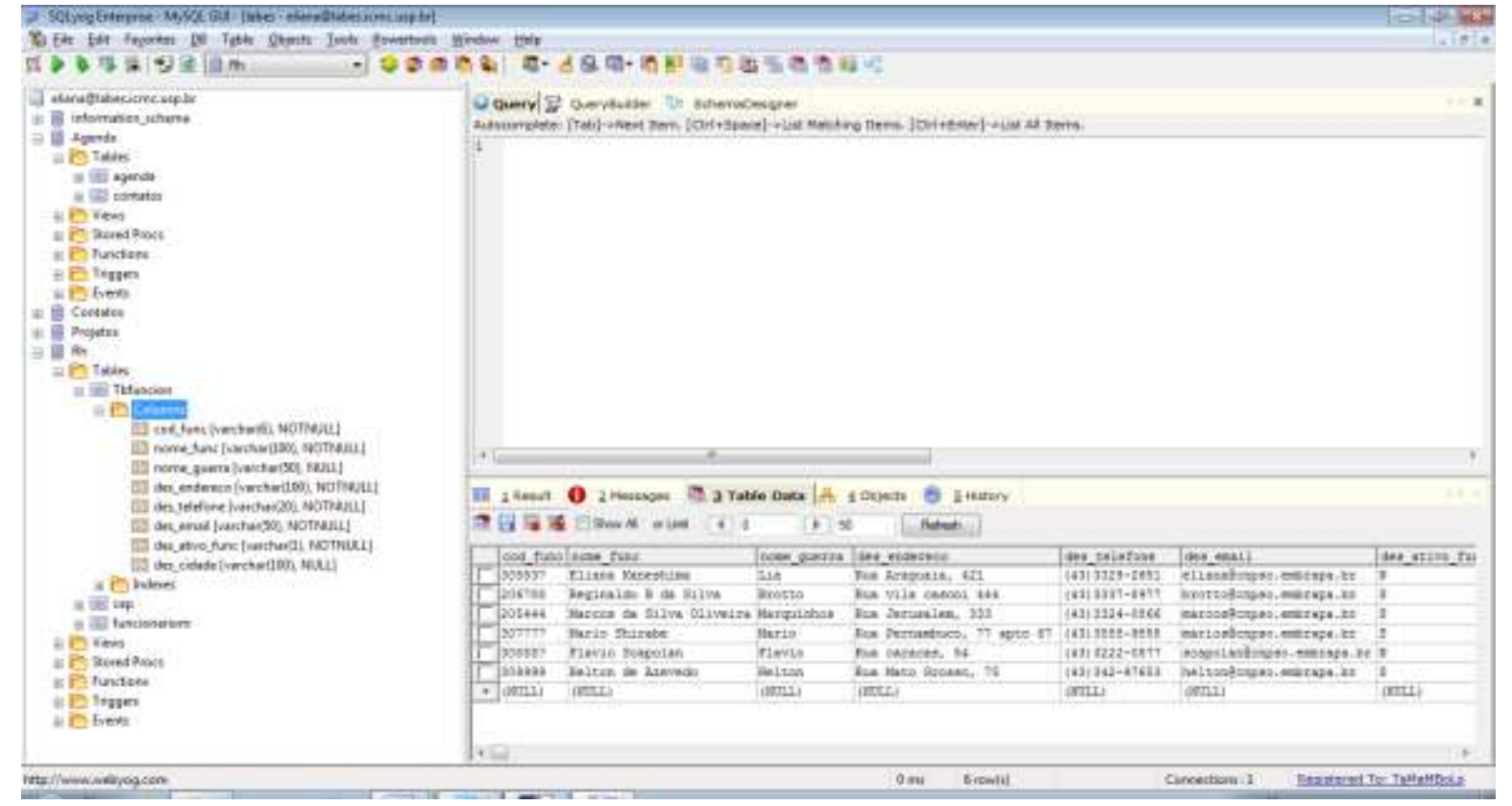

Figura B2: Tela da base Rh com a tabela de funcionários.

\section{Descrição das tarefas}

É importante ressaltar que neste programa deve-se, além de trabalhar com a integração (tanto por acesso nativo aos dados como por Web Service), manter a inclusão das informações de agendamento na tabela Agenda do Sistema Agenda, mas os dados dos contatos não ficarão mais no programa Agenda, eles estarão gravados no Sistema RH. A consulta às informações incluídas poderão ser feitas por meio da utilização da ferramenta HeidiSQL ou outra ferramenta similar ou por meio da própria consulta do sistema. Uma outra tarefa a ser realizada é a alteração no cadastro de contatos, pois, agora será utilizada a tabela de funcionários (Tbfuncion) da base Rh e não mais a tabela contatos da base Agenda.

A seguir, são definidas as tarefas a serem realizadas em cada tipo de integração. Vale ressaltar que o processo de integração é dividido em Integração por Dados e Integração por Web Services. Por favor, leia este documento antes de iniciar o estudo experimental, pois é necessário que você conheça quais os tipos de informações serão coletadas ao longo do estudo.

A fim de ajudar na implementação destas integrações, foi preparado um programa exemplo que contém uma integração por dados e outra por WS, na qual foi implementado um simples programa de Cep. Também foi criado um documento que descreve o programa Cep (Descrição do programa cep.pdf) e dois tutoriais que explicam como foram implementadas as integrações por dados (treinamento cepdados.pdf) e por Web Service (WS), o documento treinamento cep-WS.pdf. Para complementar a integração por WS, e efetuar o aprendizado de Web Services, pode-se consultar o documento: Tutorial - Criação WS do Cep.pdf que explica de forma detalhada como se cria um Web Service, trabalha com JPA e persistência, que se encontra em: http://www.icmc.usp.br/ kaneshi/estudoexp/treinamento/cep/docs/. Para o estudo experimental, esses documentos serão disponibilizados na área de trabalho do computador, na pasta docs e também juntamente com os demais documentos, estão disponibilizados na DropBox, na pasta ec. 


\section{Integração por dados (ID)}

Caso não se lembre dos conceitos de banco de dados ou não conheça o banco MySQL, é interessante rever os seus conceitos antes de começar o estudo experimental. O mesmo é recomendado para as ferramentas que acessam o banco MySQL. Durante o estudo experimental também poderá precisar revisar algum conceito, portanto anote o tempo gasto nessas atividades.

O próximo passo importante é o entendimento da integração a ser realizada e a definição do projeto da solução.

Executados os passos anteriores, pode-se começar a manutenção de integração no sistema de Agenda. O nome do projeto a ser usado é o AgendaDados-Func.

A seguir, são descritas algumas dicas para ajudar a implementar as alterações que deverão ser feitas nos formulários do projeto AgendaDados-Func, para efetuar a integração por dados. Vale ressaltar que, como foi dito no item 2.1, não será utilizada mais a tabela contatos e sim, de funcionários (TbFuncion) da base de dados Rh.

- Formulários para inserir os funcionários:

○ formInsertFunc.php, insertFunc.php: como agora será utilizada a tabela tbfuncion, da base Rh, na hora de efetuar a alteração, deve-se verificar se todos os campos foram incluídos, uma vez que esta tabela possui mais campos que a tabela contatos, da base de dados Agenda. Observa-se que, no formulário insertFunc.php, a lógica utilizada é a de acesso nativo à tabela tbfuncion;

\section{- Formulários para inserir a agenda:}

○ formInsertag.php: Neste formulário deve-se levar em conta que, como foi dito no item 1.1, não será utilizada mais a tabela contatos e sim, a tabela de funcionários (TbFuncion) da base de dados $\mathrm{Rh}$;

○ formInsertag2.php: Com a nova integração, deve-se efetuar alterações na lógica. Preste atenção no tipo de select, porque ele executa uma busca individual; e

○ insertag.php: Veja como será feita gravação da chave estrangeira (idcon), pois ele pertence à tabela contatos e a mesma não será mais utilizada.

\section{Integração por Web Service (WS)}

Caso não se lembre ou não conheça os conceitos de Web Service, é interessante efetuar um estudo destes conceitos e também aprender a implementar um WS antes de começar o estudo experimental. Fique à vontade para consultar o que for necessário durante o estudo, lembrando sempre de anotar o tempo gasto nessa atividade.

O próximo passo importante é o entendimento da integração a ser realizada e a definição do projeto da solução utilizando serviços, o que implica em analisar quais serviços precisarão ser criados.

É importante ressaltar que, deverá ser implementado um projeto novo para a criaçao do(s) serviço(s) relacionado(s) à tabela de funcionário (TbFuncion) da base de dados Rh. Neste caso, o participante deverá criar tanto o(s) serviço(s) como um cliente para este(s) serviço(s). 
Após definidos e criados os serviços, o próximo passo é fazer as modificações na aplicação cliente que irá consumir o serviço, que nesse caso é o projeto AgendaWSFunc.

A seguir, seguem as descrições dos formulários que sofrerão alterações e trabalharão com serviços. Os demais formulários que não foram descritos, possuem informações e tarefas similares aos formulários descritos no item 1:

- ObjToArray.php: é um formulário que contém uma função que converte um objeto em um array;

- Formulários para inserir os funcionários:

○ formInsertFunc.php: Como será utilizada a tabela tbfuncion, da base $\mathrm{Rh}$, ao efetuar a alteração deve-se verificar se todos os campos foram incluídos, uma vez que esta tabela possui mais campos que a tabela contatos, da base Agenda;

○ insertFunc.php: A alteração que deverá ser feita neste formulário é no serviço, pois, deve-se usar o serviço de inserção que trabalha com a tabela tbfuncion, criado anteriormente no Java;

- Formulários para inserir a agenda:

○ formInsertagFunc.php: Formulário que contém a lógica de alimentar a combobox com o nome do contato da tabela contatos utilizando Web Services (é invocado o serviço de consulta criado utilizando a tabela TbFuncion);

○ formInsertagFunc2.php: Com a nova integração, deve-se efetuar alterações na lógica. Preste atenção no tipo de select, porque ele executa uma busca individual; e

○ insertag.php: Veja como será feita gravação da chave estrangeira (idcon), pois ele pertence à tabela contatos e a mesma não será mais utilizada.

\section{Preenchimento dos Questionários EAI-Dados e EAI-WS}

Enquanto estiverem trabalhando com as manutenções da integração, pedimos que preencha o questionário a fim de computar o tempo gasto em cada tarefa. $\mathrm{O}$ questionário se encontra em: http://www.icmc.usp.br/ kaneshi/estudoexp/docs/ com o nome de Questionario-EstudoPiloto.doc. É importante ler o questionário antes de iniciar o estudo de caso, pois várias medidas serão tomadas desde o início.

\section{Entrega dos arquivos}

Para entregar os arquivos, seguir os seguintes passos:

- Para ter acesso a Dropbox ou se houver algum problema, favor enviar email para kaneshima.eliana@gmail.com;

- Os arquivos que deverão ser entregues são: 
- Da parte do serviço, acessar na máquina virtual: C:Documents and Settingslusr1\Meus Documentos\NetBeansProjects\ e compactar a pasta do serviço que foi criado e deposite na Dropbox na pasta ec $<$ nome participante>;

- Da parte do cliente, acessar na máquina virtual: $\mathrm{C}:$ XXampplhtdocslestudoexp $\backslash$ e compactar as pastas AgendaDados e AgendaWS e deposite na Dropbox na pasta ec $<$ nome participante>; $\mathrm{e}$

○ Não é necessário enviar as bases de dados.

\section{Observações importantes}

- Favor executar primeiramente a Integração por Dados;

- Não se esqueça de sempre iniciar o Glassfish no caso de serviços e na parte do cliente, iniciar o Xampp;

- Se estiver usando as máquinas do Labes, favor acessar:

- Para se trabalhar com o experimento, favor acessar a máquina virtual por meio do Virtual Box da Oracle (Oracle VM VirtualBox) e acessar a máquina que está com o seu nome.

- Se for usar a sua própria máquina:

- Favor instalar a Virtual Box antes;

- Favor pedir para eu instalar a imagem da Virtual Box; e

- Para se trabalhar com o experimento, favor acessar a máquina virtual por meio do Virtual Box da Oracle (Oracle VM VirtualBox) e acessar a máquina que está com o seu nome.

\section{Conclusão e Agradecimentos}

Agradecemos a sua colaboração e saiba que as suas informações serão de grande valia para o nosso estudo experimental. 


\title{
Patterns for Enterprise Application Integration (EAI)
}

\author{
Eliana Kaneshima $^{1,2}$, Rosana T. Vaccare Braga ${ }^{1}$ \\ ${ }^{1}$ ICMC - Universidade de São Paulo - São Carlos, SP - Brazil \\ ${ }^{2}$ Embrapa Soja - Londrina, PR - Brazil \\ $\{$ kaneshi, rtvb\}@icmc.usp.br
}

\begin{abstract}
The development of Information Technology (IT) demands the integration of systems (legacy or new), so that they can operate in a distributed way and promoting the reuse of design, code and information in a high granularity level. Enterprise Application Integration (EAI) plays a fundamental role in this scenario. It can be conducted by different means, for example, by sharing the access to databases or using Web Services (WS). Both solutions are being adopted by organizations, although they present advantages and disadvantages that should be analysed. Several restrictions can be present in the particular integration scenario, causing problems to be solved before deciding if the integration should be done by data access or WS. So, this work has the objective of documenting these problems and solutions in the pattern format, in order to make available to other developers the knowledge acquired when doing EAI. These solutions can be used to improve reuse in certain integration contexts, depending on the organization business rules.
\end{abstract}

\section{Introduction}

In the current economic and industrial context, it is desirable to restructure many enterprise systems to answer the demand from the clients, both due to changes in functional requirements and in technology. It is not just about IT problems, but organizational and strategic challenge [1].

The major challenge in this context is how to deal with the creation of new enterprise systems using current technologies and, at the same time, making possible that legacy systems remain operational on new platforms, and still keeping some systems with older technologies. The problems could be easily solved if these systems were totally independents of each other. But unfortunately, this is not true. Instead, each new system depends on information that is already being worked in the legacy system and redundancy of data is not interesting in this case. Thus, the concept of Enterprise 
Application Integration (EAI) is related to the mechanisms used by the company in developing solutions that solve this problem. According to Linthicum (1999), EAI is the "unrestricted sharing of data and business processes among all connected applications and data sources in the enterprise".

There are many mechanisms by which two systems could be integrated. One possible solution is to integrate through a shared database (DB). For example, the data from an application are available to be accessed directly by another application, which accesses the information in read-only mode or by making periodic copies of the database tables. Another possibility of integration is through Web Services (WS), where a service is provided by a system and can be called by another system to be integrated. These two solutions are being used successfully, but both have advantages and disadvantages that must be analyzed according to the business rules present in each integration context.

It is important to emphasize that the integration of enterprise applications is not an easy task to accomplish, so patterns are a possible way of helping to find the best solution. Software patterns describe solutions to problems that occur frequently during development [3]. If used correctly, integration patterns can help to fill the gap between high-level view of the integration and actual implementation of the system [4].

Five patterns for Enterprise Applications Integration are proposed in this paper: two are based on direct access to the database and three are based on Service-Oriented Architectures (SOA) [5]. More specifically, these last patterns are based on Web Services, which is a technology to implement SOA [6] and represents a major evolution for the increasingly complex challenges involved in developing software [1]. A service is a software component that encapsulates high-level business concepts and performs a unique and self-sufficient function [5]. There are three elements that participate in a SOA: the service provider, the service repository (or record), and consumer services [7]. The service repository acts as intermediary between the provider and the service consumer.

Thus, the aim of this paper is to present patterns for Enterprise Applications Integration using these two mechanisms: based on direct data access and using Web Services.

\section{EAI Patterns}

The motivation for presenting the following set of five patterns is to help the software engineers responsible for systems integration, who face different integration scenarios. Even though there are several integration patterns reported in the literature, they are written in different formats and most of them have its focus on architecture and standardization of deployment code. Therefore, they do not focus on the different contexts of business rules that can be present at the time of integration. For example, a possible business rule may require that only one system is responsible for CRUD operations, so that other systems integrated with it have read-only access to the database. We hope that the set of patterns shown below makes easier the use of EAI patterns, ensuring that the business rules are being considered.

For all the proposed patterns, the following factors are considered in the pattern application context:

- Is it difficult to share information? If the applications to be integrated belong to the same company or partner companies, it may be easier to share databases, providing right of access to applications, and without requiring the use of services. This leads to better performance, because it requires less processing of 
information resulting from the use of services. On the other hand, if no such facility exists, WS can be better;

- Is performance critical, with a big volume of accesses to data? Depending on the type of application to be integrated, a great number of accesses from one system to another may occur, making unfeasible to use WS, so direct Access is preferred. However, this should be analysed together with the other factors to have the best decision;

- Is it essential to keep data synchronized between the systems being integrated? Depending on the type of application being integrated, data should always be synchronized, with no tolerance to inconsistency of data. In other applications, some level of tolerance might be acceptable, within certain predefined periods of time; and

- Is the access to data more likely to be read-only? The integration can often be designed so that one of the systems concentrates the information (it is responsible to CRUD operations), while other systems need only to access it through read operations, without writing permission. This factor has a great influence on the solution, since more complex mechanisms are necessary to allow the modification of information.

- Is there information that is local to one of the systems? Maybe it is important to keep some information only locally, because the other systems are not interested on that information, or even the information is confidential and cannot be stored in the main database. In this case, the legacy system only provides part of the information to the integrated systems, which have local data updated by its own applications.

Table 1 shows how each pattern takes into consideration the factors discussed above. Notice that these are possible common combinations of factors, but there might be other contexts in which these patterns are not suitable, requiring other patterns to be documented in the future.

Table 1 - Context of the proposed patterns

\begin{tabular}{|l|c|c|c|c|c|}
\hline \multirow{2}{*}{ Factor } & \multicolumn{5}{|c|}{ Pattern } \\
\cline { 2 - 6 } & $\begin{array}{c}1-\text { Direct } \\
\text { access via } \\
\text { BD }\end{array}$ & $\begin{array}{c}\text { 2- Direct } \\
\text { access via } \\
\text { WS }\end{array}$ & $\begin{array}{c}3- \\
\text { Intermediate } \\
\text { Duplication } \\
\text { with access } \\
\text { via BD }\end{array}$ & $\begin{array}{c}4- \\
\text { Intermediate } \\
\text { Duplication } \\
\text { with access } \\
\text { via WS }\end{array}$ & $\begin{array}{c}5- \\
\text { Duplication } \\
\text { via monitor } \\
\text { and WS }\end{array}$ \\
\hline Is it difficult to share? & No & Yes & No & Yes & Yes \\
\hline Is performance critical? & No & No & Yes & Yes & No \\
\hline Is synchronization essential? & Yes & Yes & No & No & Yes \\
\hline Is access read-only? & No & No & Yes & No & No \\
\hline $\begin{array}{l}\text { Is there information that is } \\
\text { local to one of the systems? }\end{array}$ & No & No & No & Yes & No \\
\hline
\end{tabular}

The problem to be solved by the five patterns is the same, so it is described here and is not repeated in each pattern. 
- Problem: How to integrate information that is present in different systems, possibly developed in different platforms, avoiding information inconsistency and keeping performance compatible with the integration context?

\subsection{Pattern 1}

- Name: Direct Access via DB.

- Context: An application is being developed (e.g. System 1 or 2) in which part of the required information already exists in another application (Legacy System), possibly in a different platform (e.g., a different Database Management System (DBMS)). Systems 1 and 2 have no interest to persist this information, but only to use them to accomplish their business goals through conventional search. All systems belong to the same organization or to partner organizations where it is quite easy to share resources. Besides, it is essential to these systems that information is always consistent between applications, and the volume of access to data is low (it is not an application with high level of data access).

- Forces: we could think about importing the required data periodically, keeping them duplicated in System 1 and System 2, however this requires additional storage resources and can lead to data inconsistency problems, as data will be not updated most of the time, depending on how frequently importation is done; the direct access to the table ensures that data are always updated and consistent, although it can cause performance problems, as well as require special permissions to access the data; if the volume of data to be accessed is small and access is not frequent, it is easier to access them directly from the database.

- Solution: Figure 1 illustrates the solution proposed by the pattern, which suggests to perform the access to the Legacy System through an authorized search directly to the $\mathrm{DB}$, retrieving the information whenever it is necessary (on demand). Data retrieved are locally processed and the Legacy System is totally responsible for executing operations for including, modifying and removing data from the DB, through the CRUD-X module. Systems 1 and 2 use the retrieved data to accomplish their business goals. The decision of having read-only access to the DB was done to fulfill business rules present in organizations where integration should be conducted with the minimum impact on existing applications and keeping the DB update only in one of the systems. However, specific cases could be analysed separately, and variants of this solution could be employed, e.g., allowing the write access.

- Consequences: (1) as the access is direct, it is ensured that information is always up to date; (2) data are updated only in one application, avoiding duplication of information and making software maintenance easier, because modifications are concentrated in a single point, causing less error propagation; (3) the use of shared databases has the advantage of using generalized SQL for relational databases. Almost all development platforms can work with SQL, with the possibility of more sophisticated tools [4]; (4) 
performance can be a problem in case Systems 1 and 2 have high demand of access to DB1, or a high volume of information to be retrieved, or if many conversions are necessary in order to use the data retrieved; and (5) security: Systems 1 and 2 need special authorization to access Legacy System DB 1. A possible way of improving security is to limit the access only to the table(s) involved in the integration.

- Known uses: this pattern has been used for many years in enterprise information systems where different legacy applications need to be integrated. Figure 2 illustrates the pattern being used in the Brazilian Enterprise for Agrobusiness Research (in Portuguese: Empresa Brasileira de Pesquisa Agropecuária- EMBRAPA Soja) where systems for the Reception and Financial Control have access to restricted information about employees from the Human Resources legacy system, by searching information directly from the Employees table.

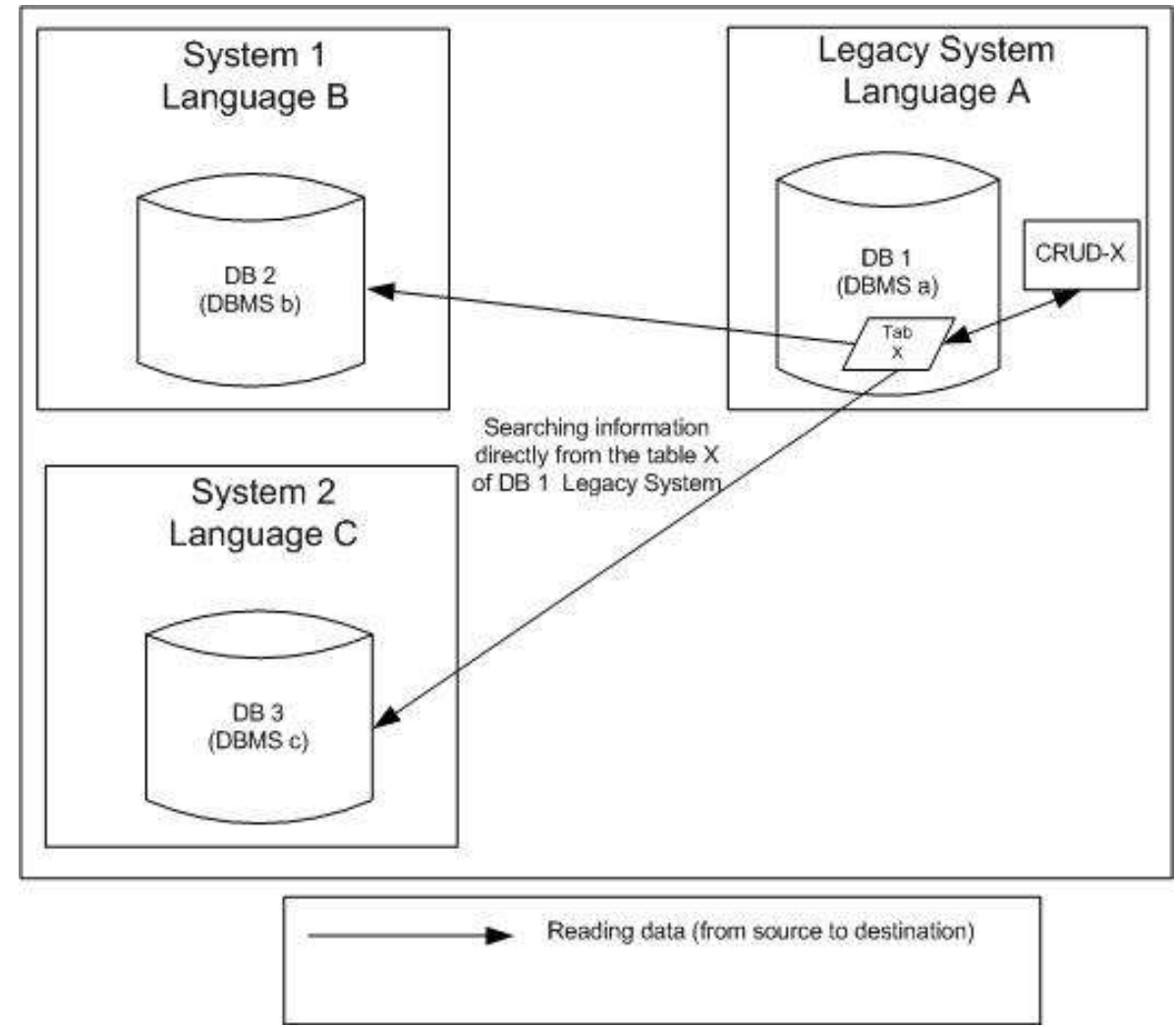

Figure 1. Solution proposed by Pattern 1.

- Related patterns: The Shared Database pattern [4] uses the same approach to allow free access to shared data (as can be seen in Figure 3). However, the pattern proposed in this paper suggests read-only access, with all writing operations performed by the Legacy System. There is also a pattern from IBM, named Direct Connection application pattern (Figure 4), which uses a similar approach, but implements an additional module with connection rules. This module is often used to control how the connector will work, depending on external factors. Examples of connection rules are: business rules for mapping data (adaptor connectors); autonomy rules (priorities for a shared environment); security rules; and availability and capacity rules. 


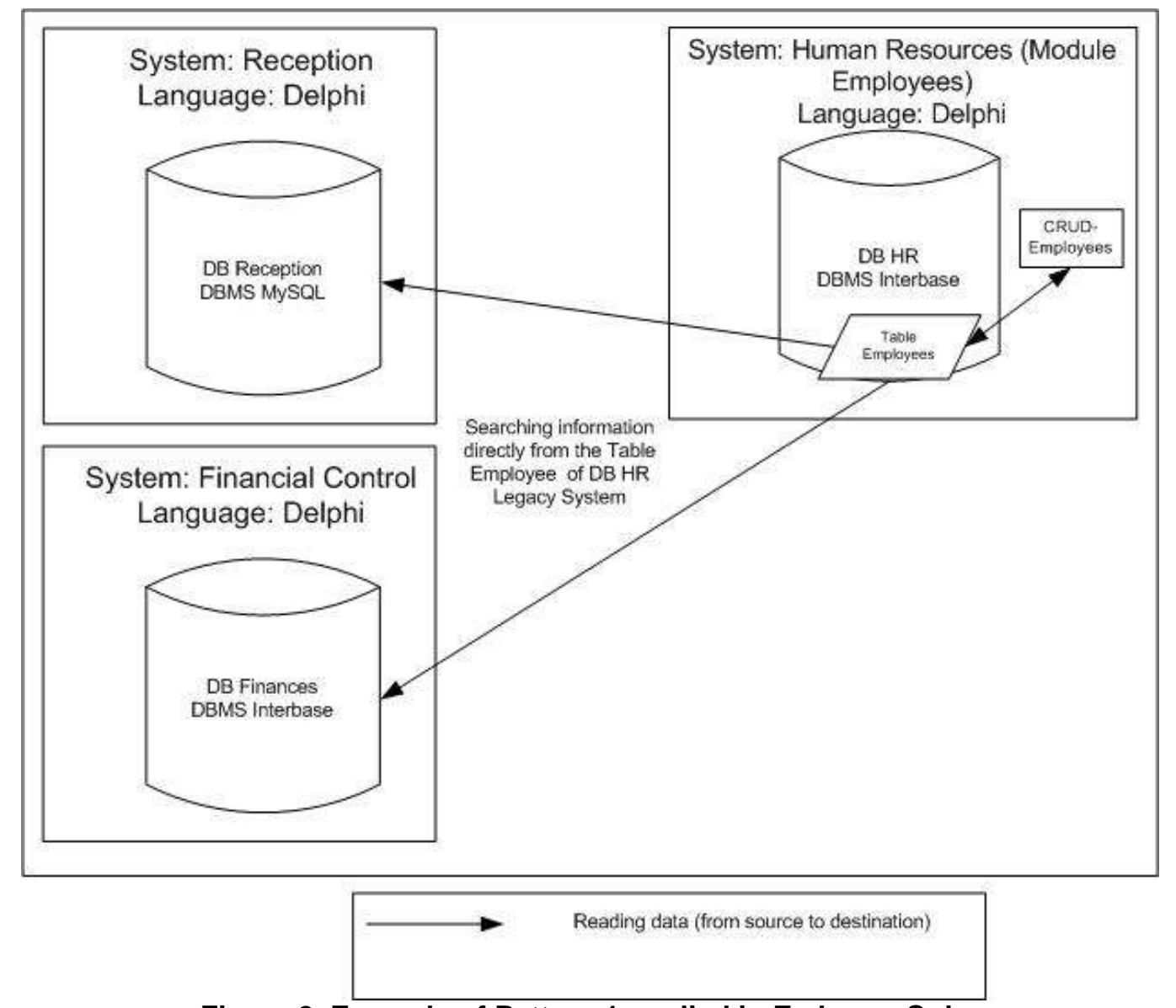

Figure 2. Example of Pattern 1 applied in Embrapa Soja.

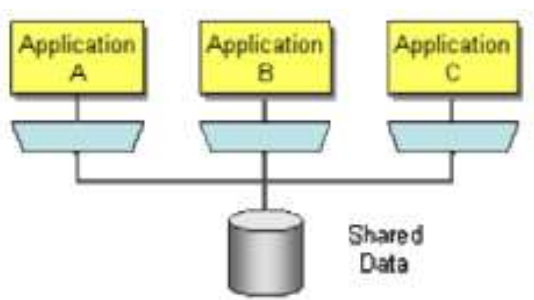

Figure 3. Shared database [4].

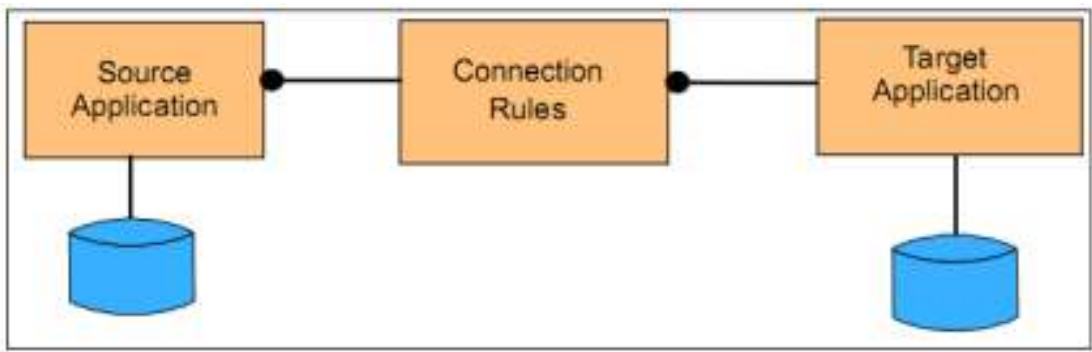

Figure 4. Direct Connection application pattern [8].

\subsection{Pattern 2}

- Name: Direct Access via WS. 
- Context: An application is being developed (System 1) in which part of the required information already exists in another application (Legacy System), possibly in a different platform. Client applications (Systems 1 and 2) have no interest to persist this information, but only to use them to accomplish their business goals. The client application eventually may want to modify or include information, but there is no need to store this information, so that the focus is on keeping information concentrated in the legacy system. Applications belong to different organizations and it is quite difficult to share resources. The volume of information to be integrated is not too big, but it is essential that information is always consistent among applications.

- Forces: We could consider the importation of the required data periodically, keeping them duplicated in System 1 and System 2, however this requires authorization to access the information, which is not straightforward in the current context; besides, problems would be caused due to required additional storage and data inconsistency; direct access to information ensures data consistency and updating, but the difficulty of sharing resources can be an issue; it might be desirable for System 1 to also update the information, rather than only reading it. In this case, it would be interesting to do these updates directly, without having to stop System 1 to ask someone to perform the updates in the Legacy System, and only then to return to System 1.

- Solution: Figure 5 illustrates the solution proposed by the pattern, which suggests to perform the access to information through a Web Service supplied by the Legacy System. Data retrieved by the WS are processed locally and the legacy system is totally responsible to perform operations for inserting, modifying, and removing data from the DB, through a CRUD-X module. Systems 1 and 2 (and other interested systems) use the retrieved data to accomplish their business goals. Optionally, a WS can be supplied to execute the maintenance of the information (WS-CRUD-X). For systems with no need to modify data remotely, only WS-Search is available.

- Consequences: (1) The access to information is direct, therefore it is guaranteed that information is updated and consistent; (2) Data are updated only in one application, easing software maintenance because, as modifications are concentrated in a single point, less propagation errors occur. As mentioned in the context, we assume that System 1 does not store data locally, delegating this task to the Legacy System. But this could be not always true, because System 1 is free to do anything with the data retrieved, including storing it. Thus, the misuse of the pattern cannot ensure a positive consequence; (3) security: the use of WS can imply better information security, because System 1 has access only to information returned by the WS, rather than to the whole DB. However, we should be careful with security issues that can be caused by WS, which could make data more vulnerable to unauthorized access; (4) reuse: other systems can access the available WS, including the WS-CRUD-X; (5) performance can be reduced if Systems 1 and 2 need to invoke WS often, or if the quantity of information to be returned by the WS is too big, or if many conversions are required to use the retrieved data; and (6) maintainability can be compromised, because there are two ways of changing the main table, i.e., through CRUD-X or 
through WS-CRUD-X (dependence relationships need to be observed when the table is updated). However, this can be easily fixed if the WS-CRUD-X serves only as a proxy WS to implement CRUD-X, minimizing this maintainability problem.

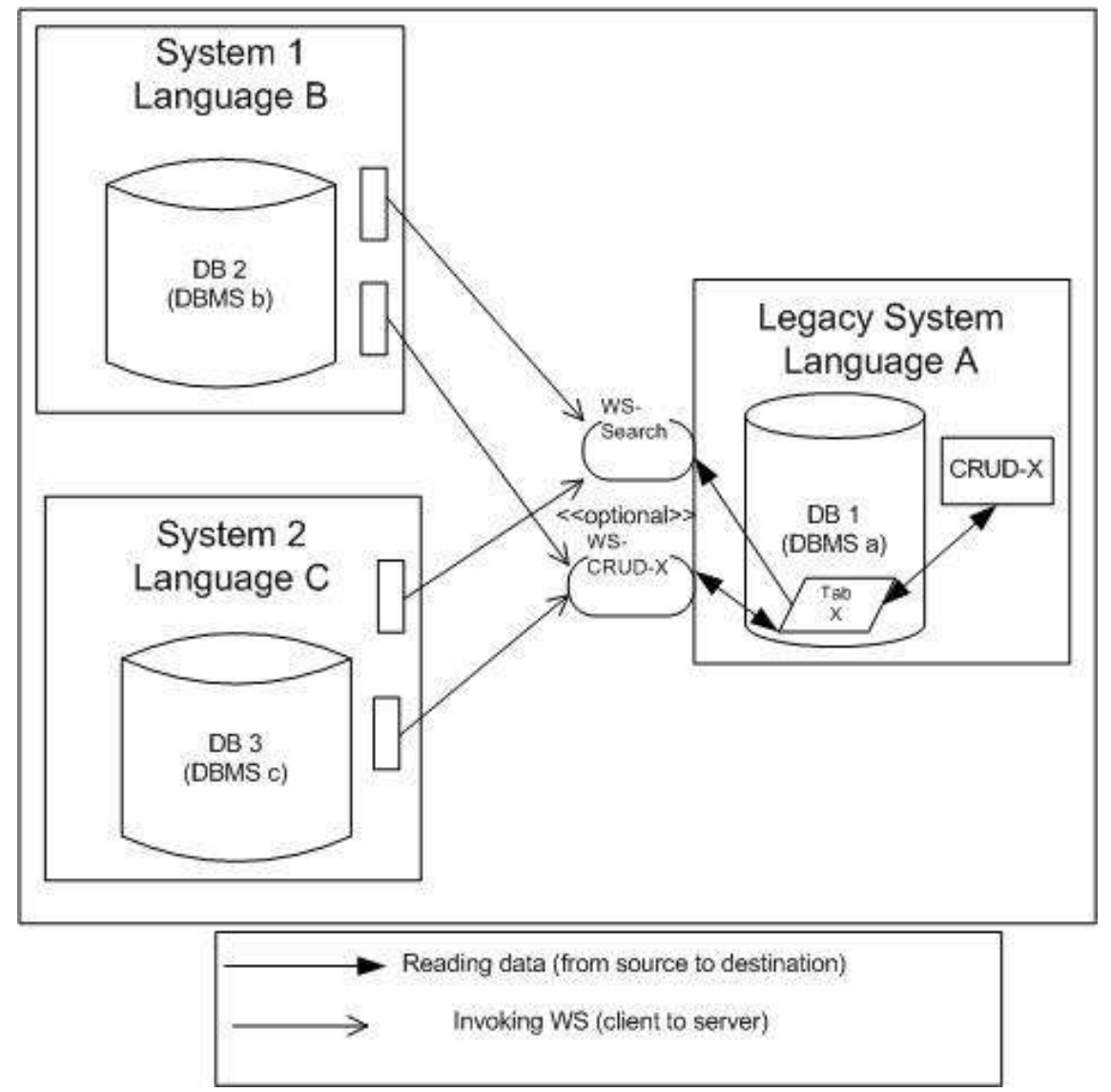

Figure 5. Solution proposed by Pattern 2.

- Known uses: with the popularization of SOA, the use of this pattern became more popular for many enterprises that want to integrate their applications, especially considering legacy systems in different platforms. Examples are: (1) the framework proposed by Deng et. al (2008), which combines EAI with the Web Services technology, allowing the use of different sources of data, even from heterogeneous systems; and the work of Gudivada et. al (2005), which describes a EAI approach using extensible Web Services to integrate legacy applications; (2) the discussion presented by Jiang (2008), about various fundamental techniques to integrate applications in heterogeneous environments. The technique consists of decomposing the functionalities of a legacy system and then wrapping them and making them available through Web Services, as illustrated in Figure 6; (3) In the book of [4], integration is approached as a SOA in which each application can negotiate a communication contract with the service. In this approach, the discovery and negotiation services are the main elements. A new application can be developed using remote services provided by other applications. So, the service call can be considered as an integration between two applications; and (4) this solution (see Figure 7) will be implemented at EMBRAPA Soja, where the systems for Reception, Conference 
Management, Publications, and Scientific Projects can have access to certain information about employees from the Human Resources legacy system using Web Services. Due to decisions made by the development team, in agreement with the enterprise managers, in this case the WS-CRUD-X will not be implemented, because they want to concentrate all modifications on the Human Resources System.

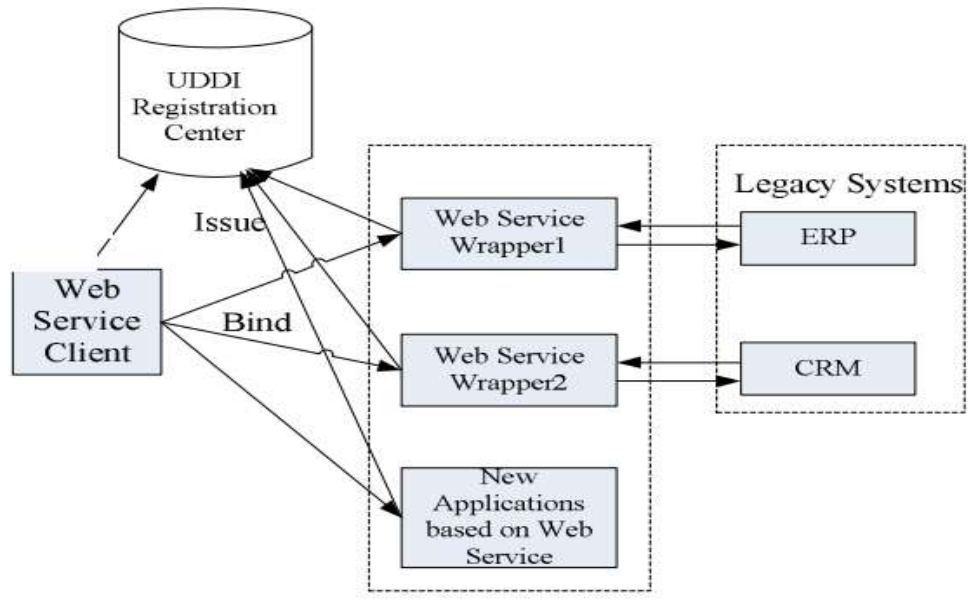

Figure 6: The Architecture of the Application Integration Based on Web Services [11].

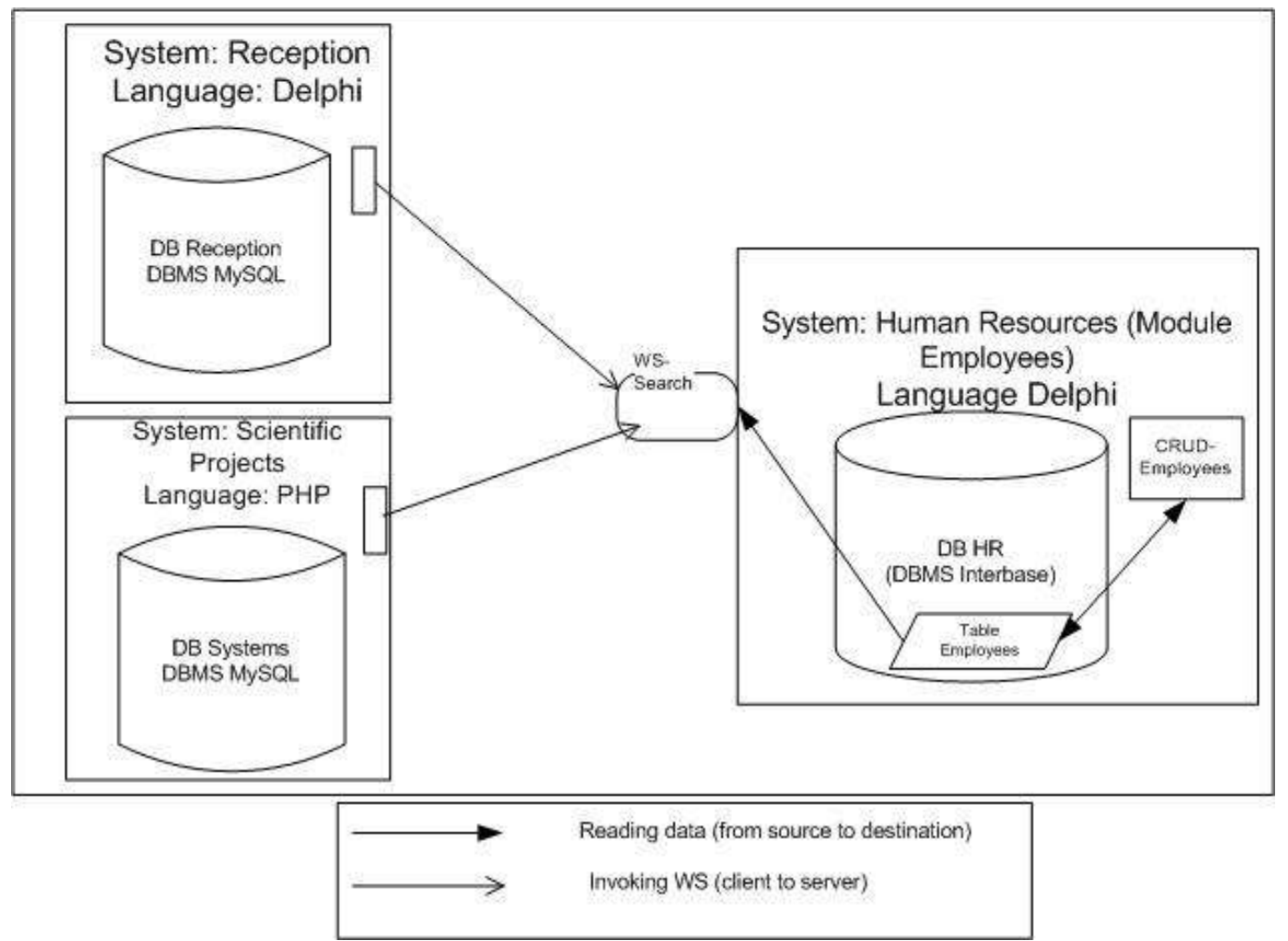

Figure 7. Example of Pattern 2 to be implemented in Embrapa Soja.

- Related Patterns: The Remote Procedure Invocation pattern, from Gregor Hohpe and Bobby Woolf, applies the encapsulation principle to integrate applications. If an application needs any information that belongs to another application, it can make the call directly to the application. If an application needs to modify information that belongs to another application, it can 
execute a call to the other application, ensuring that each application keeps data integrity, changing its internal data without affecting other applications. There is a big number of remote procedure call (RPC) technologies, such as: CORBA, COM, .NET Remoting, Java RMI, etc. Currently, Web Services are the most used, and an advantage is that they work well with HTTP (they do not present problems with firewalls).

\subsection{Pattern 3}

- Name: Intermediate Duplication with access via BD.

- Context: An application is being developed (System 1) in which part of the required information already exists in another application (Legacy System), possibly in a different platform. Client applications (Systems 1 and 2) have no interest to persist this information, but only to use them to accomplish their business goals, performing search or modification of the information. All systems belong to the same organization or to partner organizations where it is quite easy to share resources. Performance is critical, because there is a high volume of access to information during integration, although information consistency between applications is not crucial all the time, i.e., there is a certain tolerance to periodic synchronization.

- Forces: We could think about importing the required data periodically, keeping them duplicated in System 1 and System 2, however this requires additional storage resources and can lead to data inconsistency problems, as data will be not updated most of the time, depending on how frequently importation is done; as the search for information in the Legacy System is the most frequently invoked operation and consistency is not a big issue, the focus can be on performance; considering that the systems can belong to different platforms, more agility can be achieved if we keep a copy of the database with information already converted from the legacy databank to the format adopted in System 1. Additionally, filters can be applied to retrieve only information that is really necessary.

- Solution: Figure 8 illustrates the solution proposed by the pattern, which suggests having a duplication of the data that are common to both systems. This duplication is done together with the conversion of the database from the legacy system format to System 1 and System 2 format, to improve performance. In the example illustrated in Figure 8, a periodic copy of Table $\mathrm{X}$ from the Legacy System (DBMS a) is done, resulting in Table Y of the Auxiliary System (DBMS b). Furthermore, the access to the Auxiliary System is done via an authorized query to the DB, retrieving information whenever it is necessary (on demand). It is important to observe that the Legacy System is totally responsible to perform insertion, update, and removal operations from the DB, through the CRUD-X module. Systems 1 and 2 use the data retrieved to accomplish their business goals. The rationale for having this auxiliary system is based on two factors: a) the Legacy System often has a different DBMS, so conversions are required to use the information in Systems 1 and 2, which can cause performance problems or b) the number of accesses to the $\mathrm{DB}$ is very big, so performance can be substantially improved if the DB is physically closer to the application client 
and already converted to the required format. Additionally, performance can be enhanced if a filter exists to select only information that is really necessary to Systems 1 or 2;

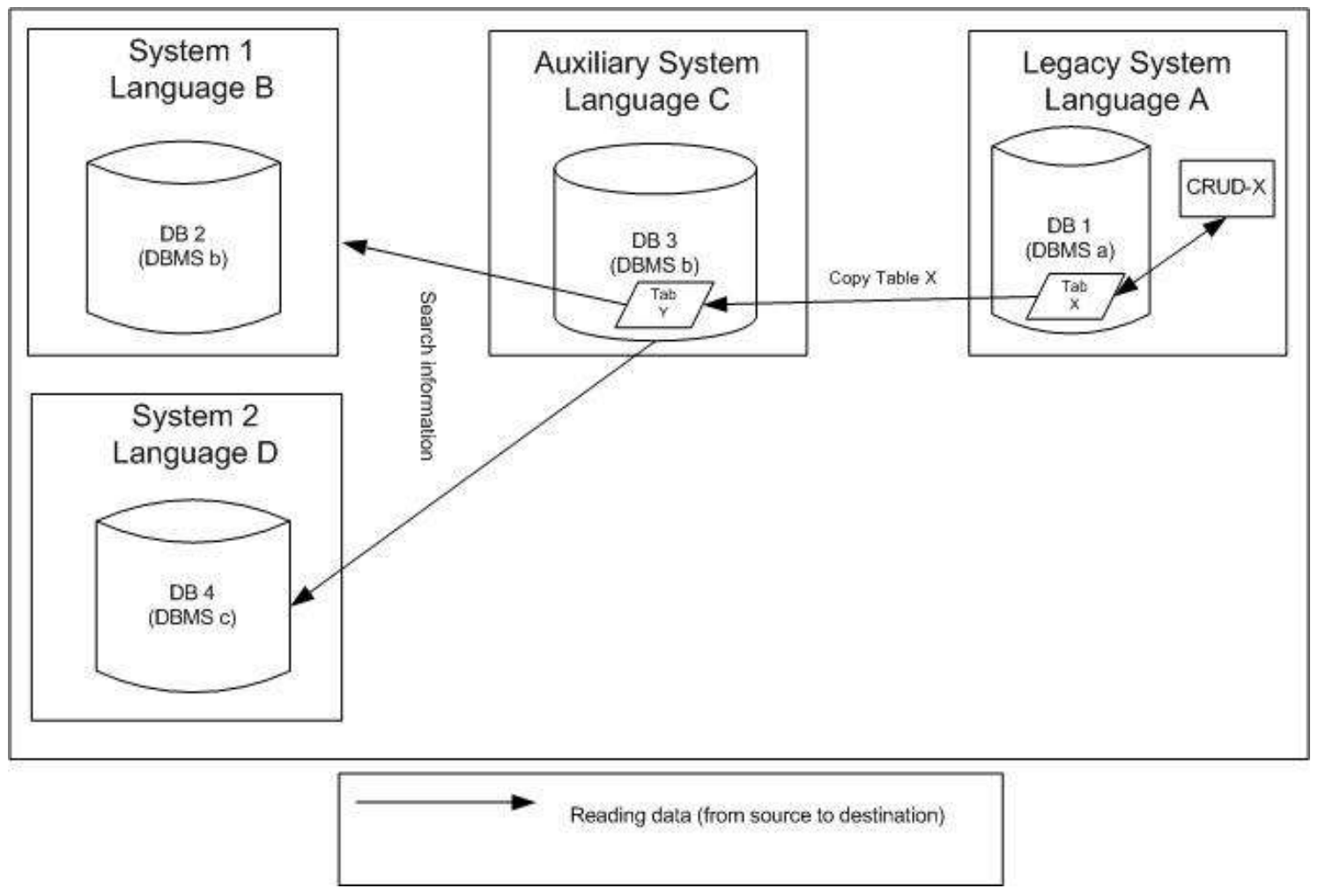

Figure 8. Solution proposed by Pattern 3.

- Consequences: (1) good performance: considering the existence of the Auxiliary System, the behavior is improved but, since a copy needs to be conducted periodically, depending on the frequency on which it is done and on the quantity of information to be copied, certain periods of low performance might occur; (2) the copy can be used as a backup in case the Legacy System fails or if data are corrupted by any means; (3) data inconsistency: there is a duplication of the information, but as the duplication is periodic, the data are not always up to date; (4) security: if Table $\mathrm{X}$ contains confidential data, you need to take some precautions before doing the copy (besides authorization/authentication mechanisms, which could allow total access to the DB, some form of access should be provided to allow to copy only certain columns or records of the table); and (5) restricted usage: it is not always enough to copy a table to solve EAI problems. In general, several related tables will be necessary to achieve the integration, involving a more complex logic.

- Known uses: (1) according to the book of Gregor Hohpe and Bobby Woolf, data duplication is often used when a number of enterprise systems need to access the same data. There are many ways to implement this, e.g., using DBMS in which suppliers have special tools to perform operations of data replication, so that data are exported to files and imported by other systems; (2) Figure 9 illustrates the Data Replication pattern, from IBM [12], which represents a type of bidirectional replication. Although this pattern does not follow the conventional pattern format, it has some similarities with pattern 
3. The bidirectional replication provides redundancy, as well as performance benefits for applications that use the same database, but are geographically dispersed. As opposed to the case of data propagation, replication assumes that the schemas of the two databases are compatible, so there is no need for data transformation, unlike the proposed pattern; (3) in EMBRAPA Soja (see Figure 10), several integrations are done using data duplication, allowing systems that use MySQL DBMS to access information that have been copied from the Human Resources Interbase DBMS; (4) In the SGPC System (System for Management of Scientific Projects), developed at ICMC-USP (University of Sao Paulo), data from research agencies and suppliers are imported periodically from the Mercurio System, which is a corporative system also from USP; and (5) in the ICMC-USP intranet, data from staff and students are periodically imported from the MarteWeb, JupiterWeb and Janus systems, which are USP corporative systems. In this case, filters are applied to retrieve only certain sets of records and/or columns of the tables, and transformations are executed to attend the intranet format.

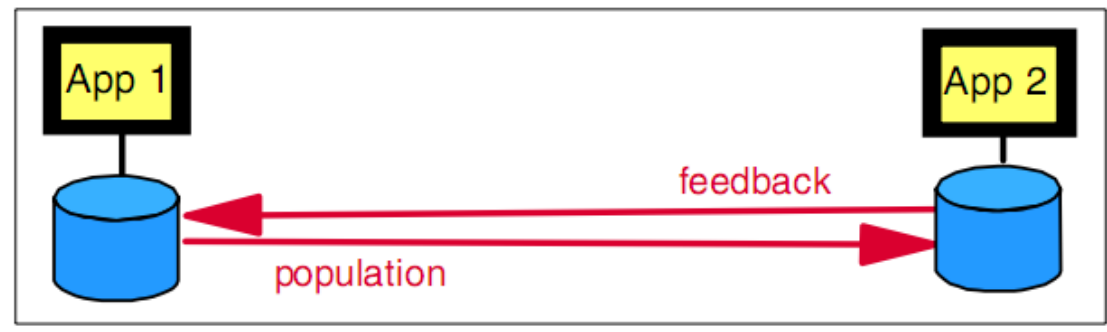

Figura 9. Exemplo de replicação bidirecional [12].

- Related patterns: In the book of Gregor Hohpe and Bobby Woolf, a pattern for file transfer is presented. Considering that the organization has several applications that have been built independently, with different languages and platforms, files are a universal storage mechanism, which can be available and serve as a way to integrate applications. Thus, one application can produce files to be consumed by other applications. The integrator part should be responsible to transform files to different formats, as illustrated in Figure 11. 

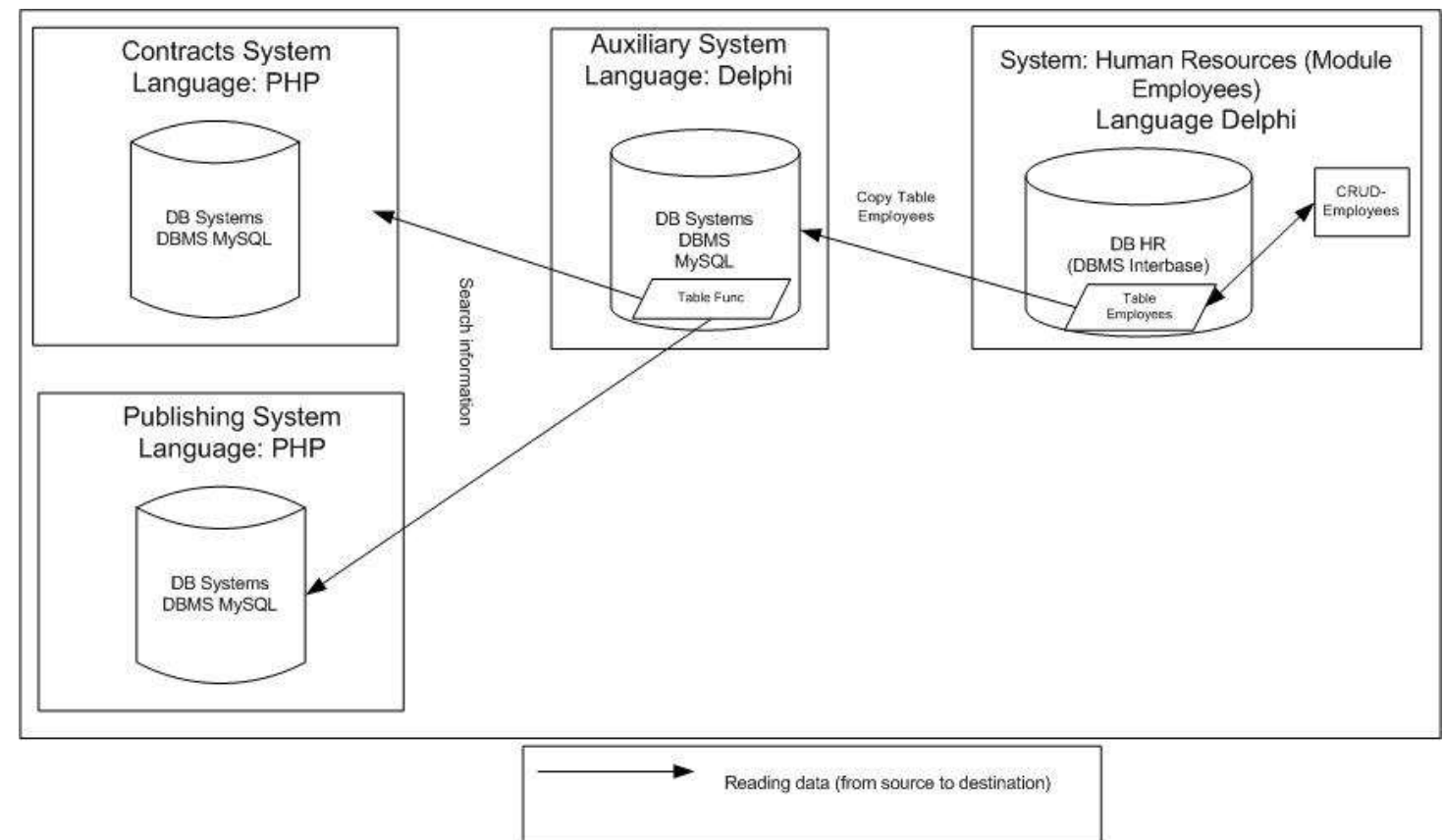

Figure 10. Example of Pattern 3 applied in Embrapa Soja.

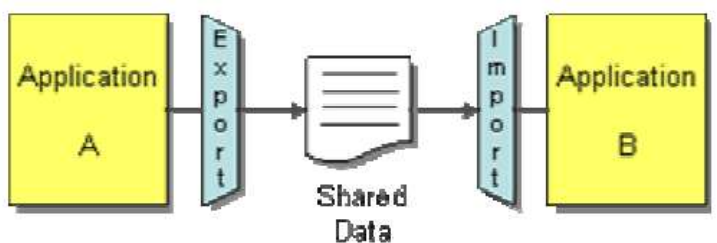

Figure 11. Example of File Transfer [4].

\subsection{Pattern 4}

- Name: Intermediate Duplication with access via WS.

- Context: An application is being developed (System 1 or System 2) in which part of the required information already exists in another application (Legacy System), possibly in a different platform. Local data for these new applications are not relevant to the legacy system and should not be stored there, i.e., they should be stored only locally in Systems 1 and 2 . Applications belong to different organizations and it is quite difficult to share resources. Performance is critical, because there is a high volume of access to information during integration, although information consistency between applications is not crucial all the time, i.e., there is a certain tolerance to periodic synchronization. Furthermore, the legacy system can have a different database schema that requires conversion before being used, causing performance problems.

- Forces: the access to the other system could be done by periodically copying information that is needed to the system. However, this requires authorization, which can be quite difficult in this case (sharing data is an issue here); the direct access to the database of the other system guarantees that the data are always synchronized, although it can cause performance problems, besides requiring special authorization to access the data; considering that local data are not of interest to the other application, they 
could be maintained only locally, requiring that CRUD modules are supplied. On the other hand, even local data could be stored in the other system, which would be responsible for keeping data for which there is no interest, but this would make it simpler to centralize the maintenance in only one place; as Systems 1 and 2 need total access to the information, i.e., to include, modify, consult, and remove data, a mechanism to perform changes locally, and then synchronize them periodically would be desirable.

- Solution: Figure 12 illustrates the solution proposed by the pattern, which suggests creating an Auxiliary System to keep local data together with data imported from the Legacy System, properly converted to the local technology to improve performance. To access to information, Systems 1 and 2 invoke a Web Service (WS-search) supplied by the Auxiliary System. The Auxiliary System periodically copies new information included/modified in the Legacy System to its own tables, through the invocation of the Web Service WS-included. It is important to observe that operations for including, modifying and removing data from the DB are done in two systems: if data are local (only Systems 1 and 2 are interested on them), they are done in the Auxiliary System, through the WS-CRUD-T. In case the data are useful for all systems, they should be maintained by the CRUD-X module of the Legacy System. For systems where there is no need to modify data remotely, only the WS-Search is supplied. A decision was made concerning the maintenance of data in an auxiliary system. This was due to a business rule that can be present in the pattern application context, where there are some specific information that are peculiar only to one of the systems, and should not be available in the legacy system.

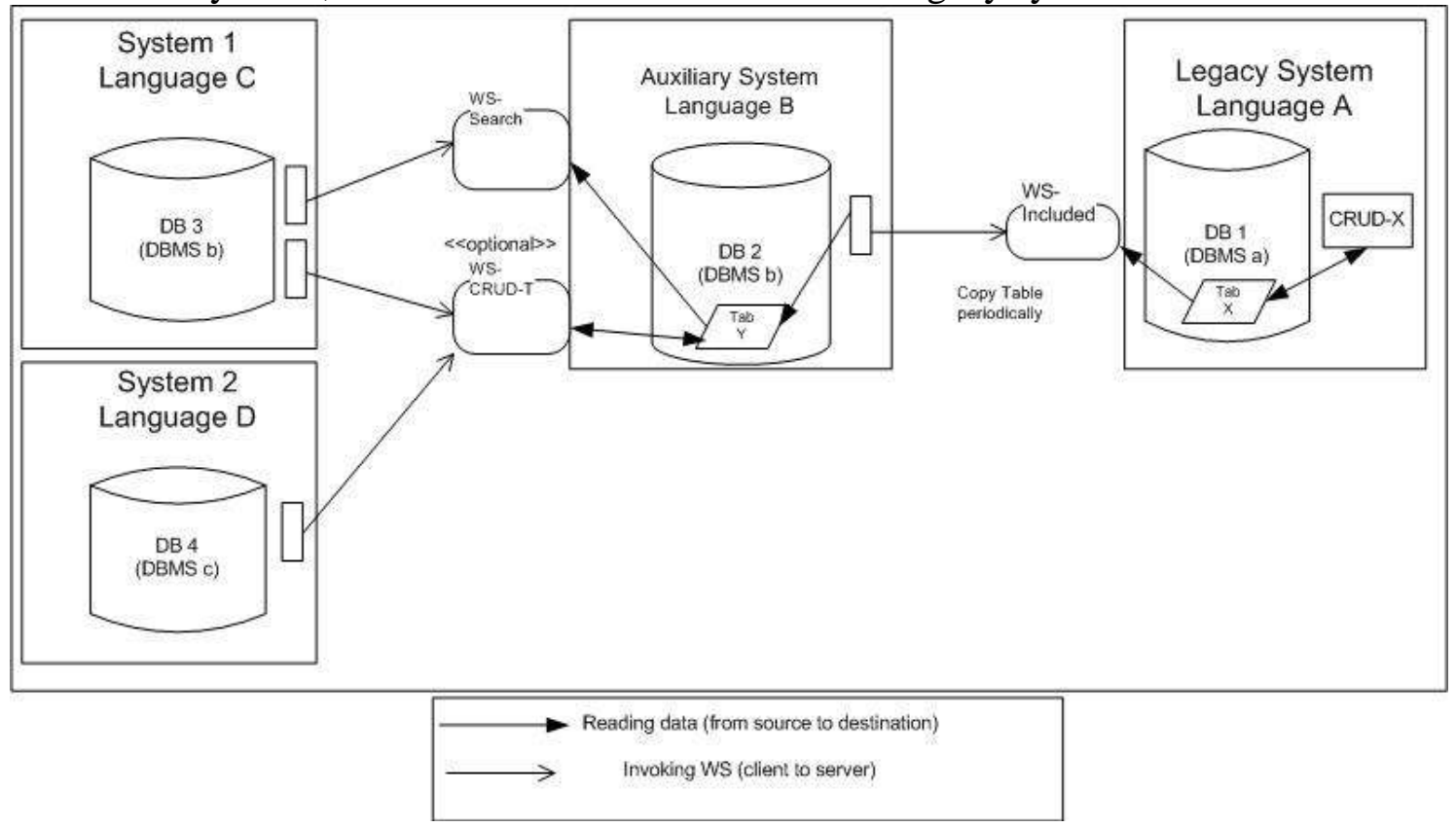

Figure 12. Solution proposed by Pattern 4.

- Consequences: (1) security: access is done by the WS, therefore only data made available by the service are returned; (2) reuse: other systems can access data through WS-search and WS-CRUD-T; (3) maintainability: WSCRUD-T concentrates all the logic of inclusion/modification/removal of local 
records; (4) storage saving: data that are not of interest to the other system are kept only locally (this can also characterize a data inconsistency disadvantage if the data are included in the Legacy System in the future); (5) data inconsistency: two forms of inconsistency can occur: data maintained locally are not visible to the other system and data synchronization is dependent on the frequency of periodic updates invoked by the Auxiliary System; and (6) performance: in case the volume of data to be copied is big (for example, the whole table, or several tables, or many records related to a big volume of data) or in case the Legacy System is frequently updated, the use of WS can compromise performance.

- Known Uses: (1) this solution is being implemented in EMBRAPA Soja (See Figure 13) to ease the inclusion and/or maintenance of outsourced staff who are not registered in the Human Resources System. Additionally, other systems will be able to search, include, modify and remove information invoking WS-Search and WS-CRUD-T; and (2) in the SGPC system, developed at ICMC-USP, information about people (e.g. students and staff) is imported periodically from the intranet, but it is allowed to register new people only locally. In the current version of the system this is done via DB, but it is expected to be replaced by services in the next version.

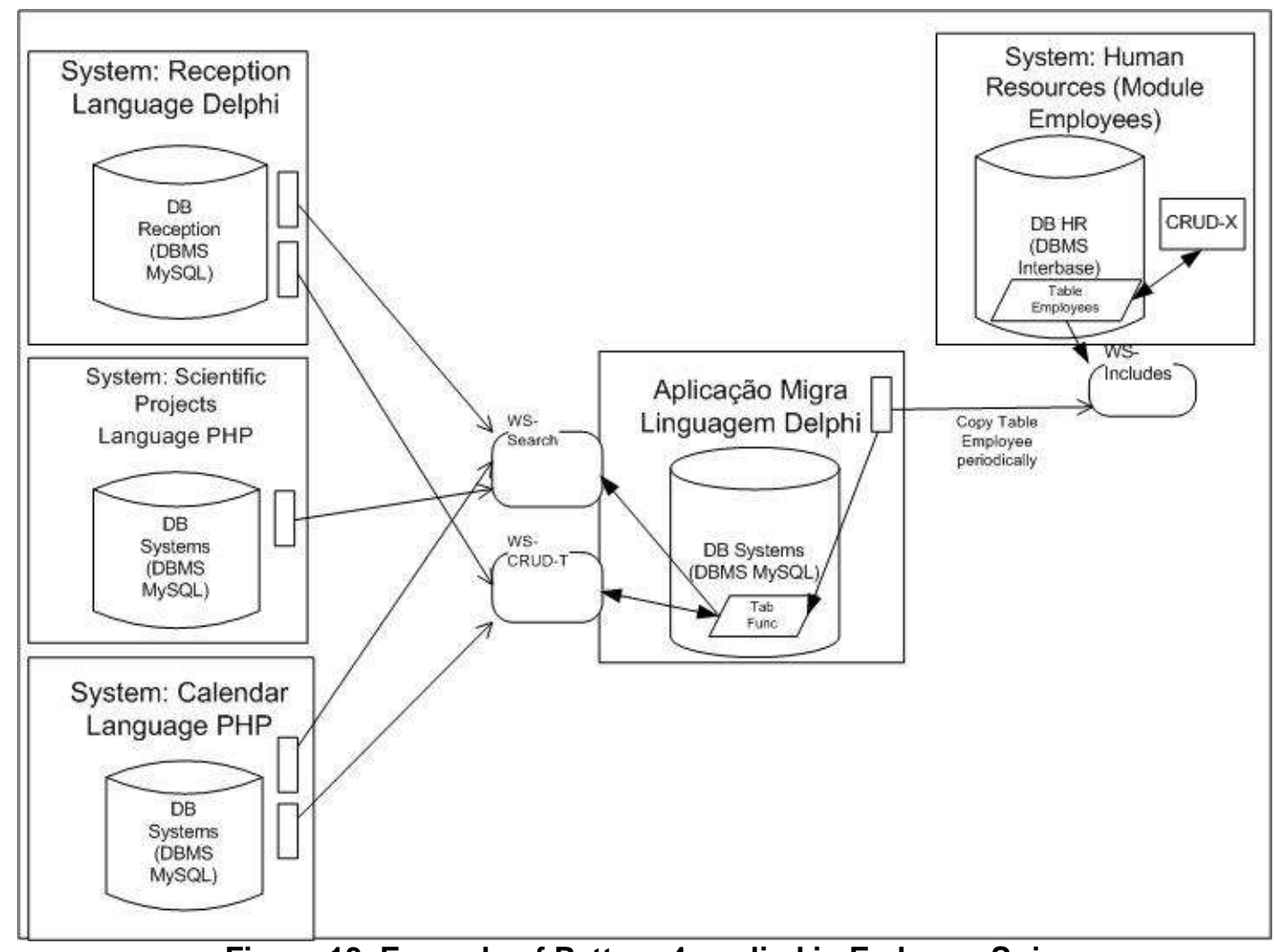

Figure 13. Example of Pattern 4 applied in Embrapa Soja.

- Related patterns: the File Transfer and RPCs, described in patterns 2 and 3 (from Gregor Hohpe and Bobby Woolf) are also related to this pattern, in fact it can be considered as a combination of File Transfer and RPCs to solve the EAI problem in the specified context. 


\subsection{Padrão 5}

- Name: Duplication via monitor and WS;

- Context: One or more applications are being developed (System 1, System $2, \ldots)$ in which part of the required information already exists in another application (Legacy System), possibly in a different platform. Applications belong to different organizations and it is quite difficult to share resources. The volume of information to be integrated is not too big, but it is essential that information is always consistent among applications.

- Forces: (1) as the data have several potential interested parts, synchronization among them should be done in a precise way. A monitoring mechanism should be provided to detect changes and to notify the interested systems; (2) periodic copies of the table would not be efficient in this case, because the time needed to detect changes could compromise performance; and (3) although notifying the systems about each change might seem to be the best alternative, it involves more system processing, since any inclusions, modifications or removals would need to be detected and propagated.

- Solution: Figure 14 illustrates the solution proposed by the pattern, which suggests keeping copies of the common tables updated in all systems that are interested on them, such that these tables are always synchronized. The solution includes having a WS Server, named Monitor, with two services: manifest interest in changes and monitor changes. Systems 1 to $\mathrm{n}$ register in this Server, manifesting their interest in any changes that occur in the tables of the Legacy System. If the Legacy System includes, modifies or removes one or more records, this monitor detects the change and propagates the same operation to the other interested systems. The change is done through invocation of Web Services that perform CRUD operations. Systems can also cancel their interest in changes anytime, as illustrated in Figure 14 by message $\mathrm{m} 2$. It is important to notice that the monitor is also a service, so it is independent of programming language. 


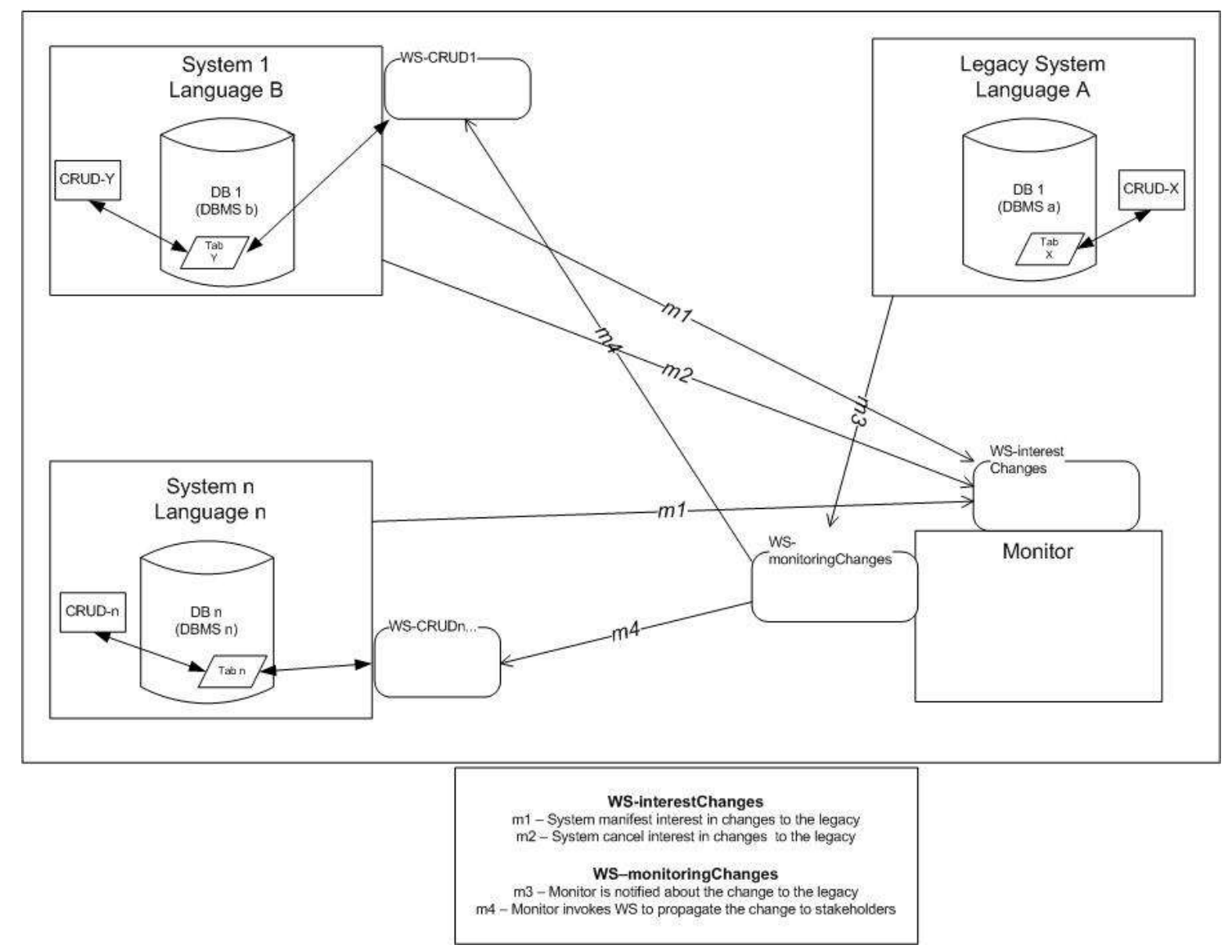

Figure 14. Solution proposed by Pattern 5.

- Consequences: (1) security: access is done by the WS, therefore only data made available by the service are returned; (2) data consistence: tables are always updated and synchronized; (3) table copies can serve as backup in case of system failure; (4) performance: since there is more processing (due to the monitor), performance can be worse; and (5) logic is more complex because it is necessary to implement both the manifestation of interest and the change notification and propagation;

- Known uses: We still need to identify applications where this pattern has been used, but as it is based on the Observer pattern [3], we believe that many applications will benefit from it.

\section{Acknowledgements}

We would like to thank Prof. Dr. Rodrigo Bonifácio, for the valuable contribution to the set of patterns, with discussions that were very important to improve the writing. Also, the participants of the writers' workshop at SugarloafPLoP'2012, for the contribution to the final version of the patterns.

\section{References}

[1] K. Channabasavaiah, K. Holley, E. M. Tuggle, Migrating to a Service-oriented Architecture. New York: IBM, 2004. Available:

$<$ http://www.ibm.com/developerworks/library/ws-migratesoa/>. Accessed: 27 may. 2012., 2004 
[2] D. S. Linthicum, Enterprise Application Integration, 1st ed. Wesley: Addison, 1999, pp. 400 .

[3] E. GAMMA; R. HELM; R. JOHNSON; J. VLISSIDES. Design Patterns - Elements of Reusable Object-Oriented Software. Reading-MA, Addison-Wesley, 1995.

[4] G. Hohpe and B. Woolf, Enterprise Integration Patterns: Designing, Building, and Deploying Messaging Solutions, vol. 1. Wesley: Addison, 2003, pp. 574.

[5] D. Krafzig, K. Banke, and D. Slama, Enterprise SOA: Service-Oriented Architecture Best Pratices, 1st ed. Indianapolis: Prentice Hall, 2004, pp. 384.

[6] Q. H. Mahmoud, Service-Oriented Architecture ( SOA ) and Web Services : The Road to Enterprise Application Integration ( EAI ), 2005. [Online]. Available:

http://www.oracle.com/technetwork/articles/javase/soa-142870.html. [Accessed: 20May-2012].

[7] M. P. Papazoglou and W.-J. Heuvel van den, "Service oriented architectures: approaches, technologies and research issues," The VLDB Journal, vol. 16, no. 3, pp. 389-415, Mar. 2007. Available:

http://www.springerlink.com/content/d2228066725332u2/. Accessed: 22 may. 2012.

[8] M. Endrei et al., Patterns: Service-Oriented Architecture and Web Services, 2004. [Online]. Available: http://www.redbooks.ibm.com/abstracts/sg246303.html?Open. [Accessed: 10-May-2012].

[9] W. DENG; X. YANG; H. ZHAO; D. LEI; H. LI. Study on EAI Based on Web Services and SOA. 2008 International Symposium on Electronic Commerce and Security. Anais... [S.1.]: IEEE. Available:

$<$ http://ieeexplore.ieee.org/lpdocs/epic03/wrapper.htm?arnumber=4606033>. Accessed: 27 may 2012, 2008.

[10] V. N. Gudivada and J. Nandigam, Enterprise application integration using extensible Web services, In Proceedings of the IEEE International Conference on Web Services (ICWS'05), vol. 1, pp. 41-48. IEEE Computer, 2005. Available:

<http://ieeexplore.ieee.org/lpdocs/epic03/wrapper.htm?arnumber=1530781>. Accessed: 10 may 2012, 2005.

[11] B. Jiang, Developing Information Service Platform for Clusters of Small-Medium Enterprises in Heterogenous Environment, In ISECS International Colloquium on Computing, Communication, Control and Management, pp. 249-253. 2008. Available: < http://ieeexplore.ieee.org/stamp/stamp.jsp?tp=\&arnumber=4609835\&isnumber=4609776>. Accessed: 28 may. 2012.

[12] S. P. Nielsen, J. Hartley, A. Larmour, S. Sudarsanam, A. Walmsley, and H. Yamamoto, Applying the Patterns for e-business to Domino and WebSphere Scenarios, 2001. pp. 24. Available: http://www.redbooks.ibm.com/abstracts/sg246255.html. Accessed: 22 may. 2012. 


\section{Apêndice}

Tabela 1 - Valores de t nos níveis de $10 \%$ a $0,1 \%$ de probabilidade

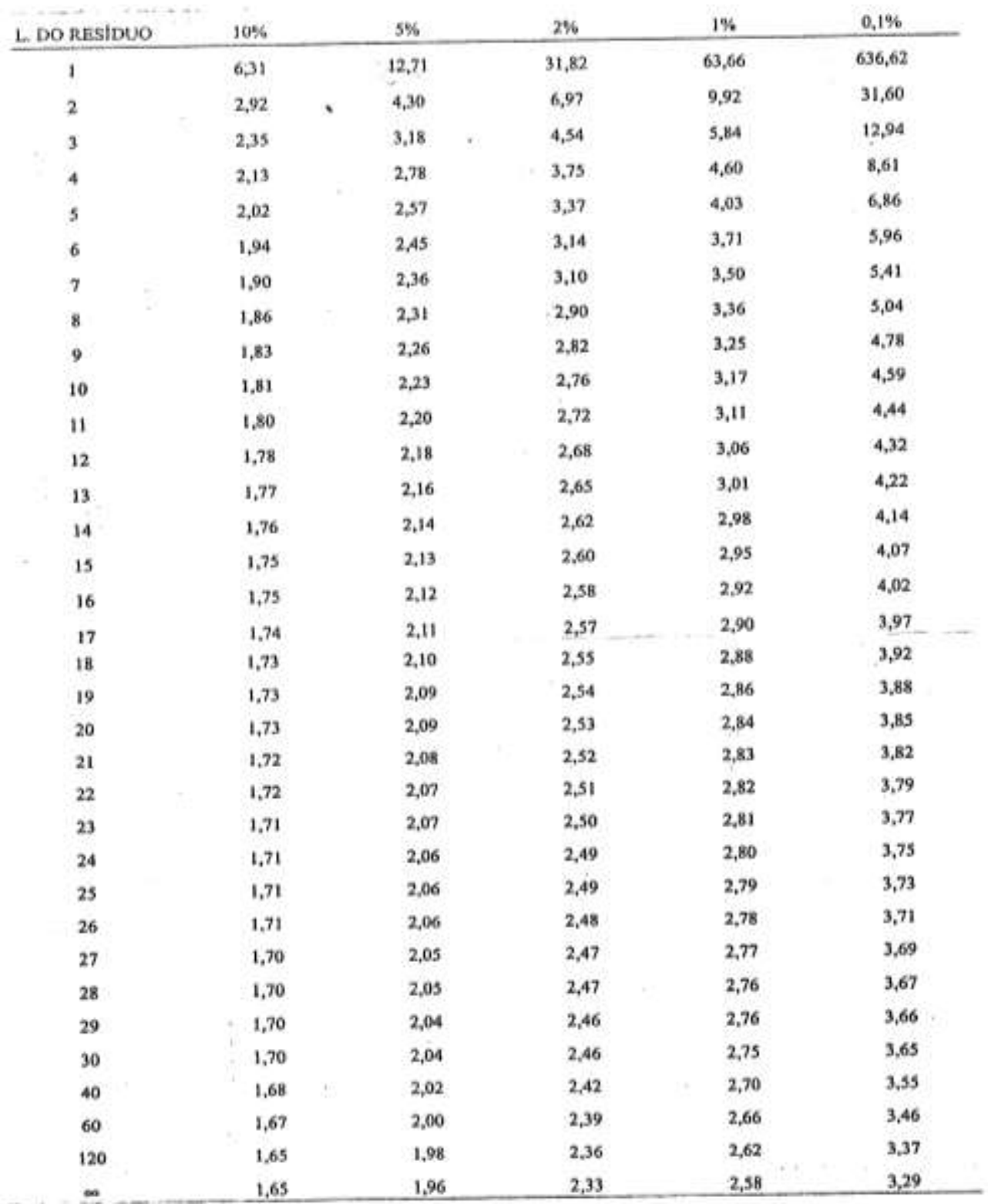

